\title{
COLD FLOW TESTING OF LABORATORY-SCALE HYBRID ROCKET ENGINE TEST APPARATUS
}

\author{
By \\ Shivanand R. Patil, B.E. \\ Mechanical Engineering \\ Visvesvaraya Technological University, India, 2012
}

A thesis submitted to Ryerson University

in partial fulfillment of the requirements for the degree of

Master of Applied Science

in the program of

Aerospace Engineering

Toronto, Ontario, Canada, 2014

(C) Shivanand R. Patil 


\section{Author's declaration}

I hereby declare that I am the sole author of this thesis.

I authorize Ryerson University to lend this thesis to other institutions or individuals for the purpose of scholarly research

Shivanand Rajashekhar Patil

I further authorize Ryerson University to reproduce this thesis by photocopying or by other means, in total or in part, at the request of other institutions or individuals for the purpose of scholarly research

Shivanand Rajashekhar Patil 


\title{
COLD FLOW TESTING OF LABORATORY-SCALE HYBRID ROCKET ENGINE TEST APPARATUS
}

\author{
Shivanand R. Patil \\ Master of Applied Science, Aerospace Engineering, Ryerson University, Toronto, 2014
}

\begin{abstract}
A cold-flow experimental investigation is performed on the Ryerson University lab-scale hybrid rocket engine test apparatus, in order to gain a further understanding of transient phenomena affecting the engine's hot test firing results to date. The hot test firing data was characterized primarily by noticeable thrust oscillation magnitudes at low frequency being measured by the test stand's thrust-measuring load cell, relative to somewhat lower magnitude low-frequency pressure oscillations being measured by a head-end pressure transducer. The present investigation allows for the evaluation of the fluid-structure interaction behaviour of the rocket engine's combustion chamber and upstream oxidizer feedline/injection apparatus (along with the surrounding test stand structure). Pressurized air at a moderate temperature acts as the working fluid (rather than hot gas arising from combustion), passing through the internal flow system, and exiting at the engine's exhaust nozzle. Cold flow tests are conducted at three different flow-regulating orifice-plate conditions upstream of the head-end injector: 1) unchoked, 2) marginally choked and, 3) choked, in order to potentially observe any trends in that regard, as tied to feed-system stability/instability. The cold flow test results, from the experimental time-dependent measurement of pressure, thrust and axial acceleration, in turn undergo FFT analyses to help identify any frequencydependent trends in regard to transient behaviour. Hammer tests are conducted to further establish the relevant lower frequency natural modes of structural vibration of the test apparatus with the engine in position The potential applicability of Karabeyoglu's wellknown thermal lag-combustion-gasdynamic predictive model (for estimating a characteristic frequency), which captures to some degree the intrinsic low frequency combustion-based instability behaviour of hybrid rocket engines, is considered for the present test engine setup. There are some promising comparisons in terms of relevant frequencies of mechanisms in the $20 \mathrm{~Hz}$ range, mechanisms that might be coupling to produce a noticeably augmented oscillation condition (as was observed in the hot firing thrust measurements).
\end{abstract}




\section{Acknowledgements}

This thesis would not have been possible without contributions of many individuals. I express my sincere gratitude to my thesis supervisor Dr. David Greatrix, Associate Professor, Ryerson University, Canada for his continuous support throughout my thesis. Dr. Greatrix provided a great working culture and degree of freedom to work at my pace. My supervisor has shown a lot of patience in order to finish my thesis in a timely manner.

Special thanks to Mr. Jerry Karpynczyk for his constant dose of enthusiasm, encouragement, and hot chocolate. I had wonderful time learning about practical engineering under his guidance. He makes the working environment lighter and cheerful. He helped me in so many ways.

Finally, I would like to thank my parents for their invaluable support, co-operation and the care that they have shown me. Thank you very much!! 


\section{Table of contents}

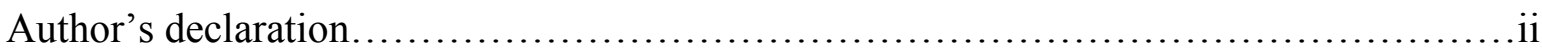

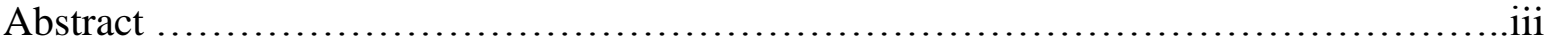

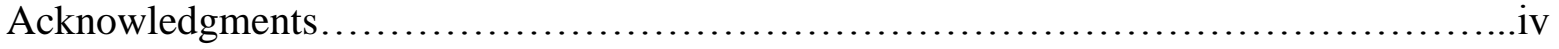

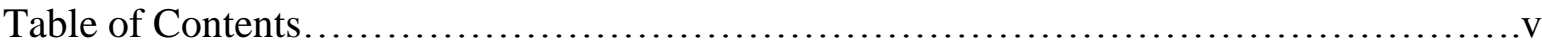

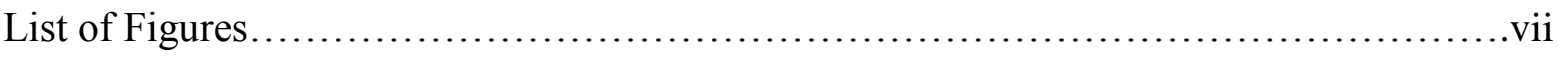

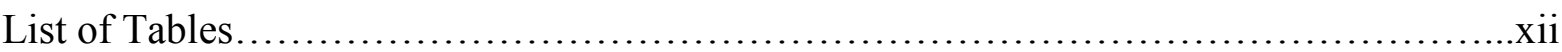

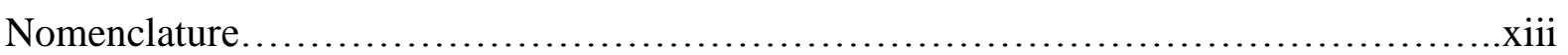

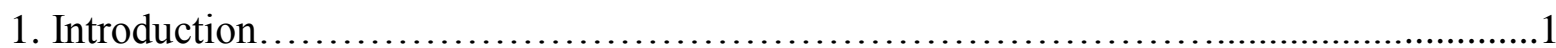

1.1 Basics of Hybrid Rocket Engines........................................

1.2 Combustion Instabilities in HREs........................................ 4

1.3 Previous Related Research on Hybrid Rocket Engines..............................6

1.4 Objectives of Present Study ................................................. 10

1.5 Layout of Current Report............................................... 12

2. Thermal Lag-Gas Phase Combustion-Gasdynamic Coupled Model.....................14

2.1 Thermal Lag Model.......................................................... 15

2.2 Gas-Phase Combustion Model.................................................... 16

2.3 Thermal Lag-Combustion Coupled System..................................17

2.4 Gasdynamic Model.......................................................... 18

2.5 TC-Gasdynamic Coupled System........................................ 19

3. Ryerson University's Hybrid Rocket Engine..........................................22

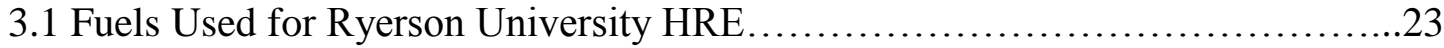

3.2 System Components.....................................................24

3.3 Experimental Test Firings................................................. 31

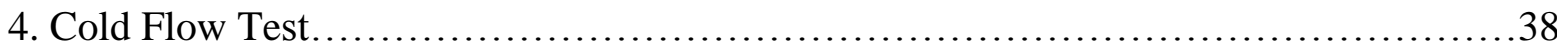

4.1 Test Apparatus............................................................. 39

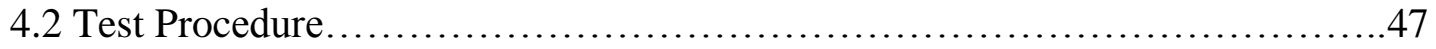

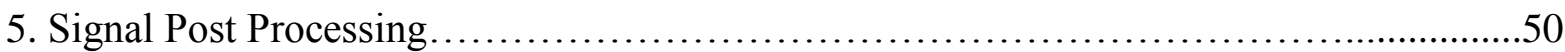




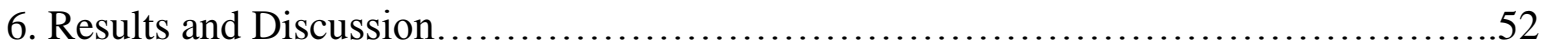

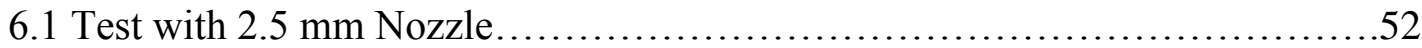

6.2 Test with $2.79 \mathrm{~mm}$ Nozzle...................................................56

6.3 Test with $3.05 \mathrm{~mm}$ Nozzle...............................................58

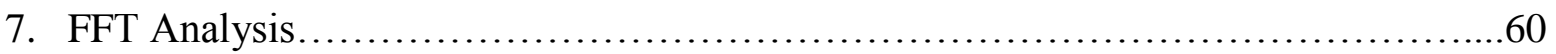

7.1 Test with $2.5 \mathrm{~mm}$ Nozzle.............................................60

7.2 Test with $2.79 \mathrm{~mm}$ Nozzle...............................................61

7.3 Test with $3.05 \mathrm{~mm}$ Nozzle................................................63

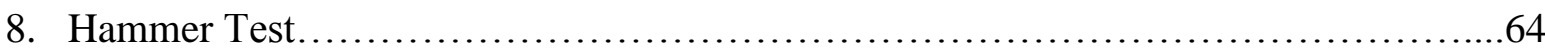

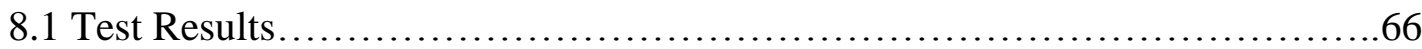

8.2 Vibration Induced by Feed System Coupling................................69

8.3 Characteristics of Fuel Used............................................. 71

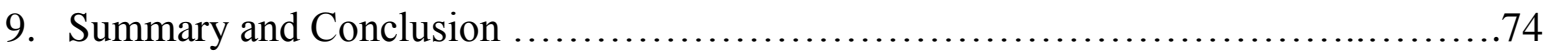

Appendix A:Pressure Transducer Calibtaion..................................... 76

Appendix B: MATLAB Code Used for FFT Process............................. 87

Appendix C: Sensor and Transducer Calibration Certificate........................ 88

References............................................................. 92 


\section{List of figures}

Fig. 1.1: Schematic of hybrid rocket engine .1

Fig. 1.2: Port configuration......................................................2

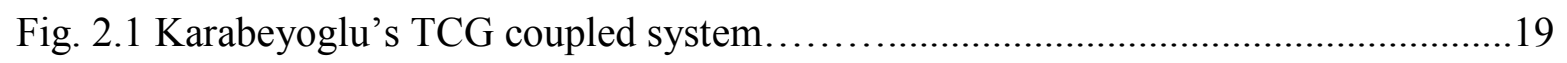

Fig. 2.2: Schematic of 2V-port model developed by Karabeyoglu et al...................20

Fig. 3.1: Ryerson University's hybrid rocket engine, in preparation for the Oct. 2010 firing at Continuum Aerospace outdoor test facility .22

Fig. 3.2: Combustion chamber pipe design dimensions.... .25

Fig. 3.3: Oxidizer feed distribution panel. 27

Fig. 3.4: Combustion chamber head end plumbing.... 28

Fig. 3.5: Graphite nozzle configuration. .29

Fig. 3.6: Ryerson hybrid rocket on test stand. .30

Fig. 3.7: Sketch to show the placement of pressure transducer placement to record chamber pressure data... .31

Fig. 3.8: Photo of Ryerson University labscale hybrid rocket engine 
Fig. 3.9: Experimental pressure-time profile for Ryerson's LDPE / GOx test firing.

Fig. 3.10: Experimental thrust-time profile for Ryerson's LDPE / GOx test firing. .34

Fig. 3.11: Photo of Ryerson's paraffin / GOx HRE being fired at the Continuum Aerospace test site. .35

Fig. 3.12: Experimental pressure-time profile for Ryerson's paraffin / GOx test firing. .36

Fig. 3.13: Experimental thrust-time profile for Ryerson's paraffin / GOx test firing.

Fig. 4.1: Flow of gases trough an orifice plate

Fig. 4.2: Rocket engine with the test stand and the instrumentation connected to the rocket engine

Fig. 4.3: Omega ${ }^{\circledR}$ 's $P X 4100$ series strain gauge transducers .44

Fig. 4.4: Transducer Techniques® MLP-200 load cell .45

Fig. 4.5: Accelerometer placement on the rocket engine. .46

Fig. 4.6: WaveBook 516 data acquisition system. . .47 
Fig. 6.1: Chamber pressure vs. time plot obtained from test of configuration 1 .53

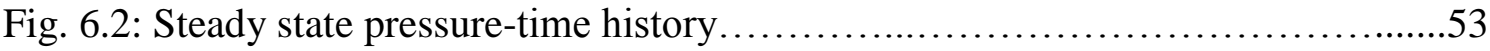

Fig. 6.3: Thrust vs. time obtained during test of configuration $1 \ldots \ldots \ldots \ldots \ldots \ldots \ldots \ldots 54$

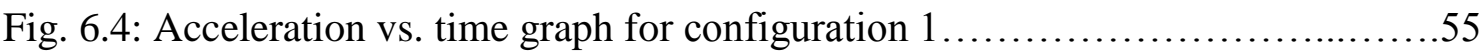

Fig. 6.5: Chamber pressure vs. time plot for configuration $2 \ldots \ldots \ldots \ldots \ldots \ldots \ldots \ldots \ldots \ldots$

Fig. 6.6: Pressure time history during steady state...............................56

Fig. 6.7: Thrust vs time obtained during test of configuration $2 \ldots \ldots \ldots \ldots \ldots \ldots \ldots \ldots . \ldots \ldots$

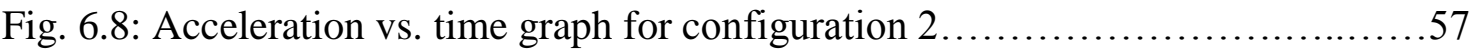

Fig. 6.9: Chamber pressure vs. time plot for configuration $3 \ldots \ldots \ldots \ldots \ldots \ldots \ldots \ldots . \ldots 58$

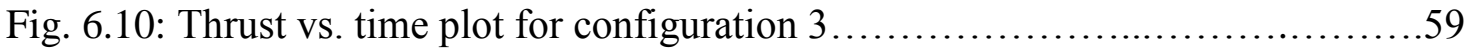

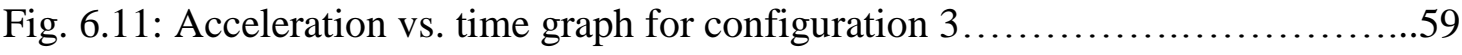

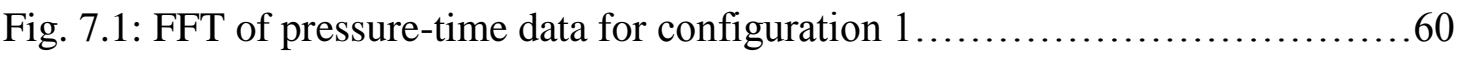

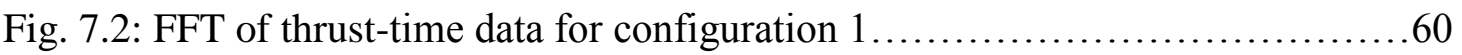


Fig. 7.3: FFT of pressure-time data for configuration $2 \ldots \ldots \ldots \ldots \ldots \ldots \ldots \ldots \ldots \ldots \ldots \ldots \ldots \ldots \ldots$

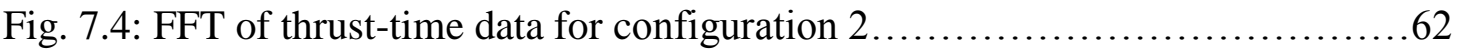

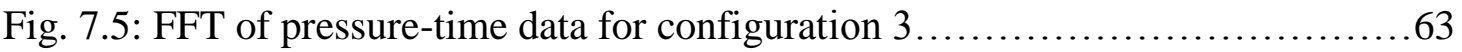

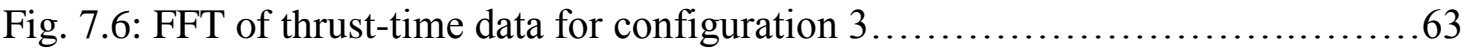

Fig. 8.1: Illustration of standard hammer test method..........................65

Fig. 8.2: Response obtained when the rocket engine is struck axially................66

Fig. 8.3: FFT analysis of acceleration data obtained when apparatus axially impacted....

Fig. 8.4: Response obtained when the structure was impacted radially....

Fig. 8.5: Magnification of Fig.41 near first peak................................68

Fig. 8.6: FFT analysis of the data obtained from striking the structure in the transverse direction. .68

Fig. 8.7: FFT of acceleration data from cold flow test data of unchoked regulator orifice configuration. .70

Fig. 8.8: FFT of acceleration data from cold flow test data of marginally choked regulator orifice configuration .70 
Fig. 8.9: FFT of acceleration data from cold flow test data of choked regulator orifice configuration.

Fig. 8.10: Liquid layer wavelet and fuel droplet of paraffin fuel .72

Fig. 8.11: Flame shape of the non-liquefying fuel (HDPE) 82

Fig. A.1: OMEGA PX4100 Series Transducer Calibration Setup. ... 77

Fig. A.2: Test setup in Laboratory (Propulsion Research Facility). .78

Fig. A.3: OMEGA PX4100 series pressure transducer calibration test result .79

Fig. A.4: Output signal obtained without a filtered input supply voltage. 80

Fig. A.5: Output signal obtained with a filtered supply voltage. .81

Fig. A.6: Apparatus setup for integrity test. .82

Fig. A.7: Integrity test results. .83

Fig. A.8: OMEGA PX4100 Series Transducer Calibration Setup using 12V dc battery. .85

Fig. A.9: Comparison of test results obtained form two methods of supplying excitation voltage. .85 


\section{List of tables}

Table 4.1: Air supply conditions for cold flow test............................38 


\section{Nomenclature}

\section{Symbols}

a Speed of sound in a given medium

$A_{l} \quad$ Cross section areas of pipe upstream of the regulating orifice plate

$A_{2} \quad$ Cross section areas of pipe downstream of the regulating orifice plate

$A_{t} \quad$ Nozzle throat area

C Orifice plate flow coefficient

$D \quad$ Fuel grain port diameter

$E_{a} \quad$ Activation Energy

$E_{L}, E_{E_{a}}$ Energy parameters

$f_{1 L} \quad$ First longitudinal acoustic mode

$G_{o} \quad$ Oxidizer axial mass flux

$G_{t} \quad$ Total oxidizer mass flux

$I_{s p} \quad$ Specific impulse

$\hat{I}(s) \quad$ Oxidizer mass flux perturbation 
$L^{*} \quad$ Characteristic length of the rocket engine

$L_{c} \quad$ Length of the rocket engine's combustion chamber

$L_{f} \quad$ Actual fuel grain length

$L_{s t} \quad$ Stoichiometric fuel grain length

$\dot{m} \quad$ Mass flow rate of the fluid

$\dot{m}_{t} \quad$ Mass flow rate of fluid through the nozzle throat

$\dot{m}_{e} \quad$ Mass flow rate of fluid exiting the rocket engine nozzle

$p_{1} \quad$ Stagnation pressure upstream of the regulating orifice plate

$p_{2} \quad$ Stagnation pressure downstream of the regulating orifice plate

$p_{c} \quad$ Combustion chamber pressure

$Q \quad$ Fluid volumetric flow rate

$\dot{Q}_{\mathrm{c}} \quad$ Wall heat flux

$\hat{Q}_{1}(s) \quad$ Laplace transform of wall heat flux perturbation 
$R \quad$ Specific gas constant

$R_{u} \quad$ Universal gas constant

$\hat{R}_{l}(s) \quad$ Laplace transform of nondimensional regression rate perturbation

$r \quad$ Ratio of pressure downstream of the orifice plate to the pressure upstream of the orifice plate.

$T_{a v} \quad$ Average temperature in combustion chamber

$T_{s} \quad$ Fuel grain burning surface temperature

$T_{F} \quad$ Flame temperature

$T_{1} \quad$ Stagnation temperature of fluid upstream of the regulating orifice plate

$u_{e} \quad$ Axial freestream velocity

$V_{l} \quad$ Velocity of fluid upstream of the regulating orifice plate

$V_{2} \quad$ Velocity of fluid downstream of the regulating orifice plate

$Y \quad$ Expansion factor used in equation 4.4

\section{Greek}

$\beta \quad$ Ratio of orifice plate hole diameter to pipe diameter 
$\gamma \quad$ Ratio of specific heats

$\rho \quad$ Density of gaseous oxygen/fluid

$\sigma_{1}, \sigma_{2}$ Gas-phase response coefficients

$\tau_{b l} \quad$ Characteristic response time required for equilibrium

$\tau_{\mathrm{b} 12}$ Time delay experienced by the wall heat flux to changes in regression rate

\section{Acronyms}

AMROC American Rocket Company

DAQ Data acquisition

FFT Fast Fourier transforms

FRF Frequency response function

GOx Gaseous oxidizer

HRE Hybrid rocket engine

HTPB Hydroxyl terminated polybutadiene 
LDPE Low density polyethylene

PE Polyethylene

PMMA Polymethyl methacrylate

QSHYB Quasi steady hybrid (ballistic simulation program)

RU Ryerson University

UHMWLDPE Ultra-high molecular weight

low density polyethylene 


\section{Introduction}

Commercial space travel is driving the research and development of alternative propulsion systems. These propulsion systems are required to be clean, safe, and controllable and, most importantly, relatively low in manufacturing and operating costs. Hybrid rocket engines (HREs) are a class of rocket propulsion systems that combine the advantages of both solid and liquid propellant rocket technology. HREs traditionally employ a solid fuel, and a gaseous or liquid oxidizer.

\subsection{Basics of Hybrid Rocket Engines}

Hybrid rocket engine systems have the potential to deliver higher specific impulse $\left(\mathrm{I}_{\mathrm{sp}}\right)$ and controllability than conventional solid rocket propulsion systems. Since the fuel and oxidizers are stored separately, hybrid rocket systems are known to be safer than solid propellant rocket motors. The use of a low cost material as the fuel helps to lower the production costs of HREs.

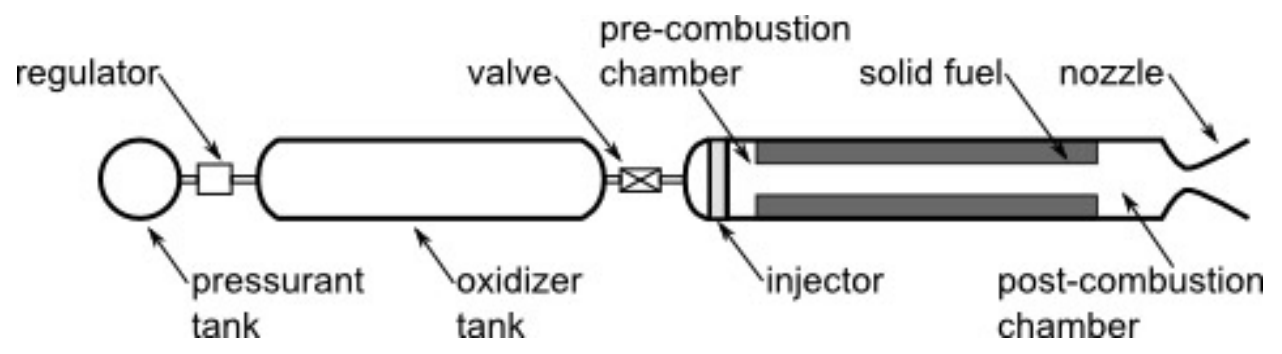

Fig. 1.1: Schematic of hybrid rocket engine.

As stated previously, hybrid rocket engines have a solid fuel, and a gaseous or liquid oxidizer. Figure. 1.1 shows a schematic of a pressure-fed hybrid rocket engine. The oxidizer is stored in a separate tank, and is released into the rocket combustion chamber through a regulating valve. The solid fuel is first ignited with a nearby ignition source. Combustion along the fuel grain is maintained by a constant supply of oxidizer into the combustion chamber. The corresponding fuel regression rate is a function of the local axial mass flux of 
the gas, predominantly, although other mechanisms can play a role (radiation, etc.). The gaseous products of combustion evolve from the burning fuel surface, and act to increase the pressure within the combustion chamber. These gases are accelerated through an exhaust nozzle which ejects the gases at a high velocity out of the rocket engine. This ejection of gases produces thrust and propels the rocket vehicle forward.

The solid fuel charges used by HREs are commonly known as fuel grains. These fuel grains have one or more internal slots that are shaped based on the required thrust profile [1]. Figure. 1.2 shows examples of a single port and a multiple port fuel grain that may be used for HREs.
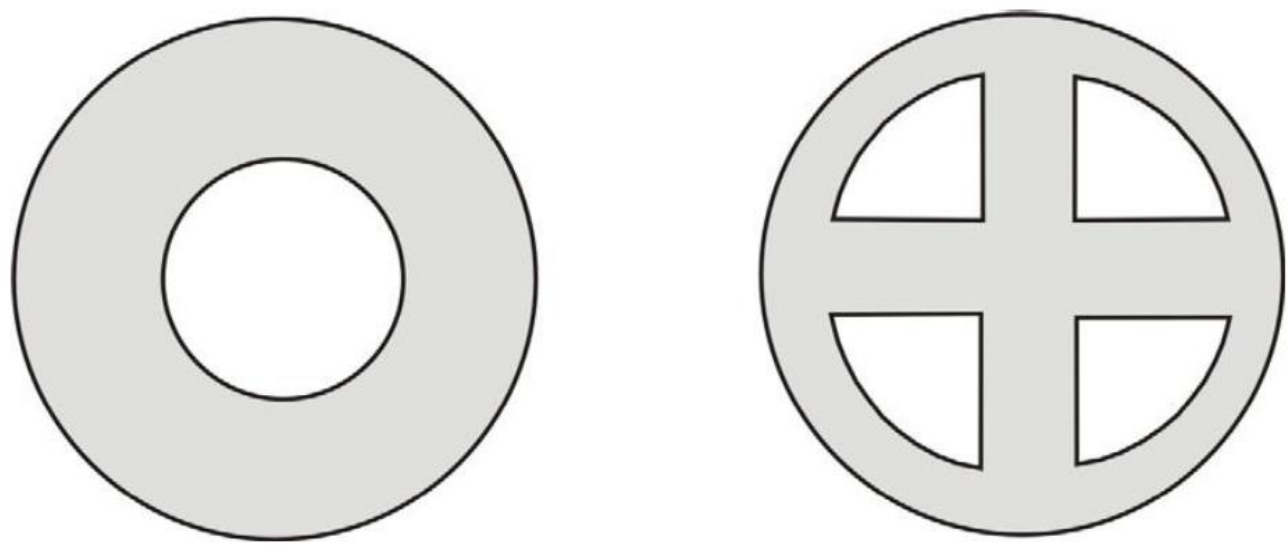

Fig. 1.2: Port configuration.

In the course of meeting the thrust requirements of a specified mission, a hybrid rocket engine may experience several transient events, which are classified as [2]: 


\section{Ignition}

The fuel charge grain has to be ignited by some heat source. The common techniques are: using a slug of hypergolic fluid, a solid squib or spark ignition of a gaseous fuel. In the ignition process, the early combustion gases leaving the motor are oxidizer-rich, approaching the steady-state oxidizer-to-fuel $(\mathrm{O} / \mathrm{F})$ towards the end of the transient ignition phase.

\section{Throttling}

In a hybrid rocket engine, throttling is accomplished by changing the oxidizer flow rate entering into the combustion chamber. The steady state corresponding to each flow rate sets a new fuel regression rate based on the appropriate regression rate law. During throttling, the gas velocity, temperature and density distributions in the hybrid combustion chamber (and the thermal contour within the solid fuel phase) require a lag time to readjust to the new equilibrium. This knowledge of the transient thermal lag in solid fuel charges is important for predicting impulse thrust management.

\section{$\underline{\text { Instability }}$}

Chamber pressure oscillations with an amplitude of at least $5 \%$ of the mean chamber value are generally defined as a pressure-based combustion instability symptom. The exact cause of pressure oscillations in HREs is not yet fully known. A few theories exist in this regard, and will be discussed in detail in the following sections.

\section{$\underline{\text { Thrust termination }}$}

During shutdown, the response time is basically the characteristic emptying time of the motor. During this relaxation, the accumulated heat in the solid is slowly transferred to the fuel surface, leading to occasionally to further vaporization or "chuffing. This 
vaporization action can impart a small additional impulse (thrust increment) to the rocket engine. For precise control of the vehicle, an understanding and ability to quantify this impulse on shutdown is important [2].

HREs can also exhibit certain disadvantages. Lower fuel regression rates compared to solid propellant rocket motors is a common problem which sometimes leads to the designing of more complex grain geometries (to increase the effective burning surface area). Also, variations in specific impulse due to more complex designs may actually initiate mixing and combustion inefficiencies that are not desirable. The internal ballistics of these complex systems can be difficult to model.

\subsection{Combustion Instabilities in HREs}

Like their solid and liquid propellant counterparts, HREs are prone to combustion instabilities. These combustion oscillations may result in corresponding pressure and thrust oscillations. The thrust oscillation levels that one can tolerate are limited by certain practical considerations, including maximum allowed acceleration loads on the vehicle structures and payload. This makes combustion stability a critical issue during development of a new propulsion system [3]. It is reported that oscillatory combustion behaviour also produces higher regression rates. For the safety of the vehicle and the payload, it is important to suppress these oscillations [4]. The different types of oscillations are discussed below.

\section{Low frequency instabilities}

These instabilities are often observed in hybrid rocket engines. The frequencies of these oscillations are present in the $0-200 \mathrm{~Hz}$ range, significantly less than the first longitudinal acoustic mode of the rocket structure which is given by, 


$$
f_{1 L}=\frac{a}{2 L_{c}}
$$

where $\mathrm{a}$ is the speed of sound in the combustion chamber, which is given by,

$$
a=\sqrt{\gamma R T_{a v}}
$$

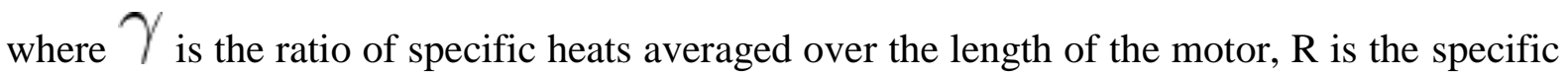
gas constant, and $T_{a v}$ is the average gas temperature in the combustion chamber and $L_{c}$ is the length of the combustion chamber. The mechanisms driving these oscillations are i) feed system coupled instabilities ii) chuffing and intrinsic low-frequency instabilities of HREs affiliated with the boundary-layer combustion process [4].

\section{$\underline{\text { Medium frequency instabilities }}$}

The frequency of oscillations lies between $200-2000 \mathrm{~Hz}$ and are usually associated with longitudinal acoustic oscillations within the rocket chamber. The pressure wave amplitudes are usually smaller than those observed in low frequency oscillations [5].

\section{$\underline{\text { High Frequency Instabilities }}$}

The oscillating frequency in these instabilities are usually above $2000 \mathrm{~Hz}$ and are related to higher longitudinal modes or transverse acoustic modes of the combustion chamber $[5]$. 


\subsection{Previous Related Research on Hybrid Rocket Engines}

There has been a growing interest in the area of hybrid rockets. Universities and corporations around the world have been developing and studying various aspects of hybrid rockets. This section will outline some of the relevant work being done on hybrid rockets around the world, that provides some background to the present thesis investigation of transient phenomena in the RU HRE test apparatus.

In a joint effort among NASA Marshall Space Flight Center (MSFC), the University of Alabama at Huntsville and Thiokol Corporation, Greiner and Fredrick [6] set up a lab-scale hybrid rocket engine test facility at MSFC. The test facility was established to conduct tests on hybrid fuels, and study the various characteristics of hybrid propulsion. As a first trial, tests were conducted on polymethyl methacrylate (PMMA) and HTPB fuels. Rocket performance at gaseous oxidizer axial mass fluxes from $0.047 \mathrm{lbm} / \mathrm{sec} \mathrm{in}^{2}$ to 0.378 $\mathrm{lbm} / \mathrm{sec}^{2} \mathrm{in}^{2}$ was evaluated for PMMA fuel and $0.378 \mathrm{lbm} / \mathrm{sec}^{\mathrm{in}}{ }^{2}$ in the case of HTPB fuel. The fuel grains were loaded as cartridges of 2 inches in length and 0.820 inches for the inner port diameter. These cartridges were weighed before and after firing to determine the solid fuel regression rates. The results showed that their lab-scale hybrid rocket engine replicated previously reported PMMA fuel regression rates, and also replicated low frequency oscillations observed with HTPB fuels [6].

To study the oscillations occurring during combustion of HTPB fuel, the team at MSFC employed a 0.306-in throat diameter nozzle with five fuel cartridges combining to give a total port length of 10-in, and used two different aft configurations. The first configuration was a short chamber giving an $\mathrm{L}^{*}$ of 16 -in and the second one was a longer chamber giving an $\mathrm{L}^{*}$ of 85-in. From the firings it was noted that the configurations employing a shorter aft mixing 
chamber length produced significantly lower frequency instabilities. The authors stated that the possible cause of instability in the engine using a short aft mixing chamber was the vortex shedding of combustion gas in the mixing chamber [6].

At Stanford University, California, Karabeyoglu et al $[3,4]$ studied the low frequency instabilities most commonly observed in hybrid rocket engines (the oscillating pressure and thrust profiles). The authors evaluated test data obtained from various hybrid propulsion studies. While explaining the formulation of the mathematical model, Karabeyoglu et al [4] suggested a plausible mechanism for the occurrence of the low frequency combustion instabilities. It is explained that the mechanism is due to the coupling of the thermal lags, the gas-phase combustion, and the gasdynamic subsystems of the hybrid rocket engine. The mathematical model allows one to estimate the frequency of the pressure and thrust oscillation within the engine. The amplitude of the oscillations, however, cannot be determined by this linear model [3].

With Space Propulsion Group Inc., Karabeyoglu investigated the feed system coupled low frequency combustion instabilities in hybrid rocket engines. In that study, the combustion chamber behaviour only included the filling/emptying dynamics. A transient model for a generic liquid feed system of a hybrid rocket engine was formulated, and the model was composed of the following key components:

- Injector element.

- Pipe system, including minor elements such as valves.

- A simplified model for the combustion chamber that has the delays for oxidizer and fuel gasification processes that take place in the chamber. 
The model predicted that instabilities are possible for systems with or without flow isolation elements (flow regulation). It was also noted that the finite compressibility of the fluid in the feed lines can lead to combustion oscillations for systems even with flow isolation elements [17].

A comparative study conducted by Boardman et al [7] employed an 11-inch diameter hybrid rocket engine with forward and aft mixing chambers. Numerous experiments were carried out to determine the flow field for different injection schemes, and also to study the characteristics of chamber pressure oscillations observed previously in hybrid rocket engines. The authors employed radial, solid $45^{\circ}$ cone, and axial injectors. For all the injections schemes, the tests were carried with and without silica phenolic inhibitors. It was found that configurations incorporating radial injectors produced pressure oscillation amplitudes on the order of 200 psi peak-to-peak, along with a vortex ring rotating in a clockwise direction in the forward mixing chamber. The $45^{\circ}$ cone injection apparatus produced the same vortex but in the counter clockwise direction, with relatively stable combustion. The stability in combustion was achieved due to the immediate proximity of the vortex ring to the forward face of the fuel grain, resulting in a stable hot-gas recirculation zone upstream of the fuel grain. When the same conical configuration was used with fuel inhibitors, unstable combustion was observed. It was reported that the lack of fuel/oxidizer mixing in the recirculation zone created the observed instability. The configuration employing axial injectors exhibited a counter clockwise vortex ring in the forward mixing chamber and a hotgas recirculation zone within the port, stabilizing the diffusion flame and hence producing stable combustion. From the FFT analysis of data obtained from the radial injection tests, two primary oscillations were observed: a low-frequency, non-acoustic mode in the $8-20 \mathrm{~Hz}$ range and the combustor's higher $1 \mathrm{~L}$ acoustic mode. In no instance was oscillation observed 
in one mode without being accompanied by the other mode. The analysis also showed that the $1 \mathrm{~L}$ mode occurred in packets whose frequency was identical to that of the non-acoustic modes [7].

Jenkins and Cook [8] conducted a preliminary analysis of low frequency pressure oscillations observed in hybrid rocket engines. The analysis aimed at understanding the phenomenon of pressure oscillations in hybrid rocket engines. Stability analysis was conducted based on the Beckstead-Price model [16], with application of the continuity equation to the combustion chamber. In the developed mathematical model, the fluctuating quantities (pressure and fuel mass flow) are added to the average quantities in the combustion chamber. The model was verified with data obtained from the firing of the AMROC hybrid rocket engine, and the results were in good agreement.

In a follow-up study, Jenkins teamed up with Cruit and Smith of Marshall Space Flight Centre, Alabama [9]. This team set up a cold flow study apparatus to study the flow dynamics in hybrid rocket engine combustion chambers. The objectives of the tests were: 1) visualization of flow and measurement of flow velocity distributions 2) identification of large-scale shear layer structures within the flow 3) determination of the interactions between flow induced shear layers with the main stream flow, the secondary through flow and solid boundaries, and 4) investigation of the interaction between wall flow oscillations and the mainstream flow pressure distribution. The test facility consisted of two 500-gallon supply tanks (water) with one 800-gallon return tank and a two-dimensional test section. One supply tank contained water which entered the test section vertically through a porous wall to simulate wall burning, while the other tank supplied water which entered the test section horizontally, to simulate mainstream gas flow. The test bed was 36 inches in length and the 
$\mathrm{CP}$ (central port) height was set at 2 inches. Four different injector and flow inhibitor configurations were used for the study. Flow visualization was achieved with helium bubbles and LDV (laser Doppler velocimetry) measurements. While verifying the test results, the slow motion replay of the high speed video showed generation of vortices from the inhibitor simulations, and flow recirculation zones in the head end for both radial and axial injectors. The shedding vortex frequency was obtained from a visual count of the vortices over a specified time interval. The axial injector with a $64 \%$ flow inhibitor configuration produced a shedding frequency of $30 \mathrm{~Hz}$ and a radial injector configuration with same flow inhibitor formed a shedding frequency of $39 \mathrm{~Hz}$. From visualization of the flow structure it was mentioned by the authors that the standing vortices may play a role in the heat addition process as oxidizer enters the engine, and travelling vortices may be an instability contribution mechanism [9].

\subsection{Objectives of Present Study}

The present work is an investigation of Ryerson University's (RU) labscale hybrid rocket engine's transient performance data (both real and spurious). In October 2010, two experimental firings of the RU engine were conducted employing two fuel grains, one employing low density polyethylene (LDPE) and the other, employing paraffin wax. Gaseous oxygen was used as oxidizer in both the firings. The ignition for the test firings were achieved using steel wool as an igniter.

From the firing data obtained it was noted that when LDPE was used as the fuel, substantial thrust oscillations were observed, while the chamber pressure oscillations were relatively lower. The present study investigates the fluid-structure interaction behaviour of 
the rocket engine's combustion chamber and adjoining test apparatus by performing cold flow tests (without combustion) for the rocket engine firing operation.

In an earlier RU investigation, Brahmbhatt $[5,10]$ had evaluated the performance of the rocket engine based on the test firing data. The principal test data collected were the firing's head end pressure-time data and the corresponding thrust-time data. A onedimensional internal ballistic simulation program was used to compare the program's predicted numerical results with the experimental test data, to develop a better overall understanding of the engine's performance behaviour. The present study is to some degree a follow-up investigation to the evaluation conducted by Brahmbhatt, in an effort to gain a further understanding of the mechanisms that may be driving transient behaviour (both real and spurious).

It was noted by Brahmbhatt [5,10] that for the Oct. 2010 firing, flow-regulating orifice plate was not choked, upstream of the combustion chamber, a condition which potentially leads to a coupling between the instabilities occurring in the combustion chamber and the feed system. With this in mind a part of the current study, cold flow tests were conducted to check the fluid-structure interaction of the combustion chamber and surrounding test apparatus for three different configurations 1) an unchoked regulating orifice plate 2) a marginally choked orifice plate and, 3) a choked orifice plate, upstream of the combustion chamber.

For the present experimental study, compressed air is used to simulate, to some degree, the conditions of a hot firing (with combustion) in the combustion chamber, and the results obtained are evaluated to check for pressure and thrust oscillations in the low 
frequency regime. Also, the results obtained from the cold flow tests are to be checked to ascertain, via the process of elimination, if any relationship exists between intrinsic combustion-based low frequency instability, a common occurrence in HREs, and the thrust oscillations observed experimentally from the LDPE/GOx firing.

\subsection{Layout of Current report}

A detailed introduction to hybrid rocket engines is given in chapter 1 . The various advantages, disadvantages and the instabilities present in hybrid rocket engines is explained. Also the primary literature review is given in chapter 1 . The objectives of the current study are also mentioned in this chapter.

In chapter 2 the intrinsic low-frequency instabilities of hybrid rockets is explained, referring to Karabeyoglu's thermal lag-gas phase combustion-chamber gasdynamics (TCG) model. The mathematical formulation of this model is also explained in this chapter.

In chapter 3 the details of Ryerson University hybrid rocket engine are mentioned. Also, the initial hot firing test data is presented in the same chapter.

In chapter 4 the cold flow test setup, a key part of the current research is explained along with all the test conditions and various apparatus setup used for the test.

In chapter 5 the signal processing technique used for analysis of cold flow test data is explained. 
Chapter 6 presents all the test data obtained from the cold flow tests for different flow configurations.

Fast fourier transform (FFT) analysis is performed on the data obtained from the cold flow test and the results are presented in chapter7. Initial discussion on the trends observed in the FFT analysis of the various data is presented in this chapter.

Chapter 8 deals with hammer test conducted on the rocket engine with the test stand, to find the natural modes of structural vibration. The results of the hammer test are presented in this chapter. Also, issues of induced vibrations and solid fuel characteristics are discussed in this chapter.

The inferences made from the results of the cold flow test and the hammer tests are summarized in chapter 9 along with the conclusions of the study. 


\section{Thermal Lag-Gas Phase Combustion-Gasdynamic Coupled Model}

Hybrid rocket engine systems typically experience finite amplitude pressure (i.e., 2 to $20 \%$ of the mean chamber pressure) oscillations. This most common hybrid instability is in the form of limit cycle oscillations with frequencies much lower than the first longitudinal acoustic mode of the combustion chamber $[3,6]$.

The exact cause of these low-frequency HRE instabilities is not yet known; a few plausible theories have been proposed [3]. The main drawback of these theories is the absence of a mathematical formulation to explain the transient behaviour of these rocket engines. The difficulty in developing these models is due to the fact that HRE fuel burn rates are typically independent of the chamber pressure. This, for example, eliminates the pressure coupling between the thermal lags in the solid and the chamber gasdynamics, which is the source of the low-frequency $L^{*}$ instabilities observed in solid rocket motors.

Karabeyoglu et al [2-4] developed a mathematical model known as the thermal lag-gas phase combustion-gasdynamic (TCG) coupled system to estimate the frequency of the intrinsic low frequency combustion instabilities which are characteristic of HREs. The model was developed by isolating the subsystems of a hybrid rocket engine as:

1) Oxidizer feed system

2) Oxidizer vaporization system in the case of liquid oxidizers

3) Diffusion and combustion in boundary layer

4) Thermal response in the solid fuel grain

5) Chamber gasdynamics. 
For the development of the TCG coupled model, the oxidizer was assumed to be in gaseous state, and the HRE was assumed to be isolated from the feed system. Subsystems 3, 4 and 5 were modelled and investigated individually, and eventually coupled by Karabeyoglu to obtain the overall system response.

\subsection{Thermal Lag Model}

The thermal lag model states that the regression rate of the hybrid rocket engine fuel grain cannot respond to the changes in the surface heat flux instantaneously, due to the finite thermal conductivity of the solid fuel. In the thermal lag model, the gasification and pyrolysis reactions at the surface are both modelled by an exponential expression of the Arrhenius type, given as:

$$
\dot{r}=A \exp \left(-E_{a} / R_{u} T_{s}\right)
$$

where $\dot{r}$ is the dimensional fuel regression rate, $A$ is a pre-exponential coefficient, $E_{a}$ is an energy parameter, $R_{u}$ is the universal gas constant, and $T_{s}$ is the fuel grain burning surface temperature. The solution of interest is obtained by perturbing the full nonlinear system around the nominal operating point. The linear initial boundary-value problem defined for the first-order perturbation quantities has been solved with use of the Laplace transformation technique. The transfer function between the regression rate perturbation and the applied heat flux perturbation is given as:

$$
F_{T}=\frac{\hat{R}_{1}(s)}{\hat{Q}_{1}(s)}=\frac{2 E_{E_{a}} s}{(1+\sqrt{4 s+1})\left(s+E_{E_{a}}\right)-2 E_{E_{a}}+2 E_{L} E_{E_{a}} s}
$$

It is to be noted that $\hat{R}_{l}(s)$ and $\hat{Q}_{1}(s)$ are the Laplace transforms of the nondimensional regression rate perturbation and the wall heat flux perturbation, respectively. $E_{L}$ and $E_{E_{a}}$ are energy parameters 


\subsection{Gas-Phase Combustion Model}

In a hybrid rocket engine, the oxidizer mass flow rate is the primary input variable that can be easily changed by the action of the valve. The actual response of the engine to a change in the oxidizer mas flow is rather complicated during a transient period. As the oxidizer mass flow rate of the engine changes, the mass flux at a characteristic point in the port reacts to the change, as does the turbulent boundary layer developed over the fuel surface. In the presence of the thermal lags, the blocking (reduction in heat transfer due to transpiration) generates a coupling mechanism in the gas phase between the regression rate and the heat flow to the surface. Based on this understanding, the classical theory (the details of which can be found in [15]) can be modified to obtain a functional relation between wall heat flux and oxidizer mass flux-regression rate combination in terms of nondimensional parameters:

$$
\overline{\dot{Q}}_{c}(\bar{t})=E_{L} \bar{G}_{o}^{n /(1-k)} R^{-k /(1-k)}
$$

where $\bar{Q}_{\mathrm{c}}$ is the average convective heat flux, $E_{L}$ is an energy parameter, $\bar{G}_{\mathrm{o}}$ is the average oxidizer axial mass flux entering the fuel port, and $k$ is the blowing correction exponent first defined by Marxman [15]. The most important conclusion is that the time required for transition from the initial equilibrium profile to the final equilibrium profile at any axial location $\mathrm{z}$ is proportional to the time of flight of a fluid particle from the leading edge of the boundary layer to the specific axial location at the speed of the boundary layer to the specific axial location at the freestream flow $u_{e}$. This very important result can be formulated for the hybrid rocket engine port's boundary layer as [3]:

$$
\tau_{\mathrm{bl}}=c^{\prime}\left(z / u_{e}\right)
$$


here, $c^{\prime}$ is a constant that needs to be determined empirically, and $\tau_{b l}$ is the characteristic response time required for equilibration. For convenience, an average boundary layer is considered, and the local distance $z$ is replaced with the half of the grain length, $L_{f} / 2$.

\subsection{Thermal Lag-Combustion Coupled System}

When the thermal lags in the solid fuel grain are coupled to the combustion transients in the boundary layer, the following transfer function between the oxidizer mass flux $\hat{I}(s)$ and the regression rate $\hat{R}(s)$ is obtained [3]:

$$
F_{\mathrm{TC}}(s)=\frac{\hat{R}_{1}(s)}{\hat{I}(s)}=\frac{2 E_{E_{a}} \sigma_{2} e^{-\overline{\mathrm{t}}_{\mathrm{bl}}^{s}}}{(1+\sqrt{1+4 s})\left(s+E_{E_{a}}\right)-2 E_{E_{a}}+2 E_{E_{a}} s\left(E_{L}+\sigma_{1} e^{-\tau_{\mathrm{B}} \mathrm{D}^{s}}\right)}
$$

The above equation, Eq. (2.5), represents the hybrid combustion block of the transient model shown in Figure. 2.1. The parameters $\tau_{\mathrm{b} 11}$ and $\tau_{\mathrm{b} 12}$ are the time delays experienced by the wall heat flux $\dot{Q}_{\text {c }}$ to the changes in the oxidizer mass flux and the regression rate, respectively. The above depicted coupled model represents the combustion phenomenon which includes the dynamics of the thermal processes in the solid, and approximates the combustion dynamics in the turbulent boundary layer of the rocket engine. Eq. (2.5) can be used to investigate the stability character of the TC (thermal lag-gas phase combustion) coupled system. The commonly used method is to map the poles of the transfer function in the s plane. The real component of a certain pole of the transfer function indicates the amplification rate associated with that pole. Similarly, the imaginary part represents the oscillation frequency.

It is important to identify the necessary conditions that must exist for the generation of TC coupled instabilities. A careful examination of the denominator of the transfer function, 
Eq. (2.5) shows that for the instability to exist, blowing exponent $k$, activation energy $E_{a}$, and delay time $\tau_{\mathrm{bl} 2}$ must be nonzero. This indicates that the instability is a result of the coupling of three physical phenomena: blocking of heat transfer by radial injection of fuel mass (transpiration), thermal transients in the solid, and boundary-layer dynamics.

Based on the various HRE firing data considered by Karabeyoglu et al, and implementing the TC coupled model on the range of data considered, the following equation to quantify the inverse relationship between the frequency and the boundary-layer delay time was obtained:

$$
f_{l f}=0.48 / \tau_{b l 2}
$$

Parameter $f$ is the frequency of 'intrinsic low frequency oscillations'.

\subsection{Gasdynamic Model}

The TC coupled system gives the response of the fuel mass generation to the changes in the mass flux in the port. However, equally significant parameters of rocket engine operation such as the chamber pressure, specific impulse, and thrust cannot be obtained solely from the TC coupled system. The gasdynamic model has to be included to obtain the stated parameters.

For consideration, a specific gasdynamic model was considered. This model, referred to as 2V-port model, has the combustion chamber divided into three components: precombustion chamber, fuel port volume, and post-combustion chamber (Figure. 2.2). The preand post-combustion chambers have been treated as zero-dimensional volume elements, but the variation of state variables along the axis of the fuel port were taken into account. The volume of the nozzle which comprises a fraction of the post-combustion chamber is taken 
into account. The mathematical formulation has been obtained after the application of the conservation laws for the three volume elements. The set of equations resembling their model was solved analytically after linearization, and as a result of that operation, a transfer function for the gasdynamic subsystem was obtained. Some numerical simulations were also performed based on the 2V-port model to validate the approximations used in the perturbation solutions.

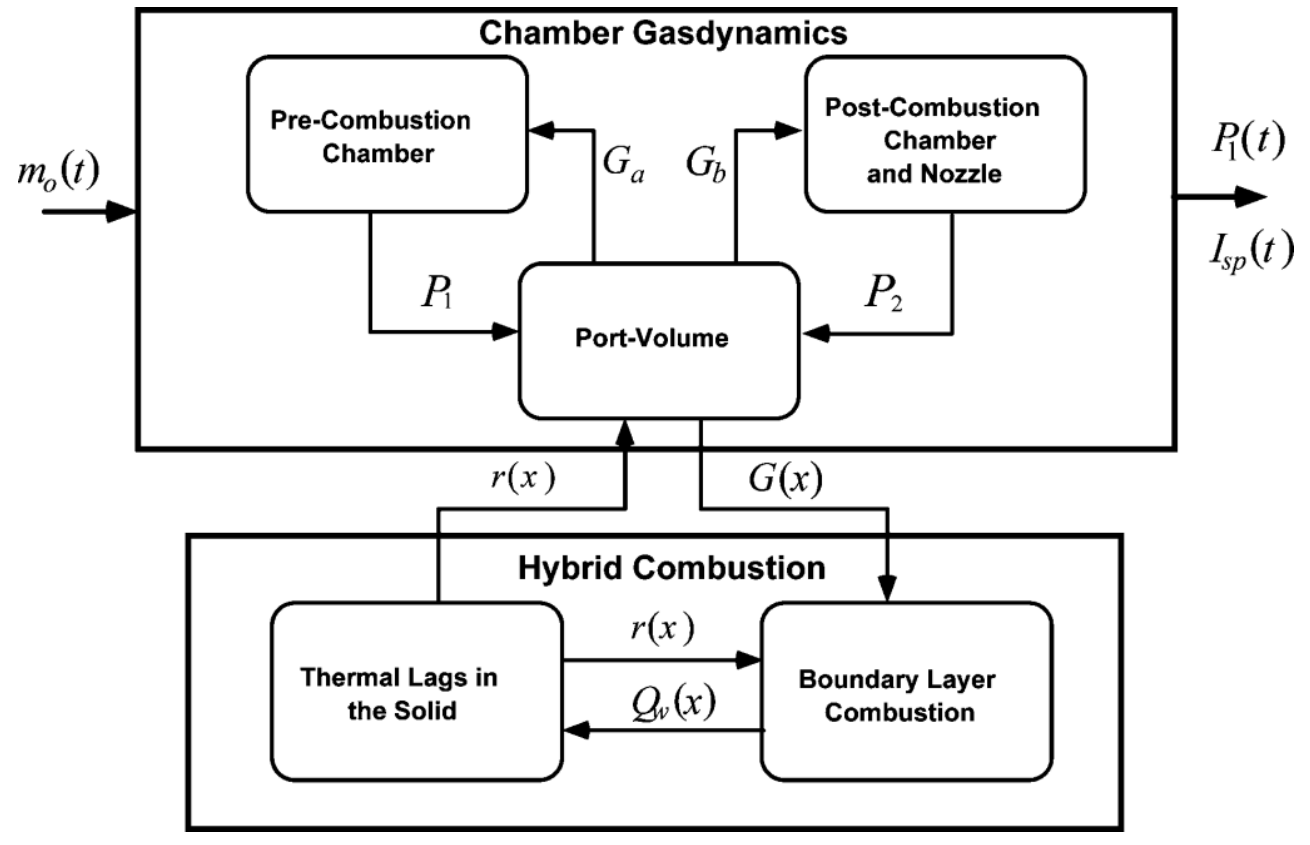

Fig. 2.1: Karabeyoglu's TCG coupled system [3]

\subsection{TC-Gasdynamic Coupled System}

The gasdynamic system was integrated to the TC-coupled system to establish the TCgasdynamic (TCG) coupled system. The TCG coupled system yields the performance of the rocket (such as chamber pressure) for the given input of oxidizer mass flow rate, which is a fundamental control parameter in hybrid rockets.

The schematic of the subsystems and the information flow between the subsystems is shown in the block diagram Figure. 2.1. The lower block in the schematic represents the TC- 
coupled system. The input for the TC-coupled system is the local mass flux information, and the output is the mass generation or the fuel regression rate. The upper block represents the gasdynamic subsystem. The gasdynamic model takes the oxidizer flow rate and the mass generation rate information, and reveals the performance parameters such as the chamber pressure and specific impulse. The TCG -coupled system can be considered as an overall model for the dynamics of a hybrid propulsion system that uses a gaseous oxidizer, provided it is delivered by an isolated feed system.

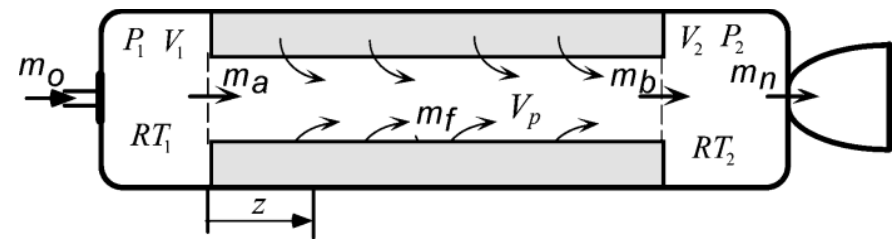

Fig. 2.2: Schematic of 2V-port model developed by Karabeyoglu et al [3].

In the TCG-coupled system, the gasdynamic module converts the fuel mass oscillations produced by the TC-coupled system into the chamber pressure oscillations. It was determined that, in the process of conversion, the oscillations produced by the TC-coupled system, that is, frequencies and amplification rates, are not altered.

The prediction of oscillation frequency requires the estimations of boundary-layer delay time, as noticed in Eq. (2.6). The port velocity was replaced by an average value $\left(G_{o}+G_{t}\right) / 2 \rho_{a v}$, where $G_{t}$ is the total oxidizer mass flux. Parameter $\rho_{a v}$ is the average density of gases in the port and is given by the gas law $p_{\mathrm{c}}=\rho_{a v} R T_{a v}$. Substituting the value of $\rho_{a v}$ and the average value of port flux levels in Eq. (2.4),we obtains:

$$
\tau_{\mathrm{bl2}}=c^{\prime}\left[L p_{c} /\left(G_{o}+G_{t}\right) R T_{a v}\right]
$$

From Eq. (2.7), it can be noted that the delay increases with increasing chamber pressure and port length, or a decrease in the port mass flux decreases the oscillation 
frequency. The total mass flux term can be eliminated from Eq. (2.7) by introducing the average $\mathrm{O} / \mathrm{F}$ (oxidizer to fuel ratio) of the motor:

$$
\tau_{\mathrm{bl} 2}=c^{\prime}\left[L p_{c} /\left(2+\frac{1}{O / F}\right) R T_{a v}\right]
$$

Eq. (2.8) can be coupled with Eq. (2.6) to obtain the frequency predicted by the TCG coupled model,

$$
f_{l f}=0.48 \frac{\left(G_{o}+G_{t}\right) R T_{a v}}{c^{\prime} L p_{c}}=0.48\left(2+\frac{1}{O / F}\right) \frac{G_{o} R T_{a v}}{c^{\prime} L_{f} p_{c}}
$$

The boundary layer delay constant c' was determined to be 2.050 , as a best fit between theory and test results considered by Karabeyoglu et al $[3,6]$. Substituting the value of $c^{\prime}$ in Eq. (2.9),

$$
f_{l f}=0.234\left(2+\frac{1}{O / F}\right) \frac{4 m_{o x} R T_{a v}}{\pi L_{f} p_{c} D^{2}}
$$

The value of $R$ and $T_{a v}$ has to be determined separately for each rocket engine firing test. The application of Eq. (2.10) for various test results gave agreeable values for lower frequency oscillations found in other HRE development programs.

For the present study, Eq. (2.10) will be employed to estimate the intrinsic low frequency oscillations that might have been a significant factor in the Oct. 2010 firings. 


\section{Ryerson University's Hybrid Rocket Engine}

The original 2008-2010 project for designing and building a hybrid rocket engine at Ryerson University aimed at developing a simple, versatile and low-cost system that allowed for rapid acquisition of experimental data for different propellant combinations and engine configurations [11]. The rocket test apparatus was required to be small and safe enough to be operated at various locations, on and off campus. The main drivers for the design of the rocket test apparatus were: thrust levels suitable for laboratory testing and burn durations long enough to collect useful data, maximum use of low-cost, off-the-shelf components, and large factors of safety on all pressurized and structural components. Figure 3.1 shows a picture of the rocket engine with the test stand, taken during the hot firing test conducted at Continuum Aerospace outdoor test facility.

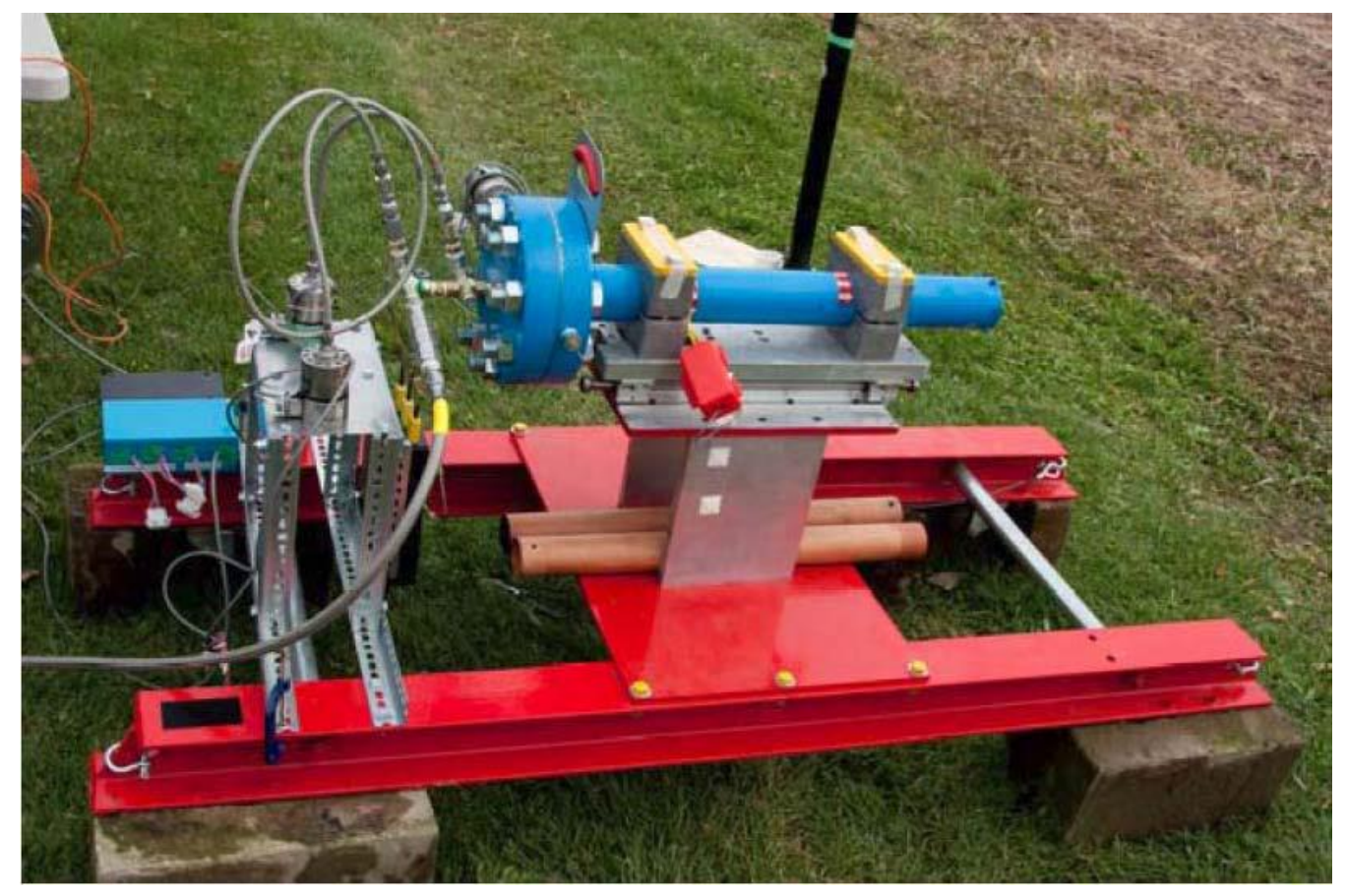

Fig. 3.1: Ryerson University's hybrid rocket engine and test stand, in preparation for the Oct. 2010 firing at Continuum Aerospace outdoor test facility [5]. 


\subsection{Fuels Used for Ryerson University HRE}

As stated previously, hybrid rocket engines mainly use a solid fuel, and a liquid or gaseous oxidizer. The main criteria for choice of propellants (fuel and oxidizer) for any rocket engine for a given mission profile are:

- High specific impulse

- Safe and controllable operation

- Simple, safe and low-cost manufacturing

- Non-toxic and non-corrosive exhaust products

For Ryerson University's labscale hybrid rocket engine, gaseous oxygen (GOx) was selected as the oxidizer for the first series of firings. The ease of handling, storage and availability in small bottles made gaseous oxygen a suitable oxidizer for this test apparatus. Gaseous oxygen, via high-pressure cylinders is effectively pressure-fed into the rocket combustion chamber.

Ultra-high molecular weight low density polyethylene (UHMWLDPE) was selected to be one of the fuels to be used for the original hot firings. Low-density polyethylene, while less energetic, is stiffer compared to the commonly used hydroxyl-terminated polybutadiene (HTPB), and also offers high strength and toughness compared to the latter. At stoichiometric conditions, a low density polyethylene fuel reacting with oxygen at the design chamber pressure potentially yields a peak flame temperature of around $2800 \mathrm{~K}$. The polyethylene fuel grain for the Oct. 2010 firings was composed of Tivar® 1000 natural virgin UHMWLDPE supplied by Pena-Plas Co. 
In addition to the use of low-density polyethylene as fuel, paraffin was also used in Oct. 2010 as a fuel for the rocket engine. Paraffin fuel was used to compare its performance relative to the polyethylene fuel grain. Paraffin is softer than polyethylene and has higher surface regression rates relative to $\mathrm{PE}$ and other conventional solid fuels. The higher regression rate helps in retaining a simpler, single port fuel grain for a given oxidizer mass flux. It is common practice to mix paraffin with opacifiers like India ink, black dye or carbon black. Along with improving structural integrity, these additives lower radiative heating from the burning surface back into the fuel. For the experimental firings held in Oct. 2010, the paraffin fuel grain incorporated 2\% carbon black. International Group Inc.'s IGI 1260 fully refined paraffin wax was used for the test firing in Oct. 2010.

\subsection{System Components}

\section{Combustion chamber}

The fuel grain of the HRE is housed in the combustion chamber of the rocket engine. The fuel and oxidizer mixture is reacted in the combustion chamber to produce hot exhaust gases, which are passed through a nozzle downstream of the chamber. For the Ryerson University labscale hybrid rocket engine, heavy-walled carbon steel drawn-over-mandrel tubing was chosen for the fabrication of the combustion chamber, whose dimensions are shown in Figure. 3.2. This material was selected for its capabilities: high strength, low cost and its ability to withstand the highest temperature and pressure present in the combustion chamber. The chamber was designed to be long enough to also accommodate a precombustion chamber, for preheating the oxygen entering the chamber and also to help ensure proper mixing downstream in the central fuel port. CPI Automation Inc. supplied the combustion chamber pipe and its dimensions are as follows: 
Outer diameter: $3.000 \mathrm{in}=76.20 \mathrm{~mm}$

Inner diameter: $2.250 \mathrm{in}=57.15 \mathrm{~mm}$

Wall: 0.375 in $=9.525 \mathrm{~mm}$

Length: 27.188 in $=690.575 \mathrm{~mm}$

The combustion chamber is illustrated in Figure. 3.2:
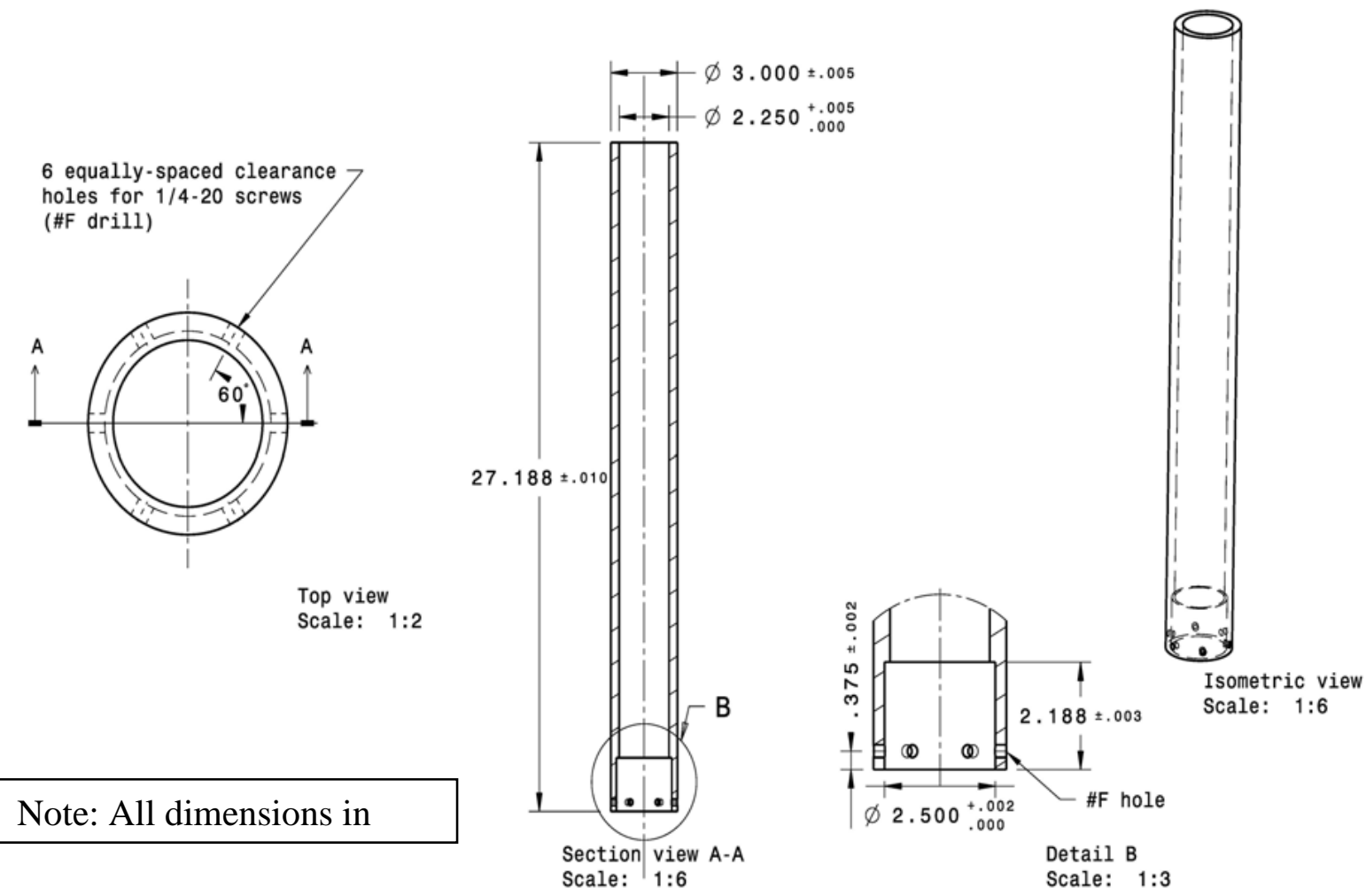

Fig. 3.2: Combustion chamber pipe design dimensions [11].

When designing combustion chambers for rocket propulsion applications, it is important to protect the combustion chamber structure from the hot gases present in the chamber. These high temperature gases can produce thermal stresses in the structure, leading to structural failure. To achieve this, the rocket engine in the current study has Type XX paper-phenolic tubing as an ablative liner. The tubing is available off the shelf with the following dimensions: 
Outer Diameter: 2.250 in $=57.15 \mathrm{~mm}$

Inner Diameter: 2.00 in $=50.8 \mathrm{~mm}$

Wall: $0.125 \mathrm{in}=3.18 \mathrm{~mm}$

Length: 25 in (note: supplied in 40-in. lengths) $=635 \mathrm{~mm}$

\section{$\underline{\text { Feed system and injector assembly: feed distribution panel }}$}

The main function of the RU test cell's feed distribution panel is to ensure uninterrupted and controlled supply of oxidizer (GOx) for start-up and the subsequent main engine firing phase. The feed distribution panel is also used to supply pre-combustion and post-combustion nitrogen purge gas (to prevent any accidental, undesired ignition of fuel). A steel orifice-plate flow regulator is incorporated in the feed line before the engine's head-end plumbing. If choked, the orifice plate ensures complete isolation of the feed system from any flow fluctuations in the engine's combustion chamber. The orifice port (hole) was calculated to be $1.93 \mathrm{~mm}$ in diameter, for a mass flow rate of $0.0307 \mathrm{~kg} / \mathrm{s}$. A pressure drop of at least $20 \%$ of the chamber pressure is required across the downstream injector to further help prevent any feed system associated combustion instabilities. To help ensure low combustion instability, a pressure drop of around $24 \%$ (across the injector) was chosen. The orifice plate flow regulator for experimental firings was supplied by O'Keefe Controls, Inc. To ensure overall safety a non-return valve and rupture disk was employed near the injector. The feed distribution system was developed by CPI Automation Inc. and is shown in Figure. 3.3, which was used for the Oct. 2010 firings. 


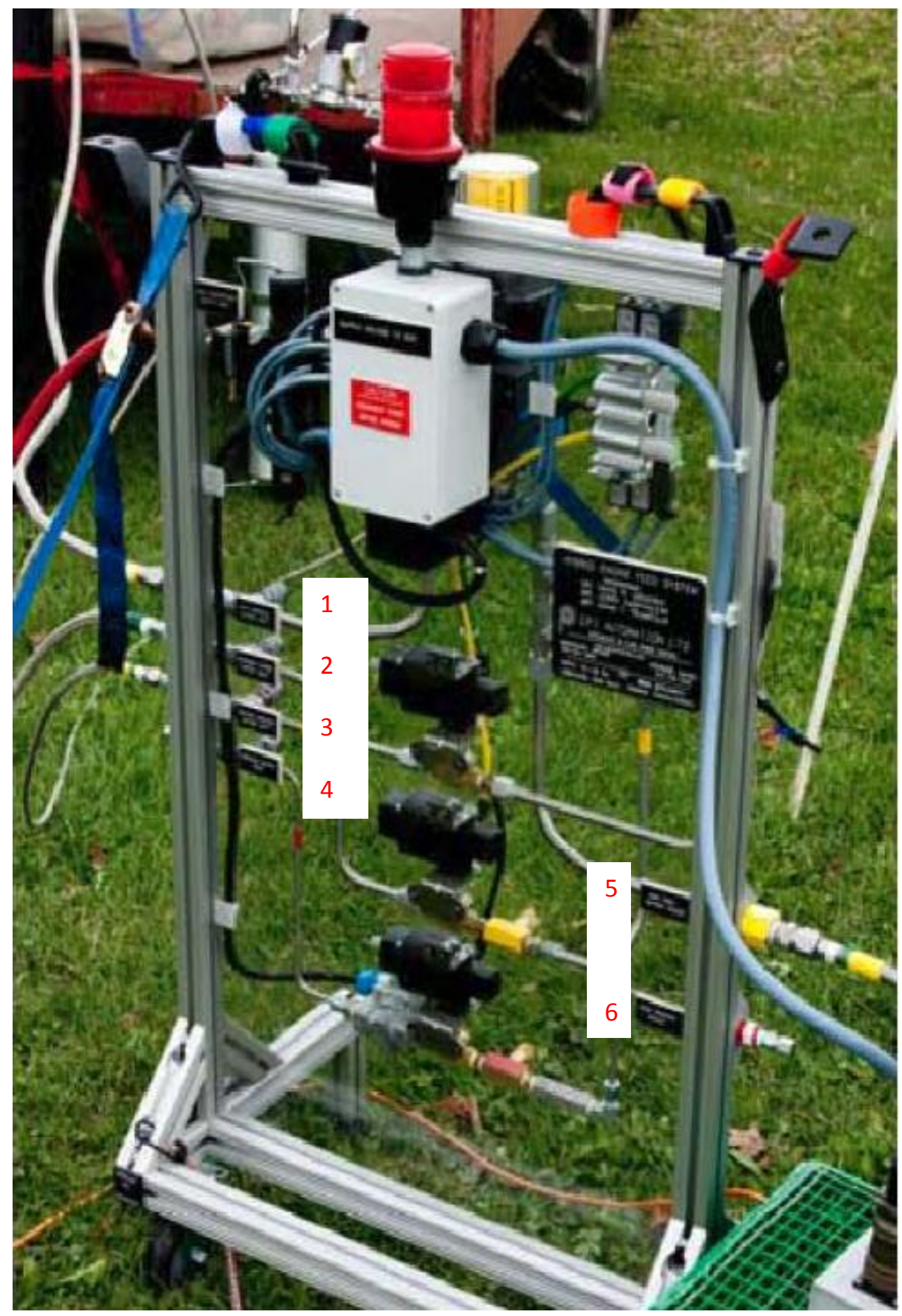

Fig. 3.3: Oxidizer feed distribution panel [5].
1. Main gaseous oxygen inlet
6. Feed propane outlet

2. Nitrogen purge supply inlet

3. Ignition gaseous oxygen inlet

4. Propane supply inlet

5. Main feed oxygen outlet 


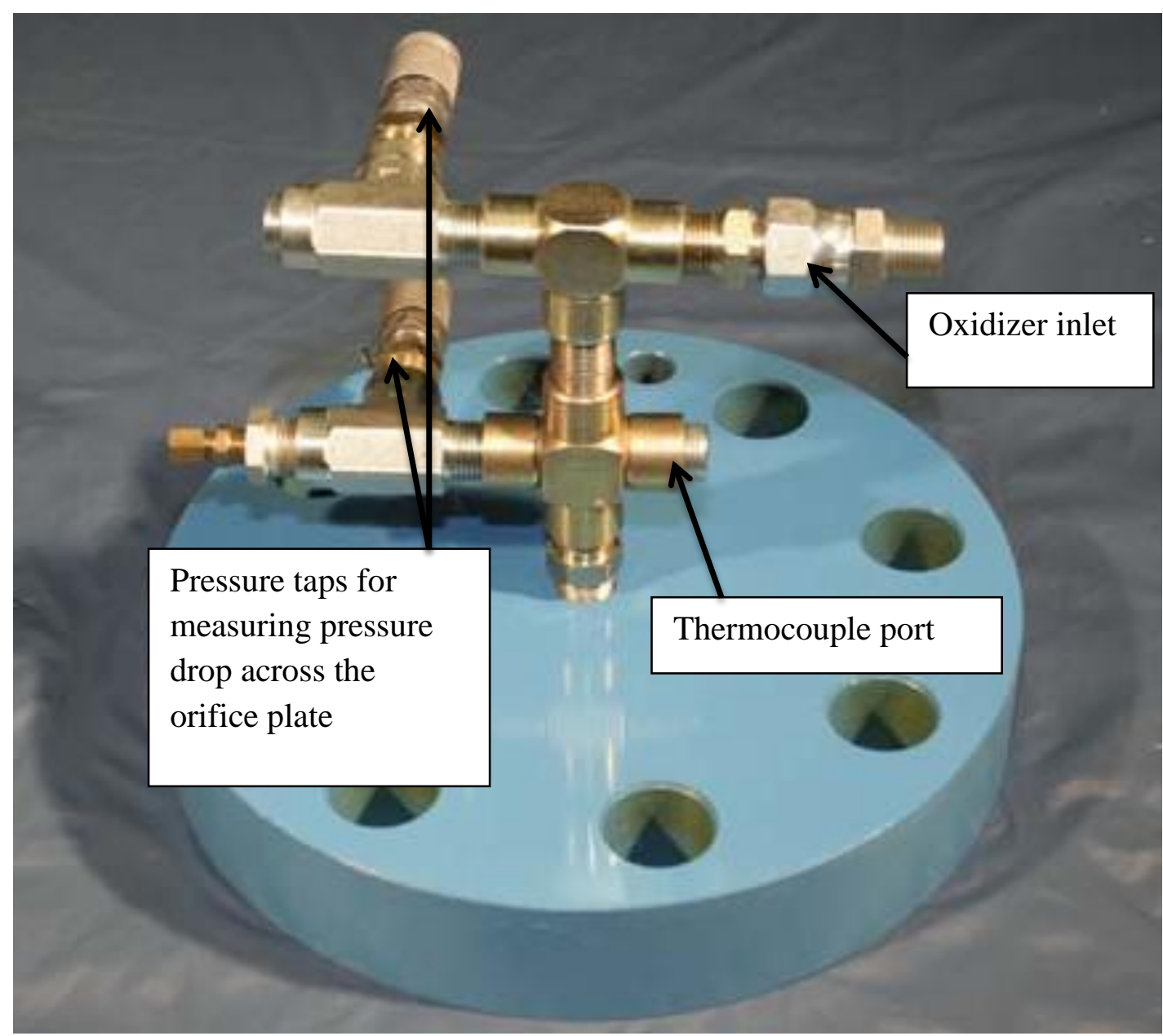

Fig. 3.4: Combustion chamber head end plumbing [11].

Figure. 3.4 shows the head-end plumbing of the engine. The plumbing set-up has separate lines for the oxidizer supply (GOx supply) and nitrogen purge supply.

\section{$\underline{\text { Nozzle }}$}

A good exhaust nozzle for rocket propulsion applications ideally should have low erosion characteristics, low cost of production, and better capacity of withstanding higher temperatures. The nozzle used for the Oct. 2010 firings is shown in Figure. 3.5. It is a conical nozzle with a convergent section of $120^{\circ}$ (full angle) was employed as the nozzle inlet, whereas the divergent nozzle section employed a $12^{0}$ (full angle) cone. Silicon O-rings were incorporated to seal the nozzle at the end of the combustion chamber. 


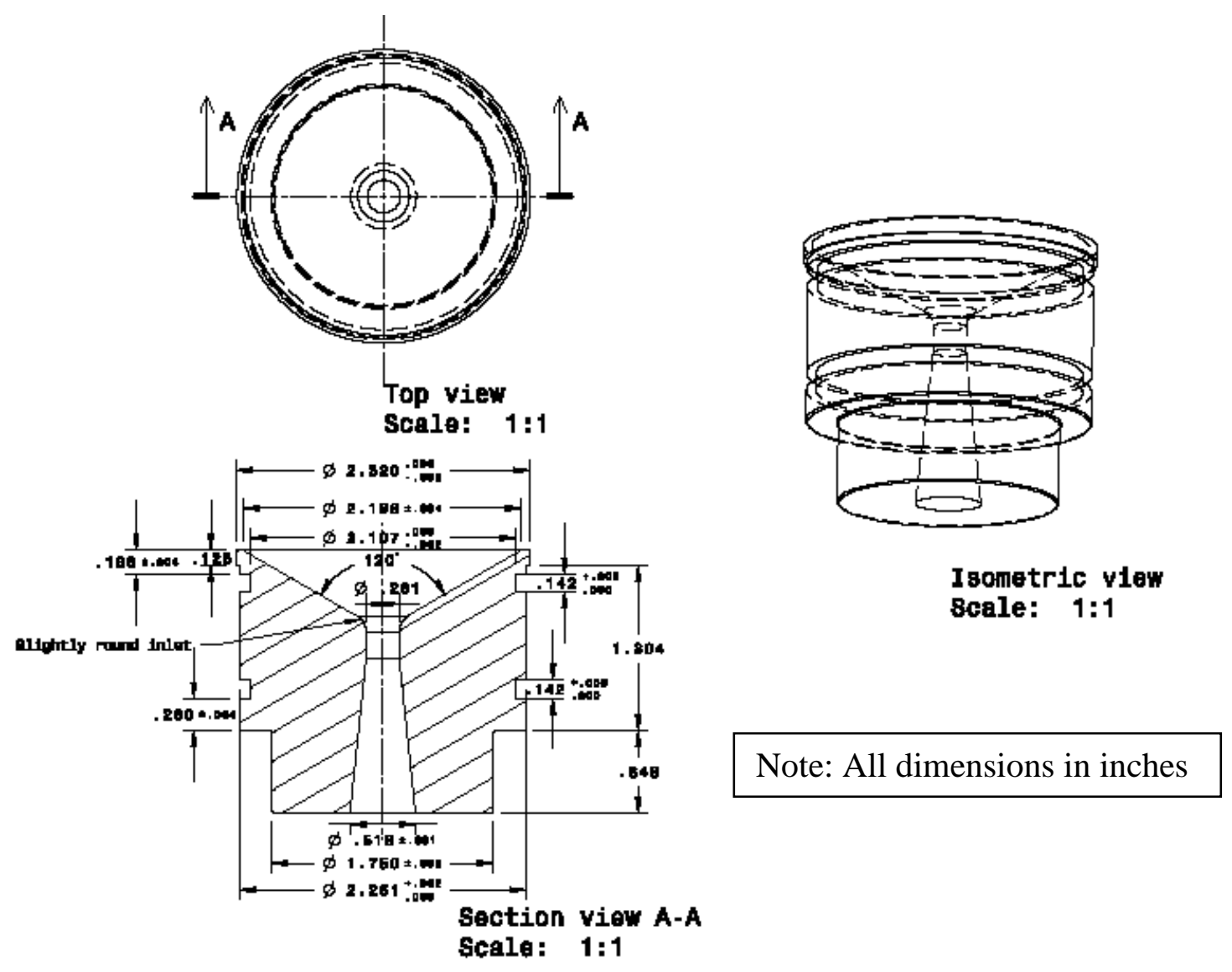

Fig. 3.5: Graphite nozzle configuration [11].

Test stand

A platform of steel I-beams was fabricated to serve as the test bed for the Oct. 2010 firings. Figure. 3.6 shows the test bed with the rocket engine at the firing site. A free sliding mechanism offers some amount of axial movement to the engine. This movement allows the engine to axially press on the load cell for thrust measurement. 


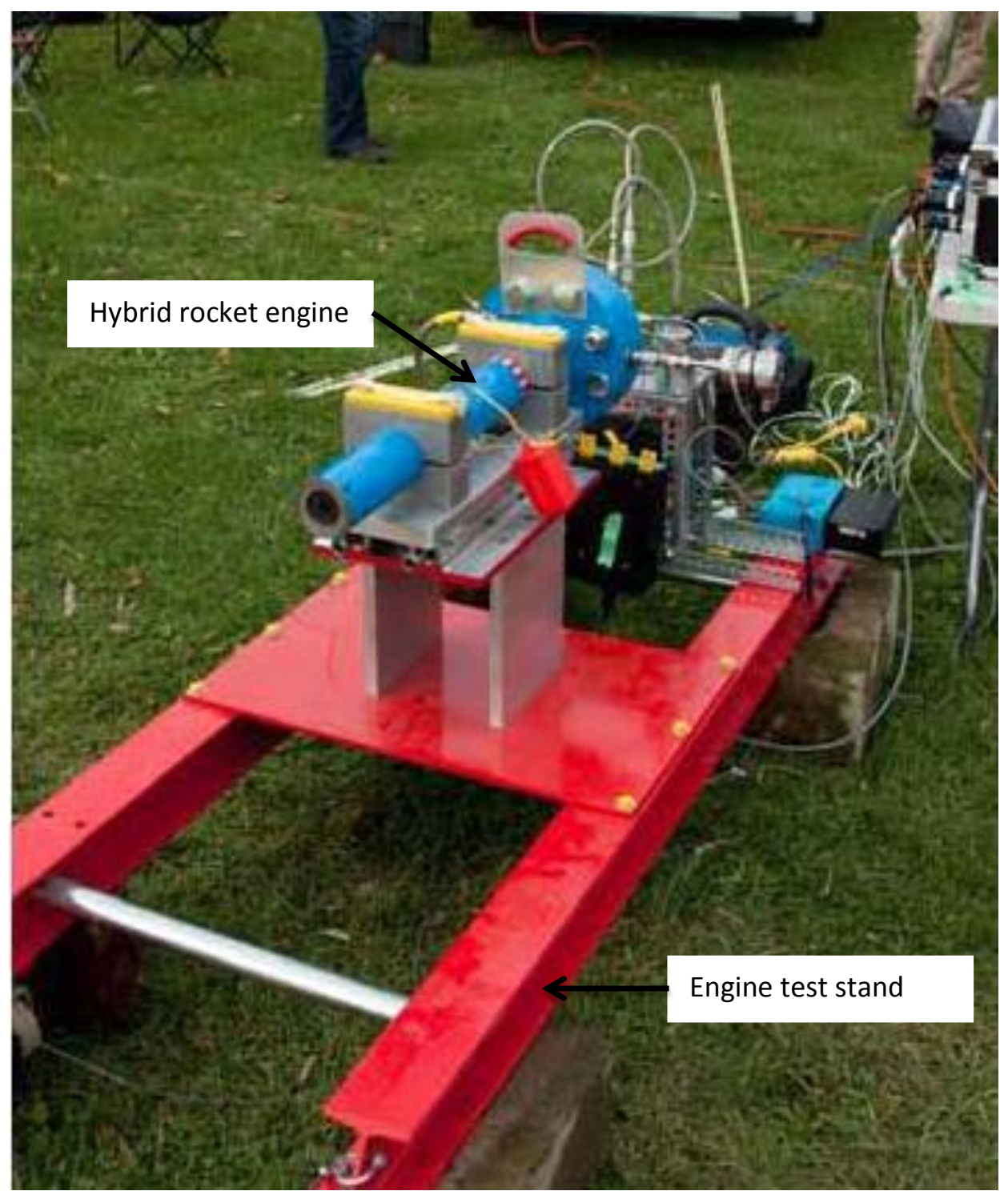

Fig. 3.6: Ryerson hybrid rocket engine on test stand [5].

\section{Instrumentation and data acquisition}

For the test firings conducted in Oct. 2010, a low-frequency strain-gauge type pressure transducer was incorporated at the pre-combustion chamber location, to measure the chamber pressure. The thrust developed by the engine was measured by a thrust-measuring load cell which is placed in the test stand, in contact with the sliding bearing. The data acquisition system was developed by Continuum Aerospace Inc. Data were sampled at 67 $\mathrm{Hz}$ (1 sample every $15 \mathrm{~ms}$, could not use data for post-processing as the sampling rate was quiet low). 


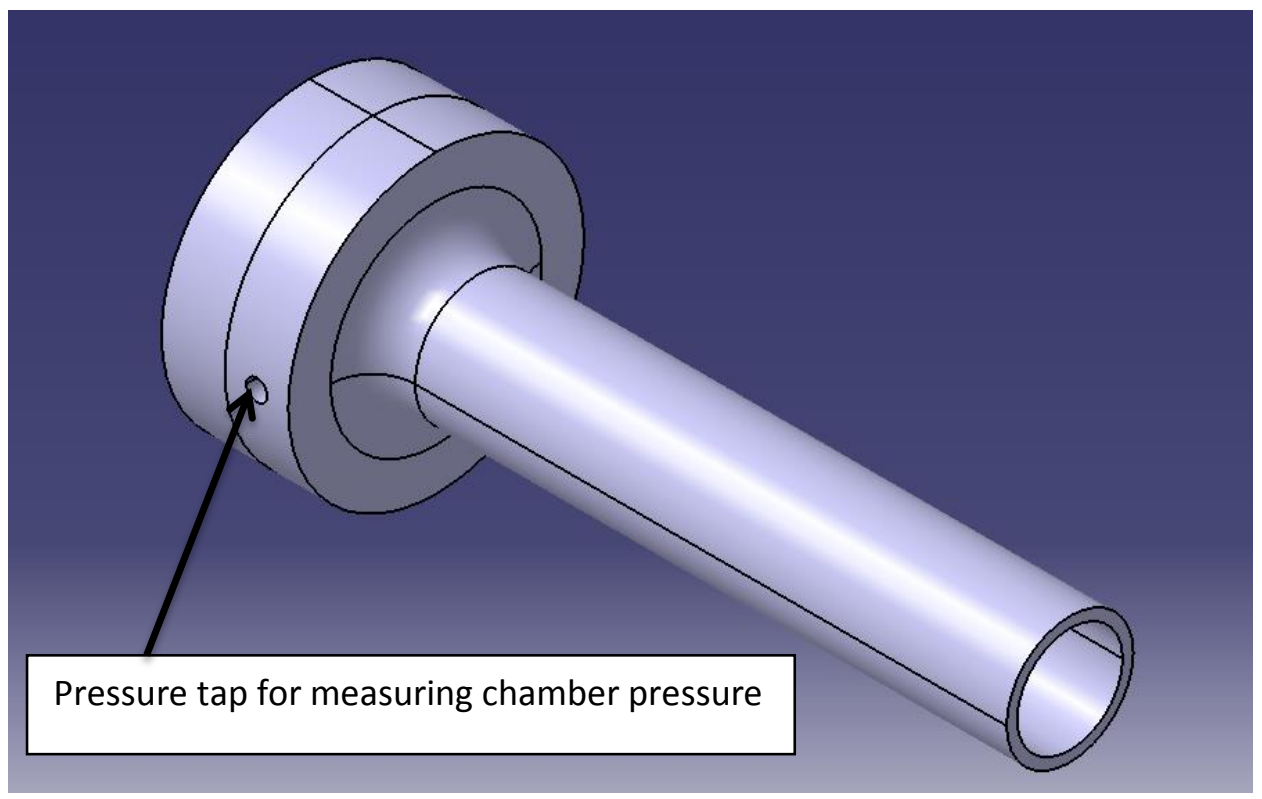

Fig. 3.7: Sketch to show the placement of pressure transducer placement to record chamber pressure data. (Note: Figure not to dimension, for illustration purpose only)

\section{Ignition system}

For both the experimental firings of 2010, ignition of fuel was achieved by placing a lump of steel wool at the head end of the engine. A high voltage sparker and GOx delivered at a lower flow rate ignited the wool and then the fuel near the head end of the engine. Subsequently, the GOx flow rate was increased to sustain burning of the fuel grain for the main firing phase.

\subsection{Experimental test firings}

The Ryerson University hybrid rocket engine was fired twice on the $24^{\text {th }}$ of October, 2010, at the Continuum Aerospace outdoor test site. The length of the actual fuel grain $L_{\mathrm{f}}$ was considerably longer than the stoichiometric fuel grain length $L_{\mathrm{st}}$. The choice of a longer fuel grain length was made to gain some understanding of post-stoichiometric-length ballistic behaviour along the aft portion of the fuel grain. This knowledge would be useful in the future refinement of the Quasi Steady Hybrid (QSHYB) internal ballistic simulation code. 


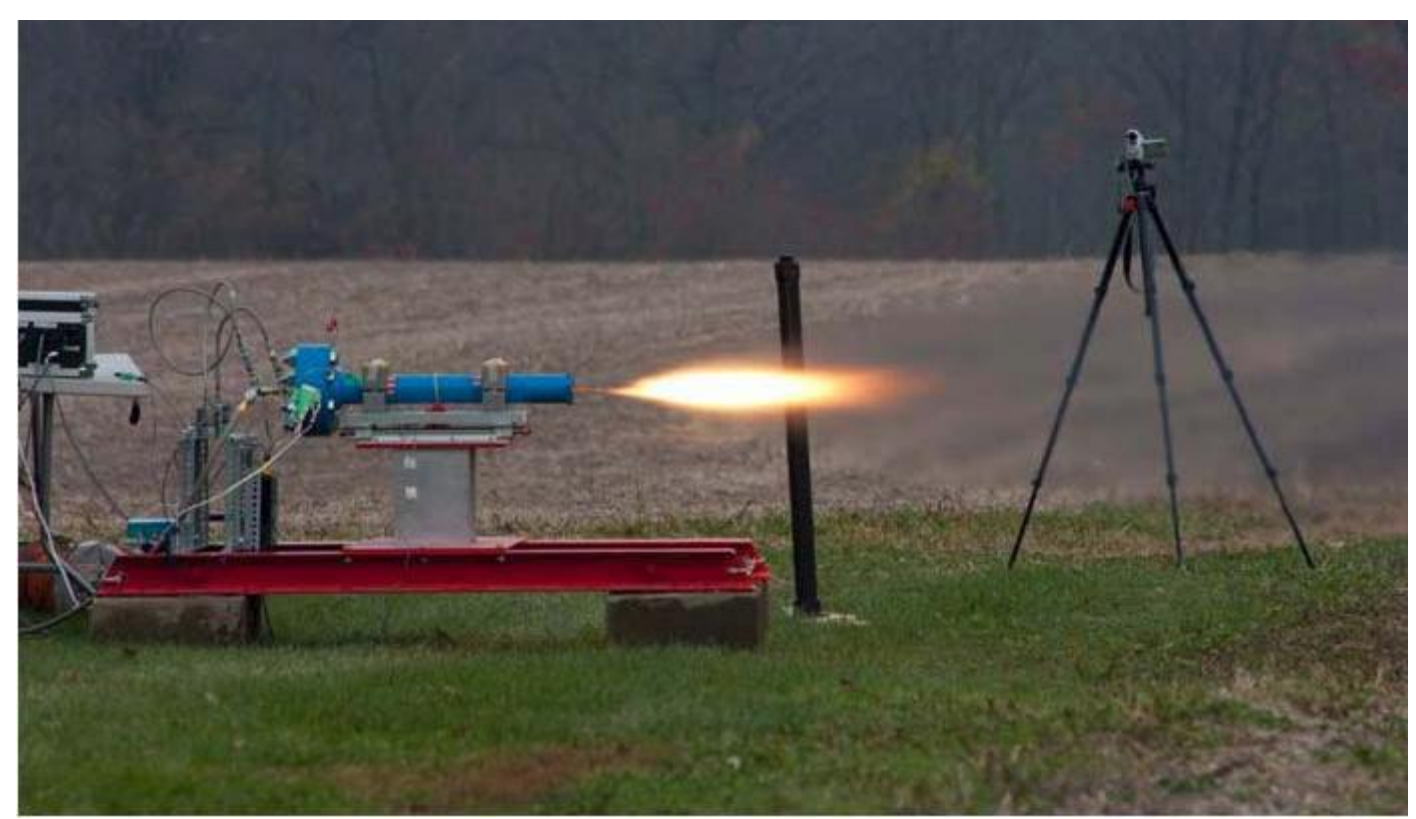

Fig. 3.8: Photo of Ryerson University labscale hybrid rocket engine (LDPE / GOx) being

fired at Continuum Aerospace test site [5]

Figure. 3.8 shows a picture taken while firing the rocket engine with the LDPE/GOx propellant combination. The orange coloured flame visible in the exhaust plume aft of the rocket suggested the presence of unreacted fuel in the exhaust of the rocket which later reacted with atmospheric air. The total time of firing was $6 \mathrm{sec}$ and the data acquisition was terminated at $7 \mathrm{sec}$. The pressure and thrust profiles obtained for the LDPE/GOx firing case are shown in Figures. 3.9 and 3.10 From the figures, one can notice that thrust oscillations of higher amplitude were recorded during the firing. The corresponding chamber pressure profile does not exhibit oscillations of higher amplitude. 


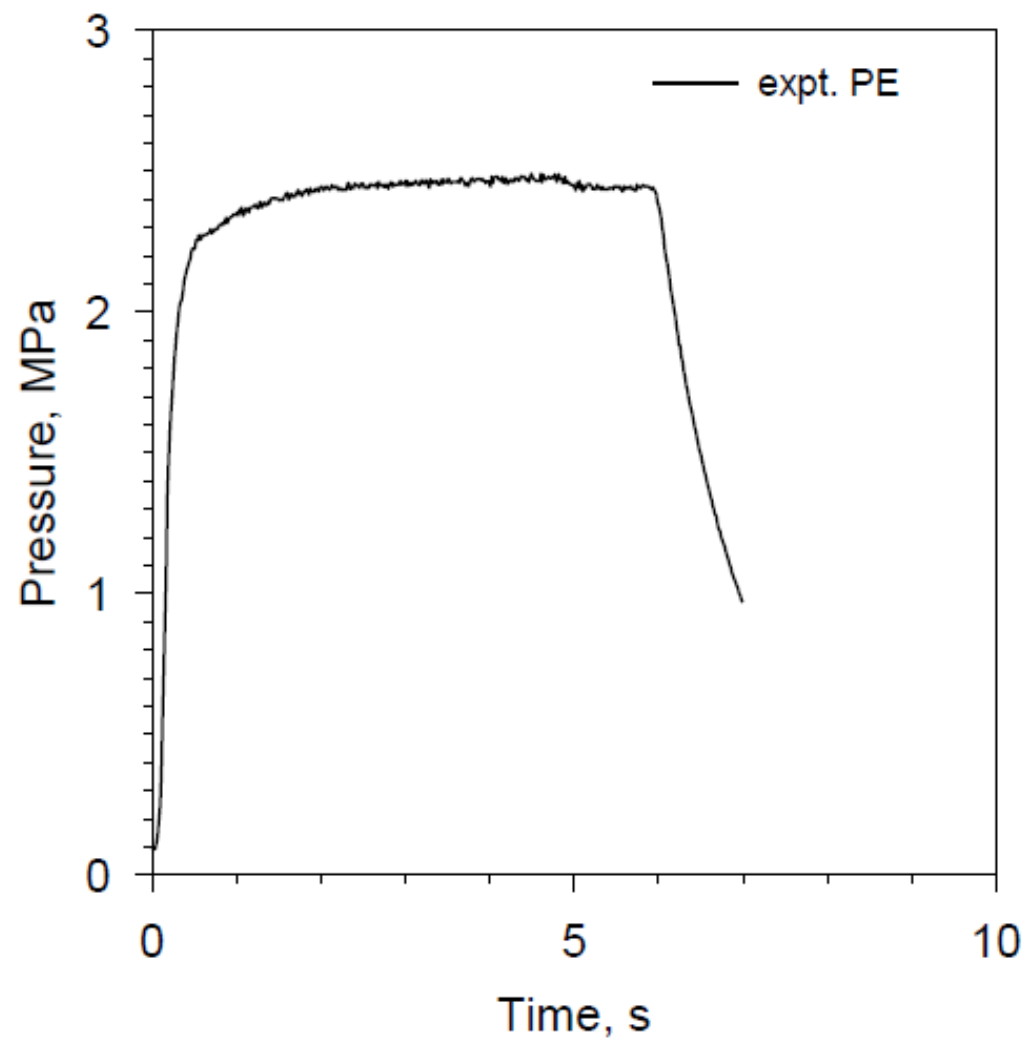

Fig. 3.9: Experimental pressure-time profile for Ryerson's LDPE / GOx test firing [5]. 


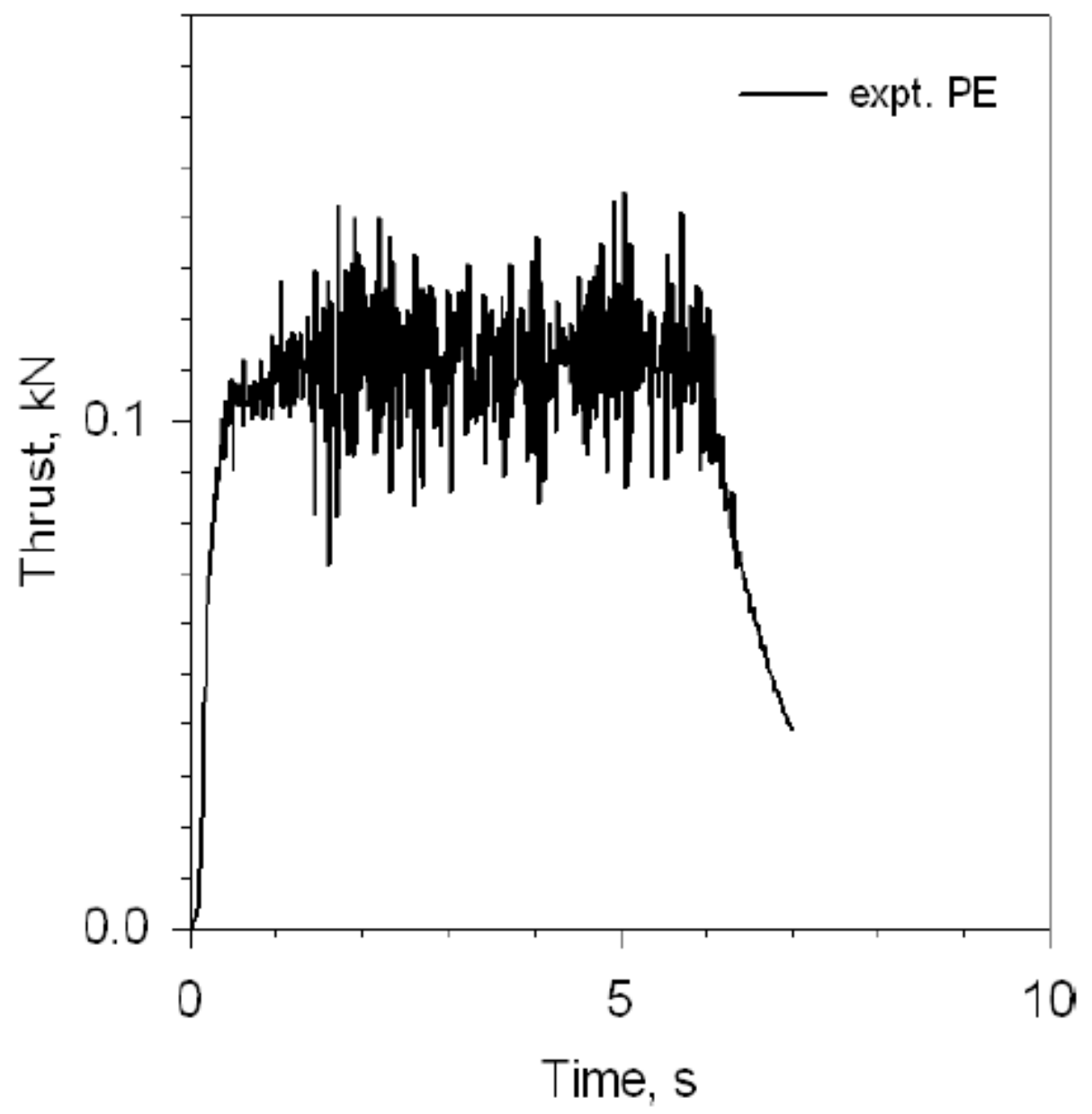

Fig. 3.10: Experimental thrust-time profile for Ryerson's LDPE / GOx test firing [5]. 


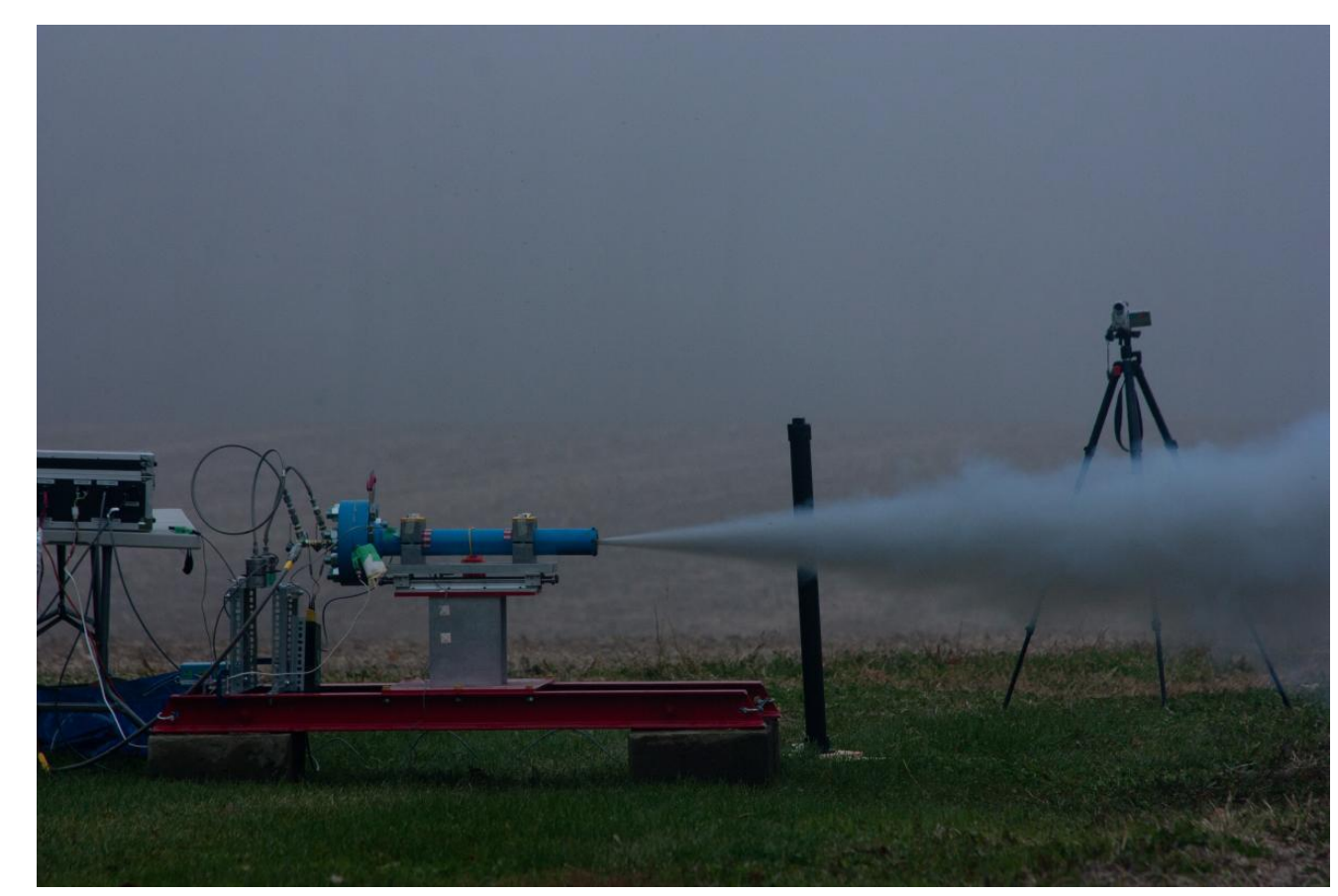

Fig. 3.11: Photo of Ryerson's paraffin / GOx HRE being fired at the Continuum Aerospace test site [5].

Figure. 3.11 shows a photo taken during the paraffin/GOx firing. The greyish exhaust plume suggested the ejection of soft unreacted paraffin droplets and vapour in the exhaust stream. The pressure and thrust plots obtained for burning of this fuel-oxidizer combination are shown in the following figures. Unlike the thrust oscillations observed in LDPE/GOx firing, the thrust oscillations observed in paraffin/GOx firing are lower in amplitude. A variation in thrust due to variation in chamber pressure is also noted from Figure 3.12 and 3.13 . 


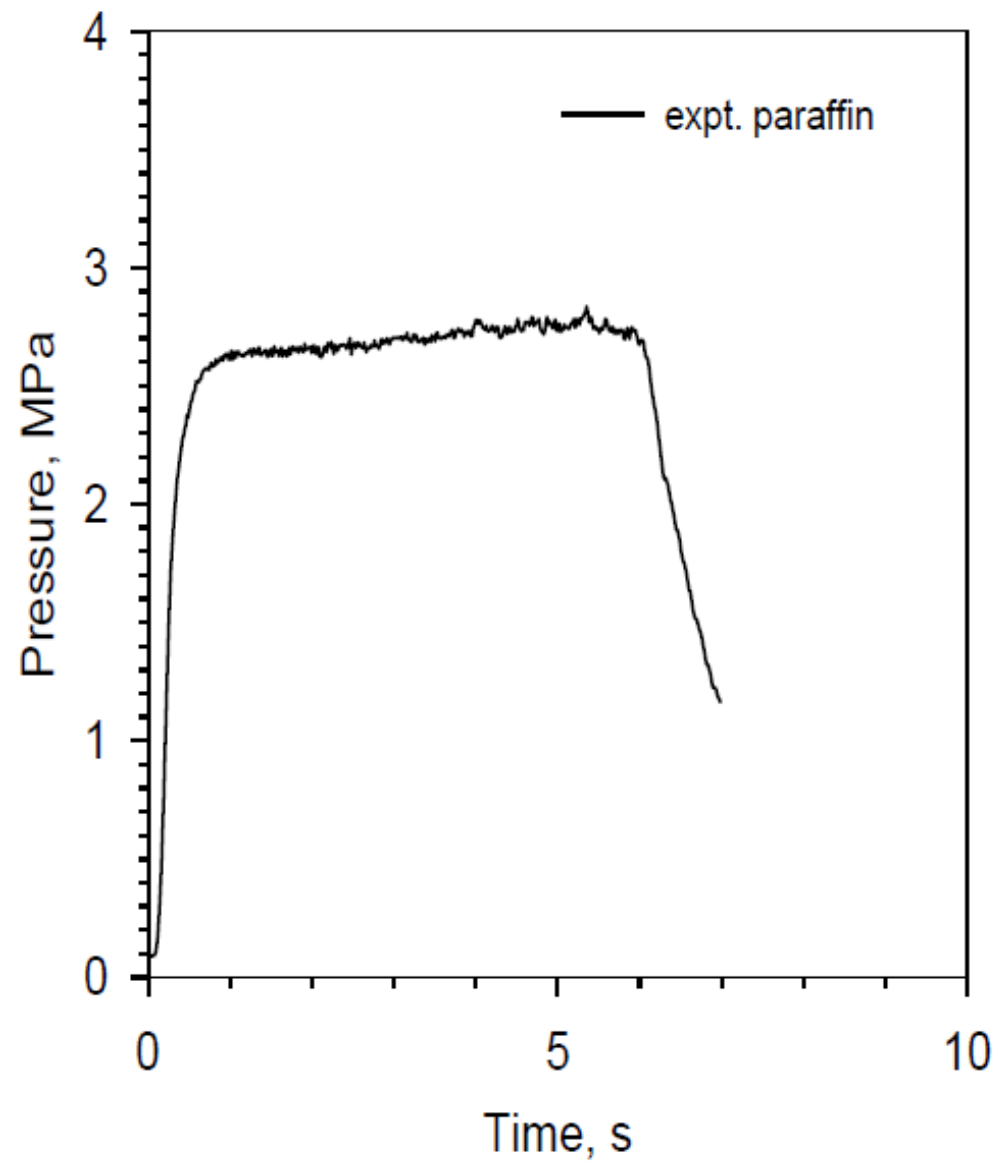

Fig. 3.12: Experimental pressure-time profile for Ryerson's paraffin / GOx test firing [5]. 


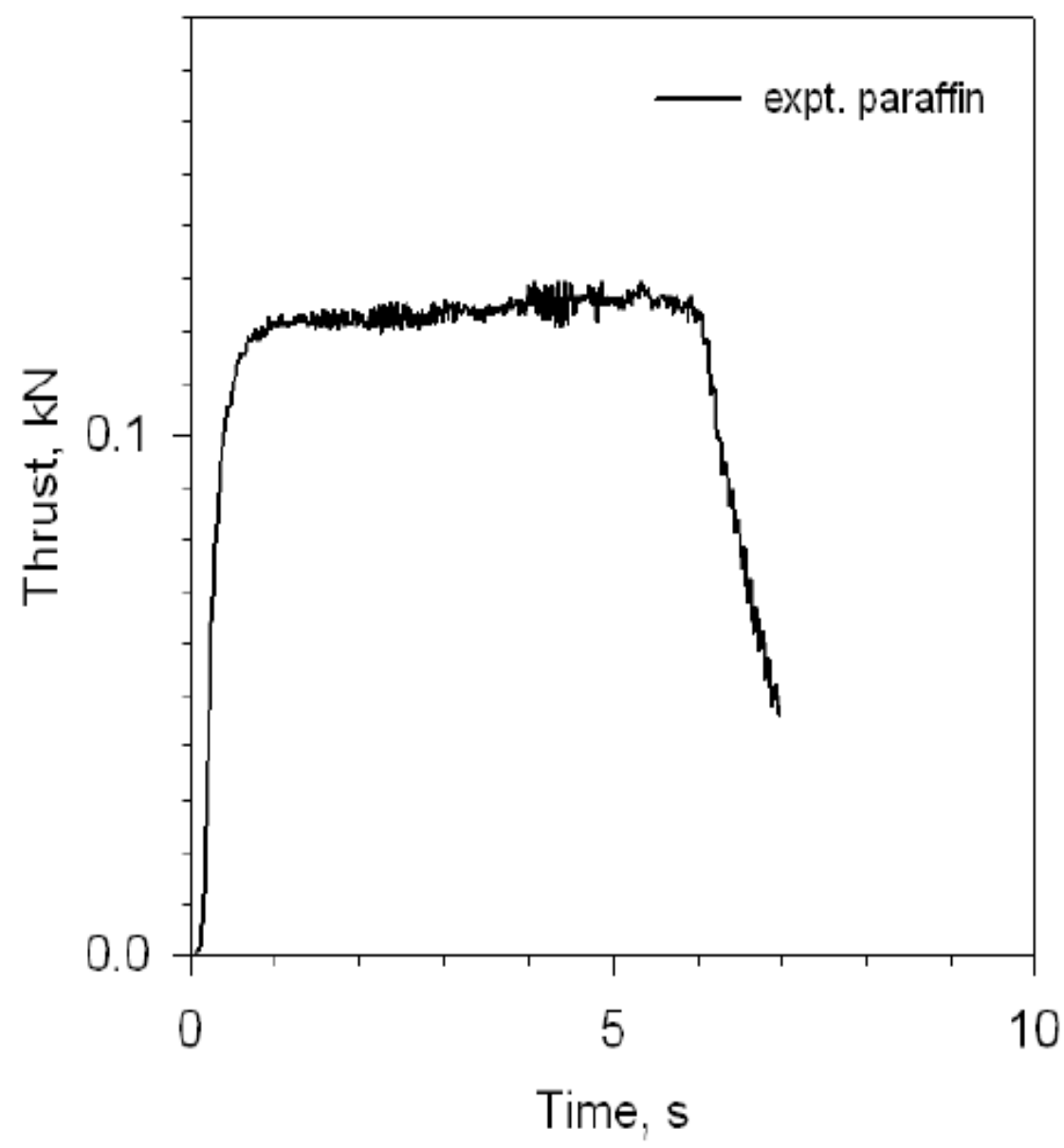

Fig. 3.13: Experimental thrust-time profile for Ryerson's paraffin / GOx test firing [5].

From Figures. 3.10 and 3.13 It can be noted that the oscillations in the thrust-time profile observed earlier for the LDPE/GOx firings are higher than oscillations observed in the thrust-time profile of the paraffin/GOx firings. It is assumed that the liquid fuel droplets present in the core flow of the paraffin/GOx firing stabilized the flow and hence, reduced the oscillations. 


\section{Cold Flow Test}

Preparing and conducting hot firings of a rocket engine (i.e., with combustion) can be an expensive and time-consuming process. To investigate the flow behaviour within a rocket engine flow system, one can employ cold- flow techniques to record and study the flow characteristics. Cold flow tests (i.e., without combustion) are chemically inert, safe and relatively less expensive to perform. Though the high amount of heat released during the combustion certainly affects the combustion chamber gas flow, elements of the flow behaviour may to some degree be similar between the two cases.

In the current study, cold flow techniques are used to evaluate the flow behaviour in the Ryerson University hybrid rocket engine flow system, and the interaction that takes place with the surrounding test structure. Pressurized air is used as the working fluid to achieve the above-mentioned flow conditions at a moderate temperature. The pressures upstream and downstream of the injecting system's flow regulating orifice plate are recorded along with the head-end pressure of the combustion chamber. Also, the gas temperature in the chamber is recorded by the HBM Spider 8 data acquisition system using a $\mathrm{K}$ type thermocouple. The details of the transducers, sensors and the data acquisition system are provided later in this chapter.

\begin{tabular}{|l|l|}
\hline Working Fluid & Pressurized air \\
\hline Supply pressure & $750 \mathrm{psi}$ \\
\hline Ideal mass flow rate & $0.03 \mathrm{~kg} / \mathrm{s}$ \\
\hline
\end{tabular}

Table 4.1: Air supply conditions for cold flow test 


\subsection{Test Apparatus}

To perform the cold flow test with the Ryerson University hybrid rocket engine on its test stand, several systems are employed such as,

\section{Air supply system}

As mentioned previously, the cold flow test on the RU rocket engine internal flow system is performed using pressurized air. Pressurized air tanks are used to supply air at the required pressure. For the tests, a feed pressure of 750 psi was used (similar to a hot firing; in that case, GOx was supplied at $750 \mathrm{psi}$ ). A high-mass-flow air regulator is used to control the feed pressure. Stainless steel braided Teflon flex hoses of $1 / 2$ inch diameter are used to connect the tanks to the oxygen feed distribution panel and to the rocket head end plumbing.

The feed system consists of a flow regulating orifice plate which is to measure the oxidizer feed rate to the rocket engine and also isolates the feed system from backwards flow of air from the combustion chamber to the feed system.

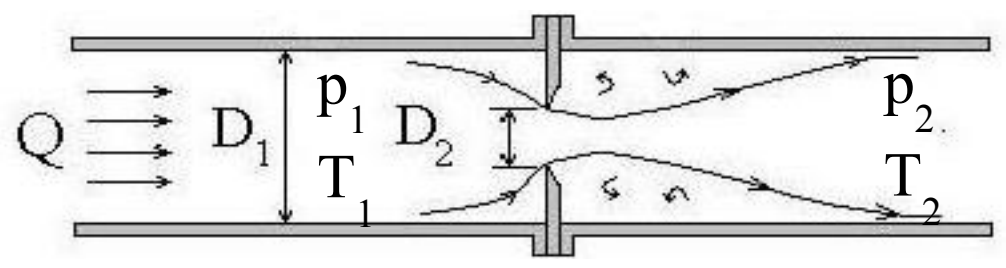

Fig. 4.1: Flow of gases trough an orifice plate

For a steady state, compressible flow through pipes the Bernoulli's equation is given as

$$
\frac{p_{1}}{\rho_{1}}\left(\frac{\gamma}{\gamma-1}\right)+\frac{V_{1}^{2}}{2}=\frac{p_{1}}{\rho_{2}}\left(\frac{\gamma}{\gamma-1}\right)+\frac{V_{2}^{2}}{2}
$$

where, $p_{1}$ and $V_{1}$ are the stagnation pressure and velocity of the fluid upstream of the orifice plate. $p_{2}$ and $V_{2}$ are the pressure and velocity of the fluid downstream of the orifice plate. And 
$\rho_{1}$ and $\rho_{2}$ are the densities of the fluid upstream and downstream of the orifice plate respectively. By the mass continuity equation, fluid flow rate is given by,

$$
Q=A_{1} \cdot V_{1}=A_{2} \cdot V_{2}
$$

Here $A_{1}$ and $A_{2}$ are the cross section areas of the pipe upstream of the orifice plate and orifice plate hole respectively. For an incompressible fluid, the mass flow rate through an orifice plate is given by,

$$
\dot{m}=\rho Q=C A_{2} \sqrt{2 \rho\left(p_{1}-p_{2}\right)}
$$

where $C$ is a dimensionless parameter known as orifice plate flow coefficient. For a compressible fluid, such as gases, the mass flow rate is given by:

$$
\dot{m}=\rho_{1} Q=C Y A_{2} \sqrt{2 \rho_{1}\left(p_{1}-p_{2}\right)}
$$

The term $Y$ is known as the expansion factor, to account for the compressibility of gases. For incompressible fluids $Y$ is equal to 1.0. The value of $Y$ is given by an empirical formula:

$$
Y=1-\left(\frac{1-r}{\gamma}\right)\left(0.41+0.35 \beta^{4}\right)
$$

The symbol $\beta$ is the ratio of orifice plate hole diameter to pipe diameter, and $r$ is the ratio of pressure downstream of the orifice plate to the pressure upstream of the orifice plate. For smaller values of $\beta$, the value of $Y$ can be calculated neglecting the effect of $\beta$.

From further simplification of Eq. (4.4) and (4.5), for choked flow, where $\mathrm{P}_{2}$ is equal to $0.528 \mathrm{p}_{1}$, the mass flow rate of air entering the chamber is calculated using the following equation:

$$
\dot{m}=C A p_{1} \sqrt{\frac{\gamma}{R T_{1}}\left(\frac{2}{\gamma+1}\right)^{\frac{\gamma+1}{\gamma-1}}}
$$


where $\dot{\mathrm{m}}$ is the mass flow rate of air. $\mathrm{p}_{1}$ and $\mathrm{T}_{1}$ are stagnation pressure and temperature upstream of the regulating orifice plate. $\mathrm{C}$ is the discharge coefficient of the regulating orifice plate and is equal to 0.77 , as ascertained by the supplier data sheet, and $\mathrm{A}$ is the area of the orifice.

Air is passed through the regulating orifice plate and led to the combustion chamber through the oxidizer injector. In a normal hot firing, the pressure built up in the combustion chamber is due to the combustion of the fuel grain. To experimentally simulate similar pressure conditions in the main chamber, the exhaust nozzle throat diameter was reduced to nearly half of the original engine's nozzle throat diameter $(6 \mathrm{~mm}$ down to $2.83 \mathrm{~mm})$ to achieve a choked nozzle condition, $\frac{p_{\text {exit }}}{p_{\text {inlet }}}=0.528$ and the desired pressure level.

The exhaust nozzle throat diameter was calculated using the following equation [1]:

$$
\dot{m}_{t}=\dot{m}_{e}=\frac{1}{c^{*}} A_{t} p_{c}=\left[\frac{\gamma}{\mathrm{RT}_{F}}\left(\frac{2}{\gamma+1}\right)^{\frac{\gamma+1}{\gamma-1}}\right]^{1 / 2} A_{t} p_{c}
$$

where $\dot{m}_{t}$ is the mass flow rate of exhaust gases through the nozzle throat. $\mathrm{T}_{\mathrm{F}}$ is the flame temperature in the combustion chamber. $R$ is the specific gas constant, $\gamma$ is the ratio of specific heats, $A_{t}$ is the nozzle throat area. $p_{c}$ is the combustion chamber pressure.

The mass flow rate was set to $0.032 \mathrm{~kg} / \mathrm{s}$ based on the pressure and temperature data upstream of the regulating orifice and adjusting the flow regulator at the air supply tanks, and the nozzle throat diameter was sized for reproducing the original hot firing chamber pressure of approximately 300 psi. For the stated chamber pressure the nozzle throat diameter was determined to be $2.85 \mathrm{~mm}$. Nozzle throat inserts with the following diameters were manufactured to vary the combustion chamber pressure above and below the nominal value 
of 300 psi, and allow for an evaluation of choked vs. unchoked upstream flow conditions at the orifice plate flow regulator position.

$2.5 \mathrm{~mm}$ - Drill bit number 40

$2.79 \mathrm{~mm}$ - Drill bit number 35

$3.05 \mathrm{~mm}$ - Drill bit number 31

\section{$\underline{\text { Transducers and Sensors }}$}

The flow, structural vibration and rocket thrust performance experimental data are measured using different transducers and sensors. For pressure measurements at different locations as shown in Figure. 4.2, the PX4100 series strain gauge type transducers from Omega Engineering Inc. ${ }^{\circledR}$ is used. These transducers have a response time of $10 \mathrm{~ms}$. The accuracy range of the pressure transducers is +/- 0.25\% Full Scale which includes linearity, and hysteresis. The pressure transducers placed upstream and downstream of the orifice plate regulator have a maximum measuring capability of $1000 \mathrm{psi}(6.895 \mathrm{MPa})$ and $600 \mathrm{psi}(4.136$ $\mathrm{MPa})$ respectively (PX4100-1KGV and PX4100-600GV). The pressure transducer placed at the head end of the combustion chamber can measure a maximum pressure value of up to 600 psi (4.136 MPa). Figure. 4.3 shows a picture of Omega's PX4100 series pressure transducer. The calibration data for the transducers can be found in Appendix A. 


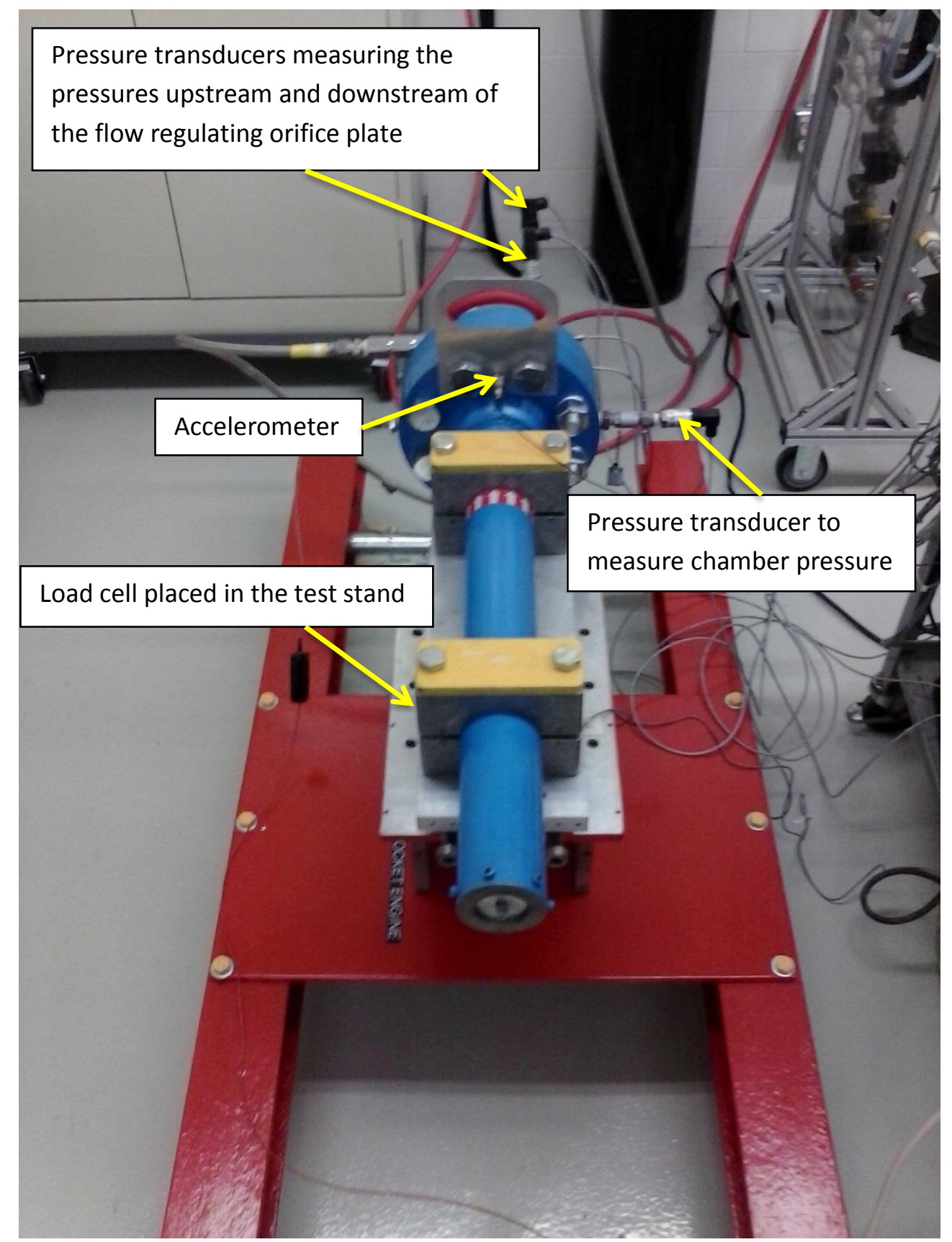

Fig. 4.2: Rocket engine with the test stand and the instrumentation connected to the rocket engine 


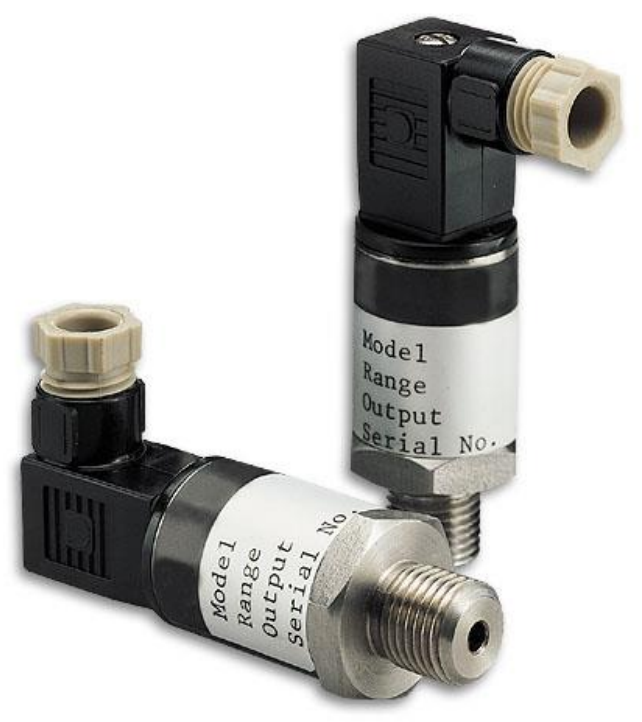

Fig. 4.3: Omega ${ }^{\circledR}$ 's $P X 4100$ series strain gauge transducers.

\section{Load cell}

Thrust produced by the RU rocket engine during the cold flow test is measured by a load cell placed in the test stand as shown in Figure. 4.2. The thrust data is collected to check for any potential oscillations in the thrust profile of the rocket engine. The load cell is connected to a signal conditioner to condition and amplify the output from the load cell. The output from the signal conditioner is connected to the data acquisition system. The load cell used is the MLP-200 series transducer from Transducer Techniques as shown in the Figure. 4.4 The details and the calibration certificate of the load cell can be found in Appendix B. 

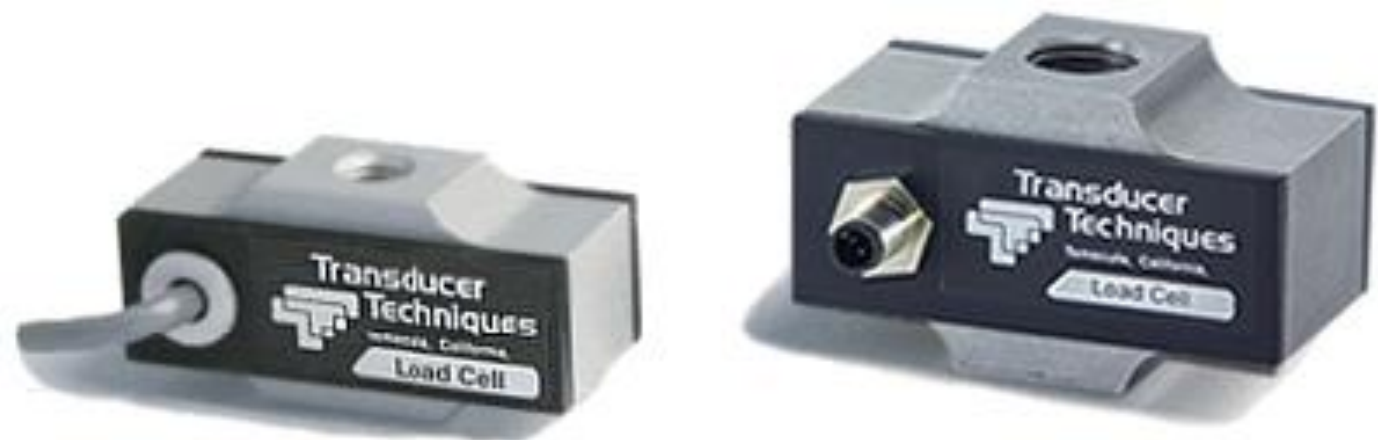

Fig. 4.4: Transducer Techniques® MLP-200 load cell.

\section{$\underline{\text { Accelerometer }}$}

A unidirectional piezoelectric accelerometer is placed on the flange positioned at the external front end of the rocket engine (Figure. 4.5). The accelerometer measures the axial oscillation of the rocket structure during the cold flow test. The oscillations are measured in units of ' $\mathrm{g}$ ', i.e., the acceleration due to gravity. The signal from the accelerometer is amplified and fed to the data acquisition system. The recorded data is used for post processing. 


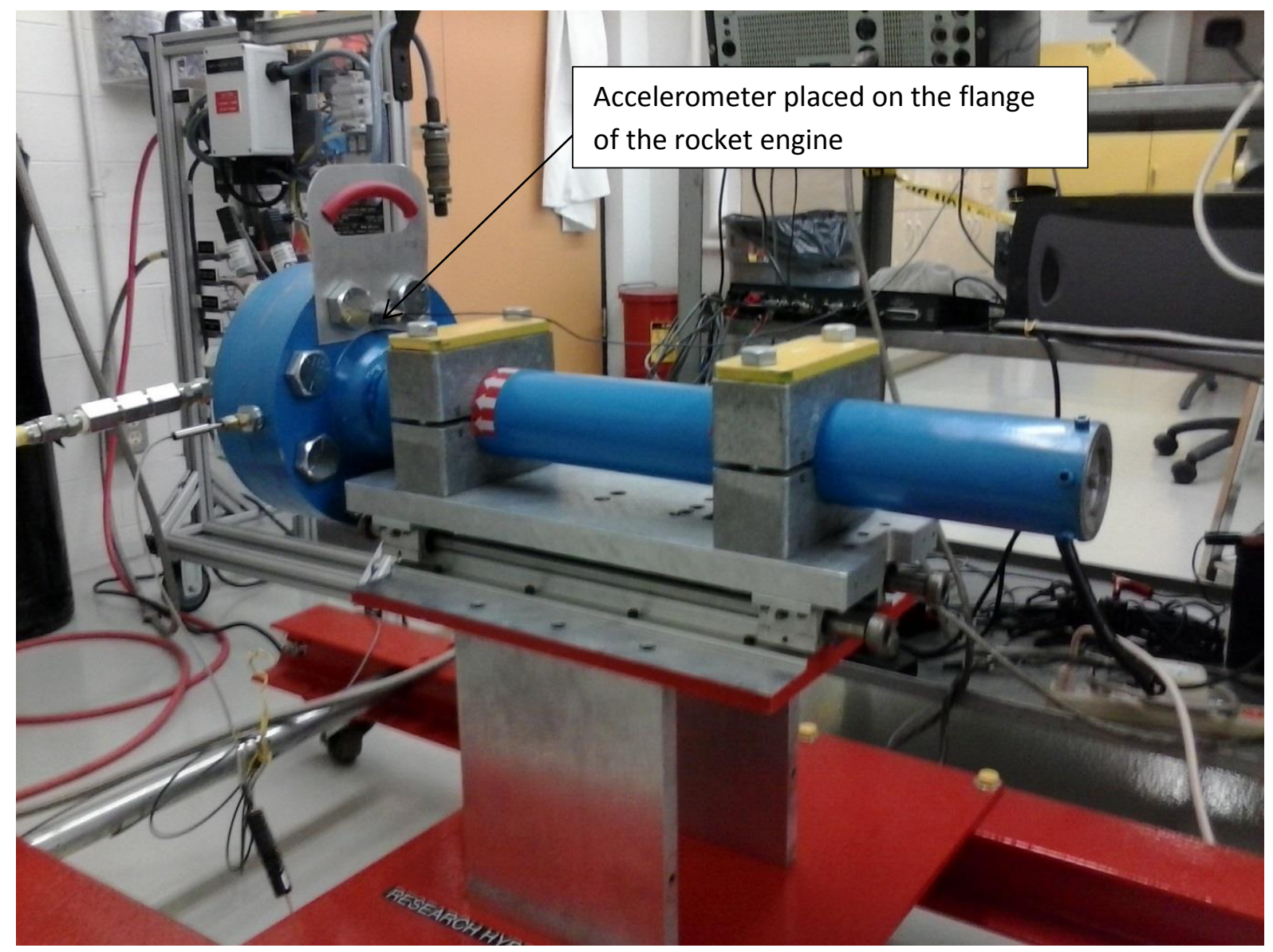

Fig. 4.5: Accelerometer placement on the rocket engine.

\section{$\underline{\text { WaveBook } 516 \text { DAQ }}$}

The data acquisition system is a crucial piece of hardware. The analog signals collected from various transducers are quantified, and converted to digital/computer readable format by the data acquisition system. Ideally, data should be sampled at a minimum of 1 $\mathrm{KHz}(1000$ samples in $1 \mathrm{sec})$ to capture the appearance of any lower frequency phenomenon. The WaveBook 516 data acquisition system is a user-friendly high-speed data acquisition system. The DAQ has 8 channels for reading inputs, as shown in Figure. 4.6 with a maximum sampling rate of $1 \mathrm{MHz}$ per channel. The sampling rate was set to $1 \mathrm{KHz}$ in all the input channels for the tests conducted. 


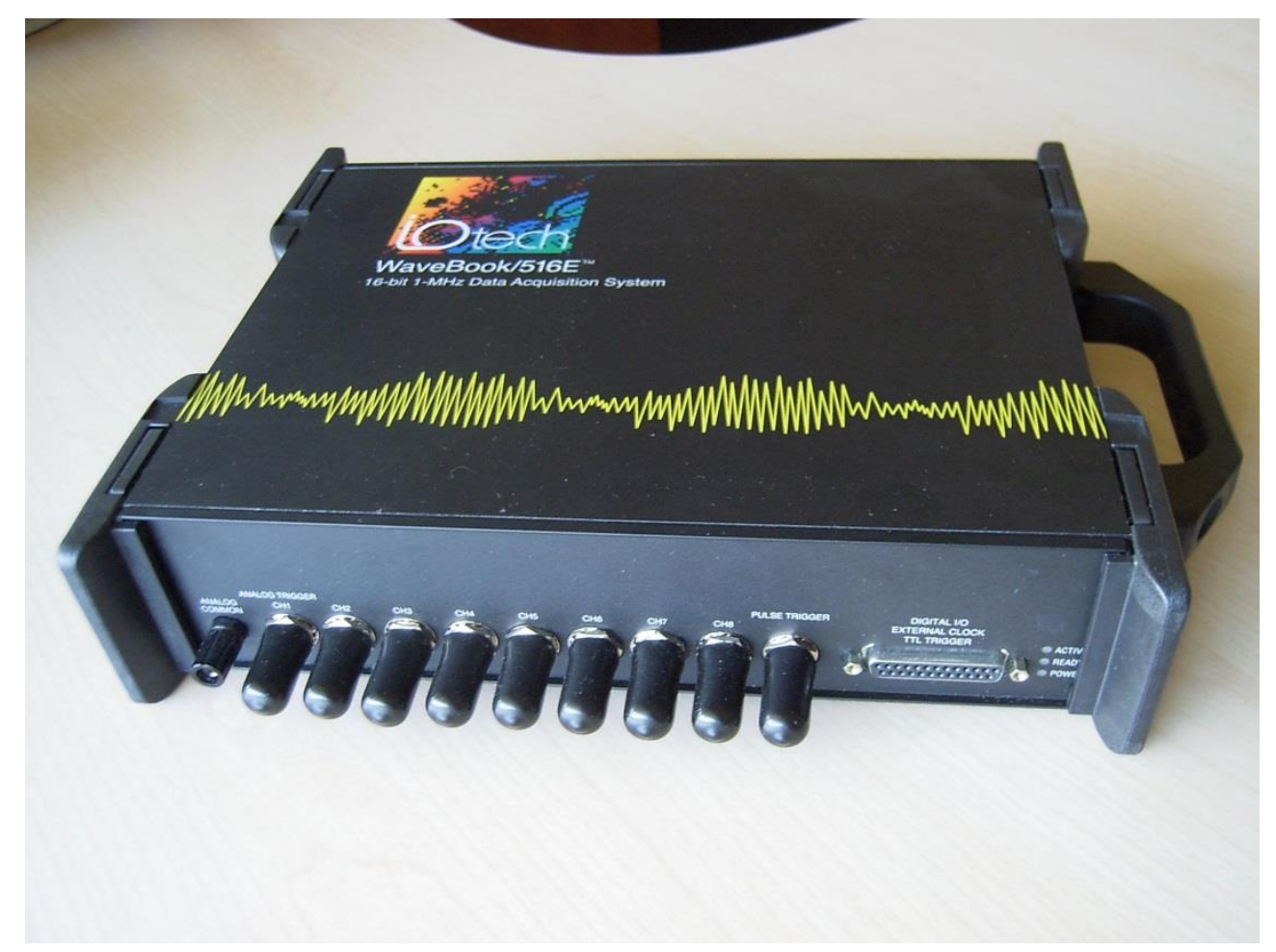

Fig. 4.6: WaveBook 516 data acquisition system.

\subsection{Test Procedure}

Cold flow tests of HREs are similar to hot firing tests at least in terms of oxidizer supply (cold in either case) and the means for data acquisition. The difference is the functional characteristic of the rocket engine. In a hot firing test, the fuel is combusted and the heat generated influences the flow characteristics (hot gas vs. cold gas), and consequently the resulting thrust and the specific impulse $\left(\mathrm{I}_{\mathrm{sp}}\right)$ delivered.

In a cold flow test, the gas flow in the chamber and the incoming oxidizer flow system are simulated with pressurized air. The difference in performance of the rocket due to a low vs. a high operational gas temperature in the combustion chamber is clearly evident by the thrust data obtained (higher temperature of gas gives higher thrust delivery plus higher acoustic frequencies). 
The steps followed in the cold flow test are:

Pre-test setup:

Air feed supply setup

- The transducer connections to the rocket engine and support structure are checked for integrity.

- The pilot pressurized air flow is turned on to arm the feed distribution panel.

- Air tanks supplying pressurized air are opened and the feed pressure is set to $750 \mathrm{psi}$.

\section{Data acquisition system setup}

- The pressure, vibration and load cell data are collected by the WaveBook 516 DAQ system.

- The temperature data is collected and recorded on the HBM Spider 8 data acquisition system.

- Once the data acquisition systems are turned on, the power supply connections to the transducers is checked, and a dry run is conducted to check the functioning of the transducers.

- Zero reading settings and minor calibrations are done if necessary.

\section{Cold flow test}

- After the pre-test setups are complete, the countdown on the Catman 4.5 Express software's graphic user interface (software package used to acquire temperature data from HBM Spider 8 data acquisition system) is started. The countdown runs from 12 $\sec$ to $0 \mathrm{sec}$.

- After the countdown reaches 0 , the data acquisition on the WaveView scope is turned on. 
- After a few seconds for acquiring the initial data, the solenoid valve in the feed distribution panel is opened for pressurized air to flow into the rocket chamber.

- The air flow channel is open until the pressure within the rocket combustion chamber reaches steady state. After the steady state pressure (main firing) phase, the air flow valve is shut off and all the systems are turned off.

- The whole setup is further depressurized to remove any air trapped in the plumbing or rocket engine setup. 


\section{Signal Post Processing}

During the development of a rocket engine, it is important to know the different types of loads that will be acting on the rocket engine, and the sources of these loads. An important characteristic of rocket engines in operation is the potential presence of undesired vibration in the engine structure. These structural vibrations can be a result of various causes, like internal combustion, a given flow process, and turbulence. These vibrations can induce various types of loads on the rocket engine, potentially, in some cases, leading to catastrophic failures. During the development phase of a rocket engine, it is important to detect these vibrations and their causes, and develop ways to mitigate these vibrations.

Loads on any structure are characterised into two major groups namely:

1) Deterministic Loads

2) Stochastic Loads

A load is considered to be deterministic if it can be defined as a specific occurrence, from which it is known that it will occur with a magnitude that can be estimated. On the other hand, stochastic loads have an essentially statistical nature. They cannot be predicted to occur with a certain magnitude at a given moment. Stochastic loads are also referred to as random loads. The vibrations observed in the rocket engine structure, the pressure oscillations in the combustion chamber, and the thrust oscillations observed during the operation of a rocket engine are commonly identified as being stochastic in nature [12].

Random vibrations which induce stochastic (random) loads cannot be characterised based on time, as the amplitude varies independent of time. Hence, a practical method of characterising these vibrations is by its frequency content. A random vibration signal is composed of a continuous spectrum of frequencies. In simulating these vibrations, loads are 
represented statistically, in the frequency domain. This is achieved by performing Fast Fourier Transforms on the obtained data (FFT). FFT results of a random vibration signal give the dominant frequencies of vibration during the acquisition period.

The time-history of pressure, vibration and load cell data obtained from the HRE cold flow test firing are post-processed in MATLAB, which employs the FFT technique to characterise the data in terms of different frequencies. The details of this method are beyond the scope of this thesis [13]. Many high speed data acquisition systems process data using an FFT technique, which essentially reduces the computational requirements necessary to convert large amounts of sampled data from the time to the frequency domain.

The data obtained and recorded during a cold flow test is typically in the time domain, i.e., the variations of various quantities like pressure and thrust is with respect to time. This data gives the time history of various parameters. To obtain the dominant frequencies of oscillation in pressure, thrust and acceleration data of the cold flow test results, it is necessary to convert the time based data to frequency-based data. i.e., to convert data from the time domain to the frequency domain. 


\section{Results and Discussion}

In this chapter, the cold flow test results, performed with different nozzle throat diameter configurations, are presented along with the post-processed results of the obtained signal. The data from all the transducers and sensors were sampled at $1 \mathrm{KHz}$, thereby fulfilling the nyquist criterion. The data obtained from the cold flow test were post processed to remove any $60 \mathrm{~Hz}$ electric supply ac noise component. The data was first processed in a lowpass filter of $0-100 \mathrm{~Hz}$ and then processed in a notch filter to remove the $60 \mathrm{~Hz}$ noise component.

\subsection{Test with $2.5 \mathrm{~mm}$ Nozzle}

Based on the pressure data collected from the pressure sensors, it was found that this configuration resulted in an unchoked orifice plate regulator. The rocket engine was as a result not isolated from the feed system. Figure. 6.1 shows the time history of main chamber pressure. The steady state $(6-7 \mathrm{sec})$ pressure-time history is shown in Figure. 6.2 Figures. 6.3 and 6.4 show the time history of main chamber pressure, thrust and axial acceleration. As stated earlier, the total duration of the test run was $15 \mathrm{sec}$. 


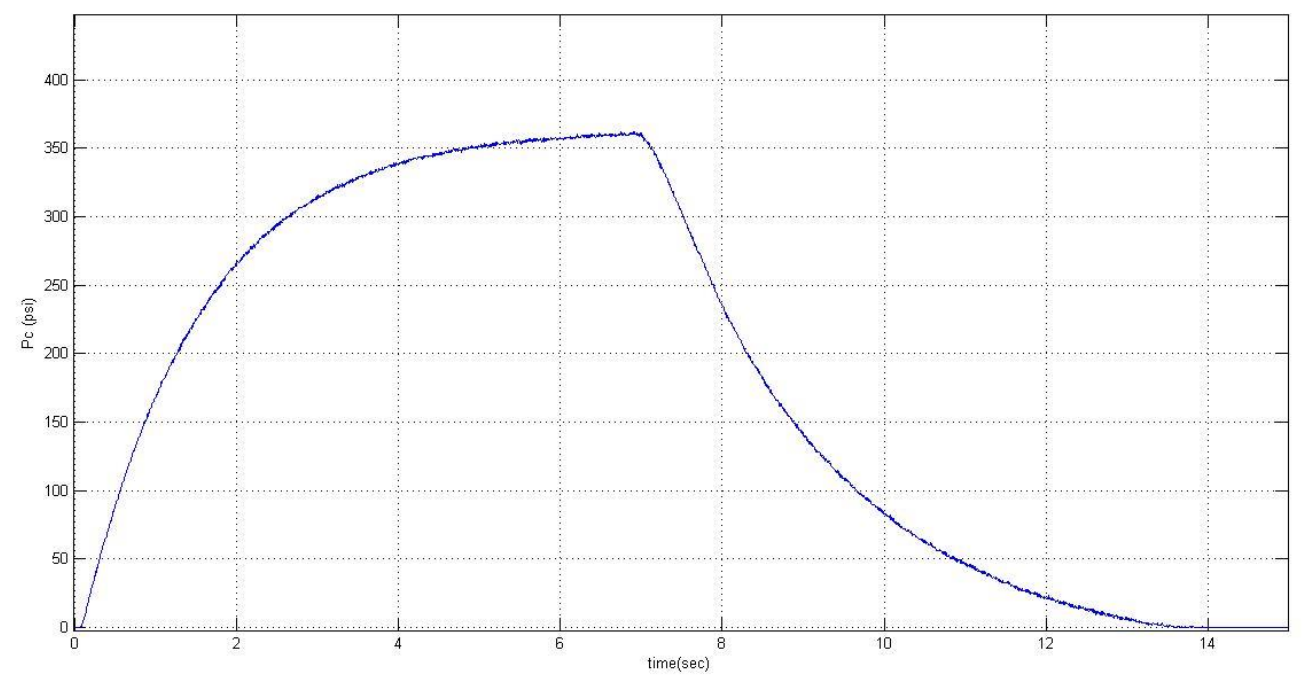

Fig. 6.1: Chamber pressure vs. time plot obtained from test of configuration 1.

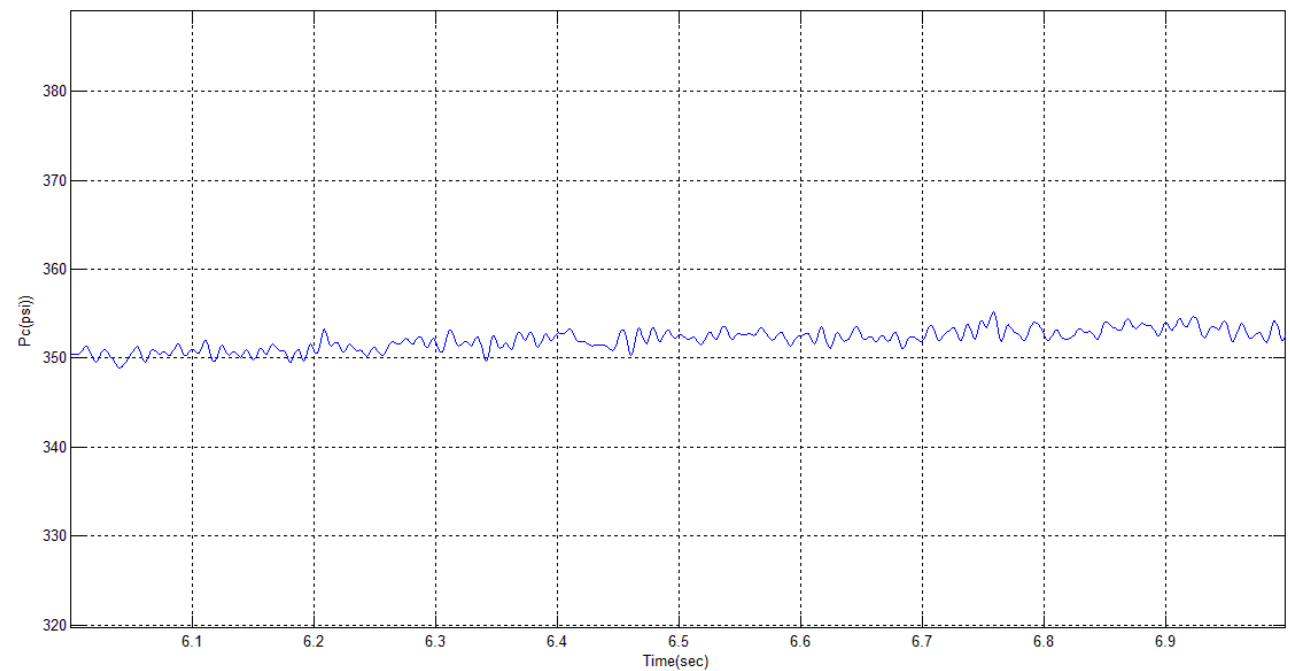

Fig. 6.2: Steady state pressure-time history in combustion chamber.

In Figure. 6.1, it can be noticed that the chamber pressure builds up progressively and then begins reaching a quasi-steady state. While in the quasi steady state, a mean chamber pressure of 350 psig was noted, with a pressure oscillation of \pm 2 psig from the mean value at various frequencies as shown in Figure. 6.2. 


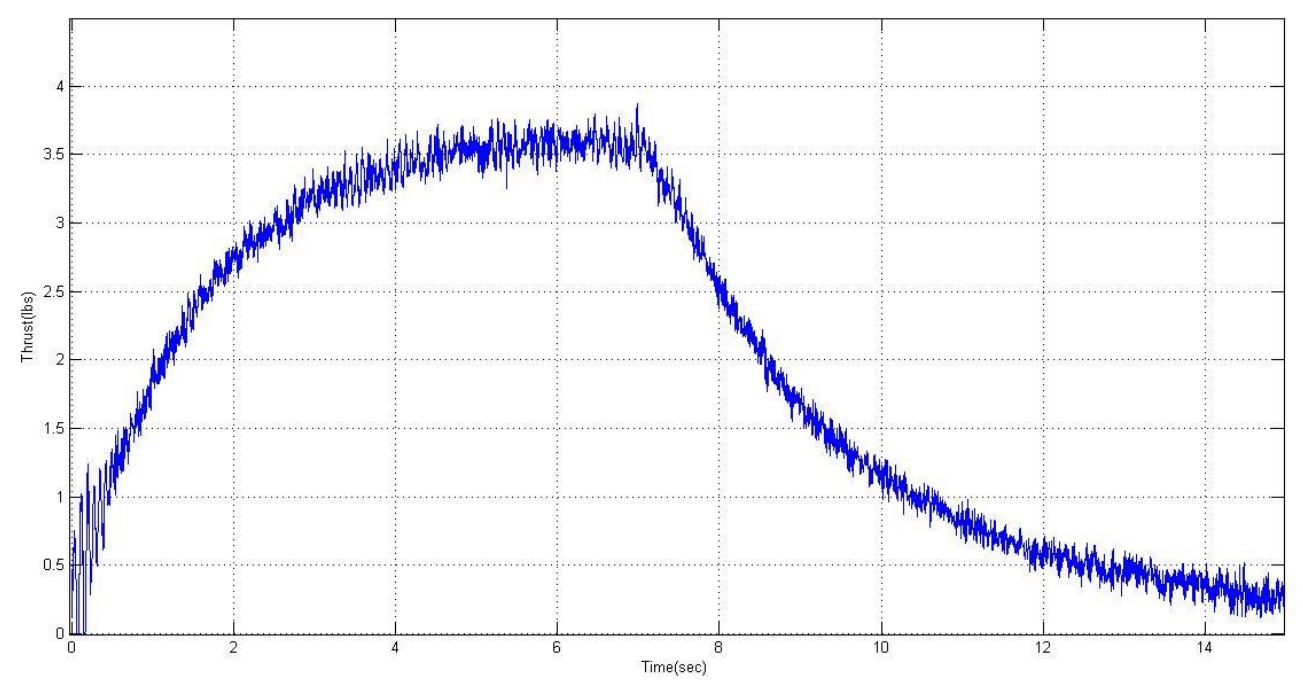

Fig. 6.3: Thrust vs. time obtained during test of configuration 1.

The thrust profile of the firing showed above exhibits a mean thrust of $3.5 \mathrm{lbs}$ during the steady state of the firing (as compared to about $25 \mathrm{lbs}$ for the hot firing). The thrust produced builds up and then starts to level off, the same phenomenon as observed in the pressure-time history. The thrust oscillation about the mean value of $3.5 \mathrm{lbs}$ found during the 6-7 sec is of the order of $\pm 0.25 \mathrm{lbs}$. 


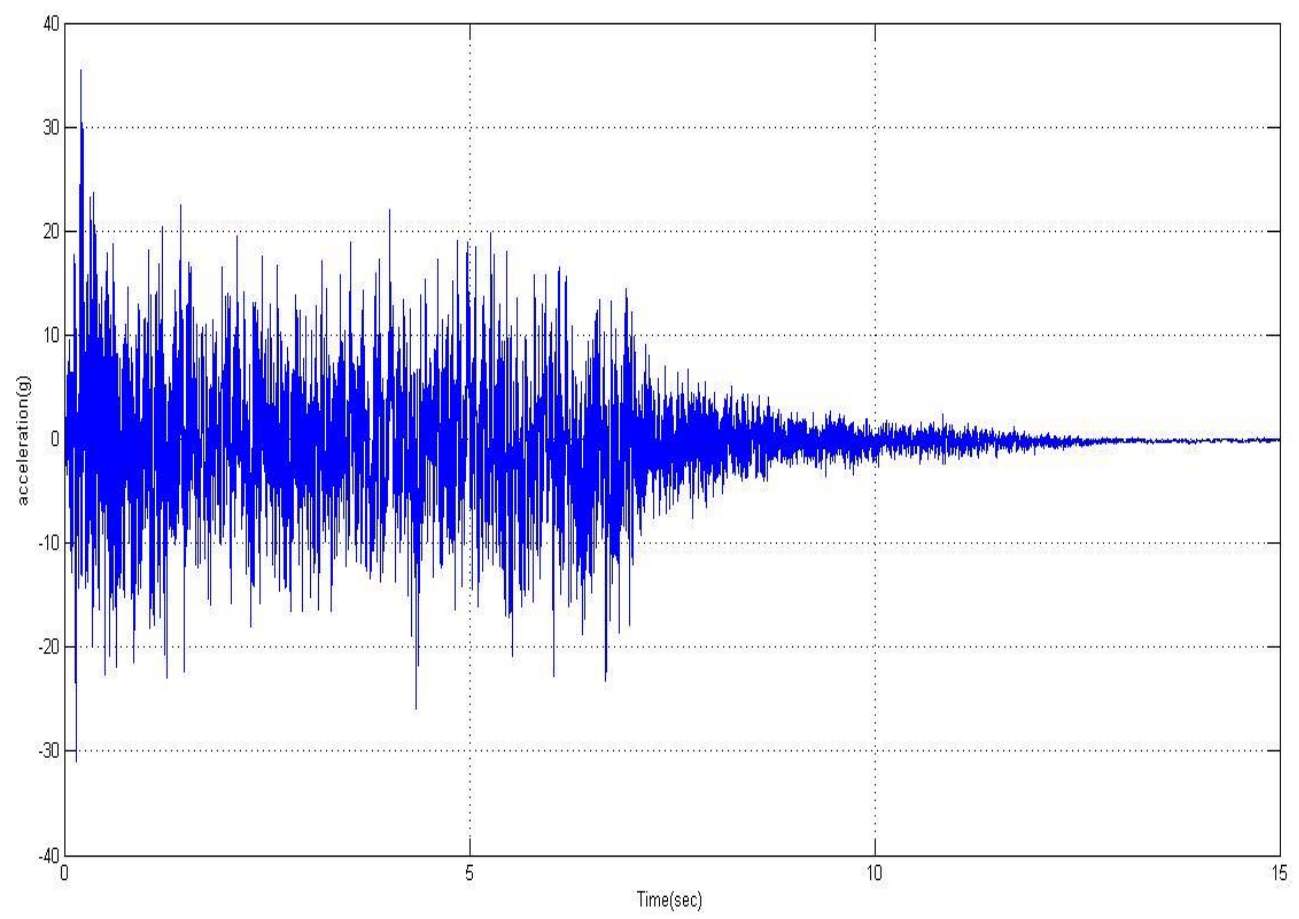

Fig. 6.4: Acceleration vs. time graph for configuration 1.

From the acceleration (displacement from state of rest) profile shown in Figure. 6.4 it can be seen that a maximum acceleration of $35 \mathrm{~g}$ (after filtering the data) can be observed during the initial period of the firing. During the quasi steady state (6 -7 sec period) the oscillations show consistency in amplitude, in contrast to the oscillation during the initial period of the firing. 


\subsection{Test with $2.79 \mathrm{~mm}$ Nozzle}

This nozzle diameter choice resulted in a marginally choked flow regulator. A bigger nozzle throat diameter gives a lower chamber pressure. The pressure and thrust profile behaviour is similar to the previous $2.5 \mathrm{~mm}$ nozzle result. The mean chamber pressure is 300 psig (reduced from 350 psig due to a bigger nozzle throat). The chamber pressure fluctuates about \pm 2 psig from the mean value, at various frequencies. The steady state pressure-time history of this configuration is shown in Figure. 6.6.

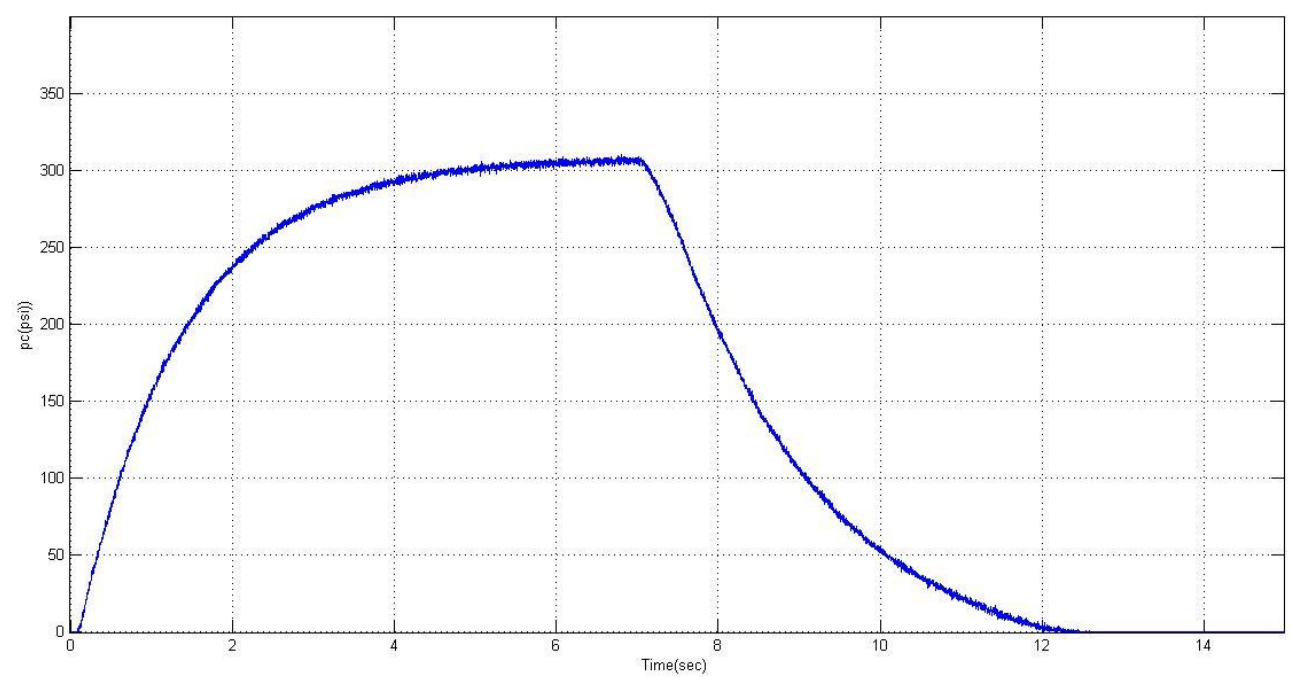

Fig. 6.5: Chamber pressure vs. time plot for configuration 2.

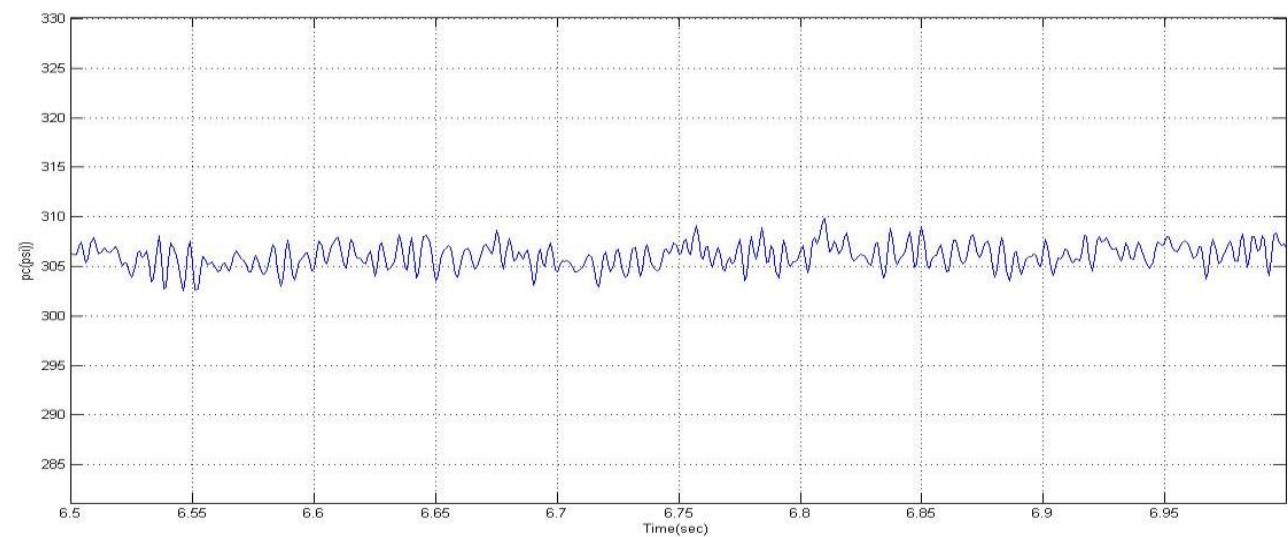

Fig. 6.6: Pressure time history during steady state. 
While a mean thrust of $3.5 \mathrm{lbf}$ is obtained during the cold flow firing, an oscillation of $\pm 0.25 \mathrm{lbf}$ in thrust is observed about the mean value, at various frequencies as shown in Figure. 6.7.

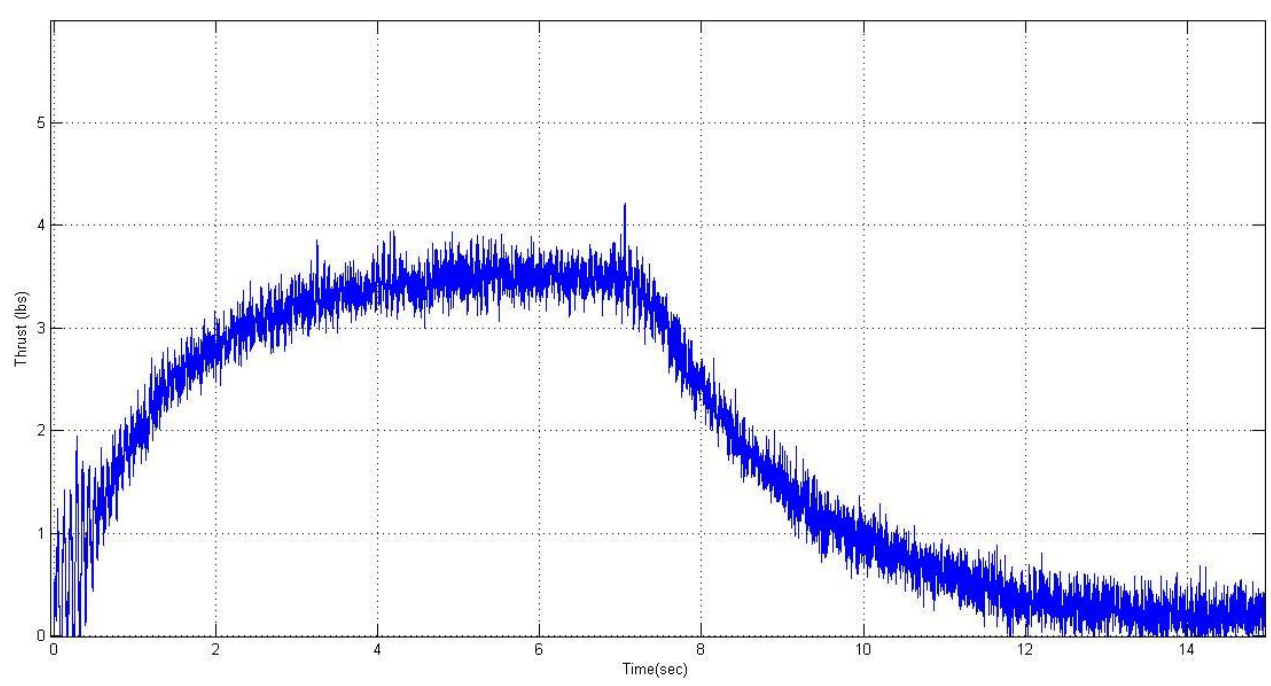

Fig. 6.7: Thrust vs time obtained during test of configuration 2.

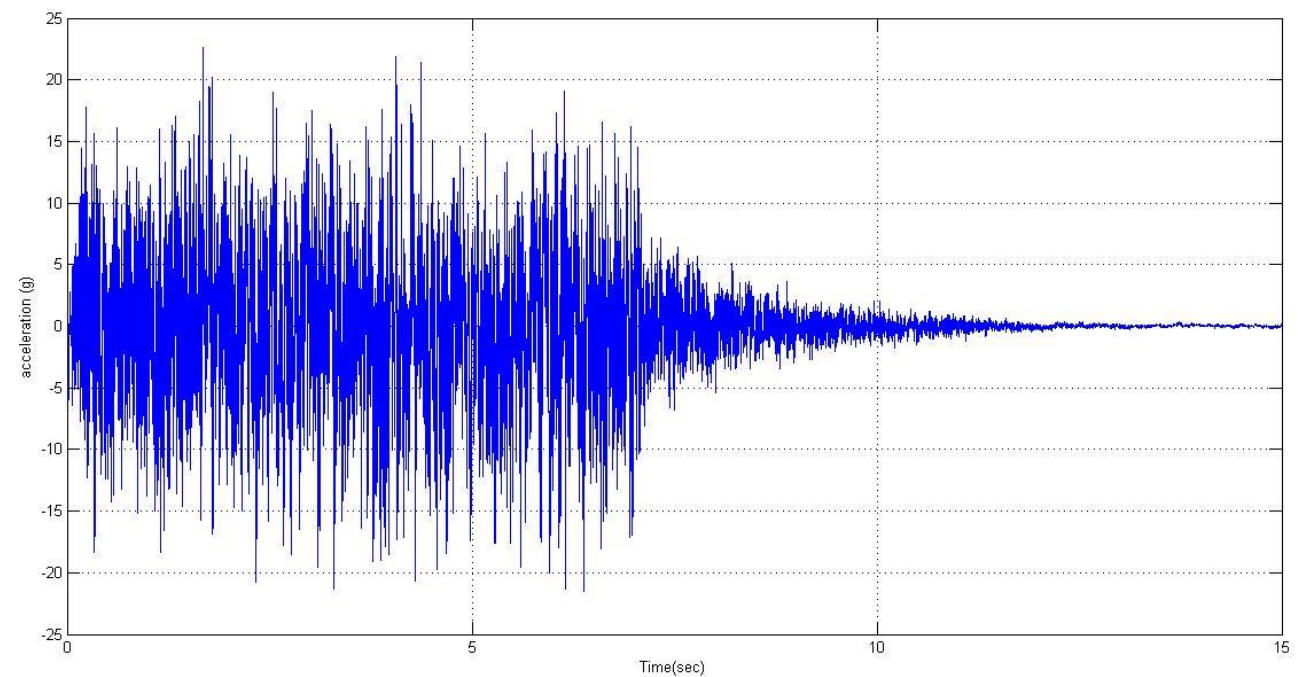

Fig. 6.8: Acceleration vs. time graph for configuration 2.

The longitudinal acceleration experienced while performing the cold flow test for this nozzle configuration is measured and the time history of acceleration experienced is plotted 
in Figure. 6.8. The amplitude of oscillations is lower, when compared to the acceleration profile from the unchoked regulating orifice plate configuration

\subsection{Test with $3.05 \mathrm{~mm}$ Nozzle}

This exhaust nozzle throat opening was large enough to produce a choked condition in the regulating orifice plate. The trend in the pressure and the thrust profiles are similar to the ones obtained from tests employing smaller nozzle throat diameters.

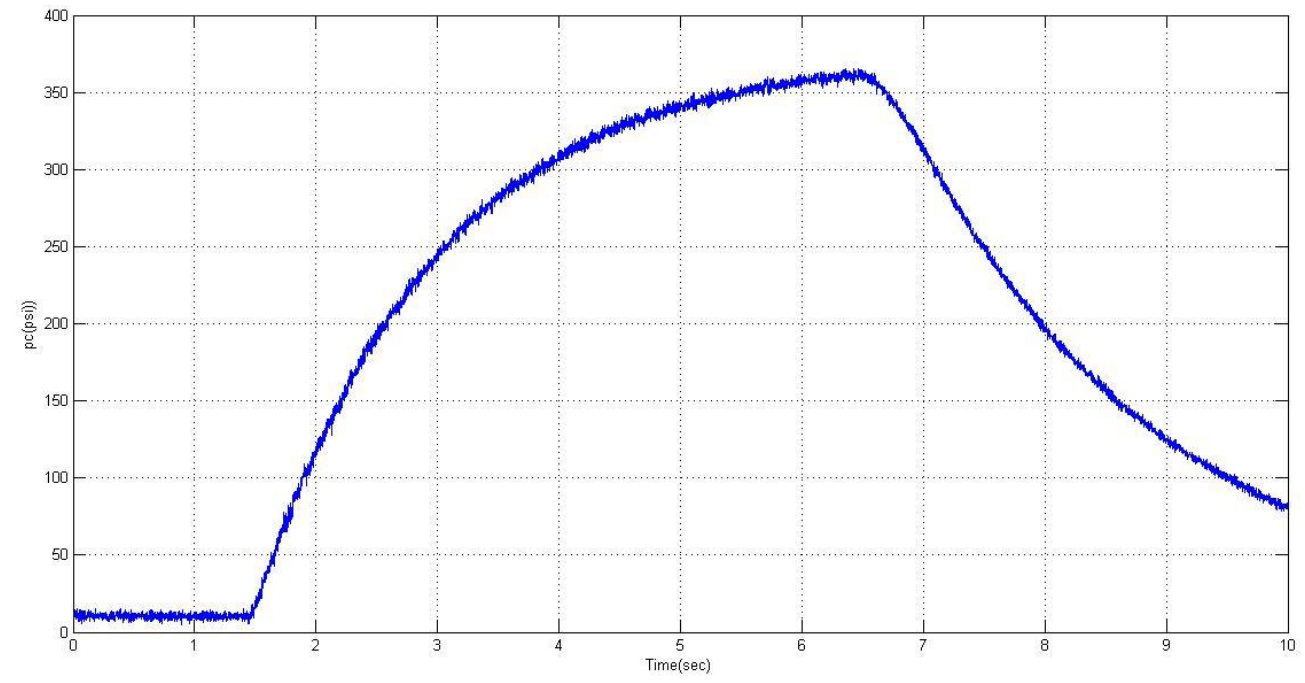

Fig. 6.9: Chamber pressure vs. time plot for configuration 3.

Figure. 6.9 shows the time history of chamber pressure for the choked orifice plate condition. In this configuration, the feed system is isolated from backflow of air from the combustion chamber and also the flow in the combustion chamber is isolated from feed system instabilities. 


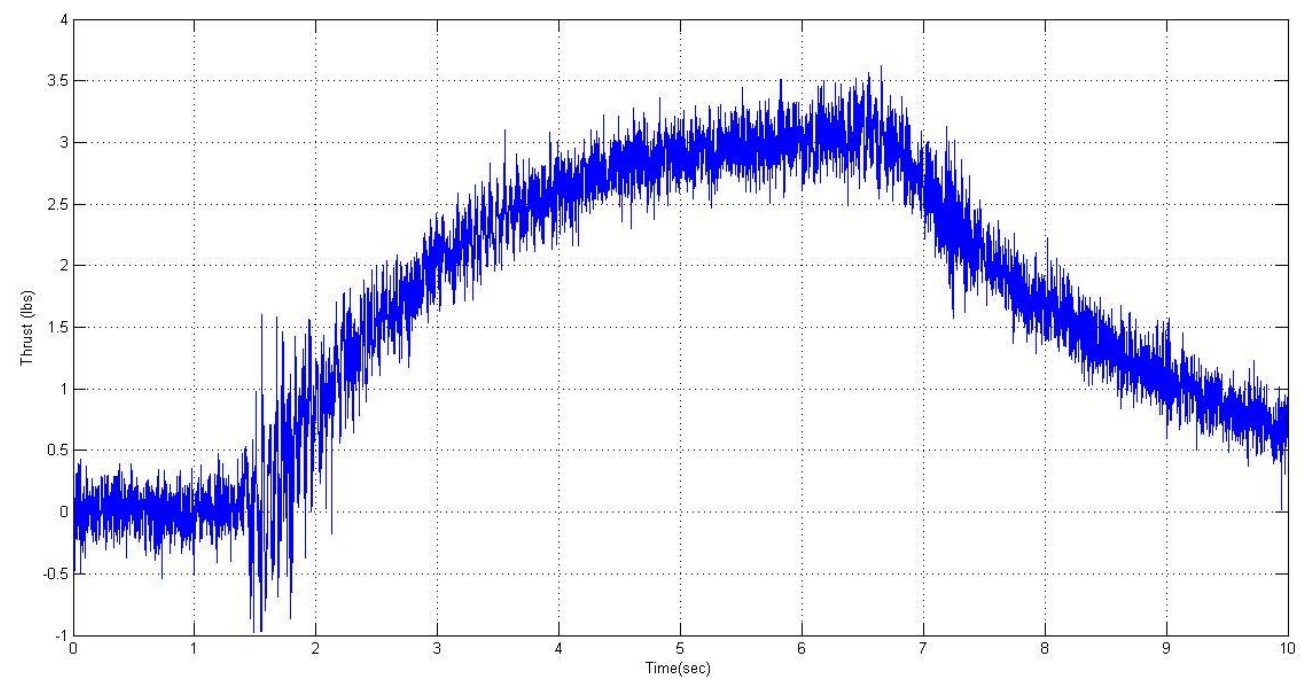

Fig. 6.10: Thrust vs. time plot for configuration 3.

In the thrust profile for this confugration, shown in Figure. 6.10, it can be noticed that the maximum thrust obtained in this configuration was $3 \mathrm{lbs}$. This drop in thrust can be attributed to the bigger exhaust nozzle throat diameter.

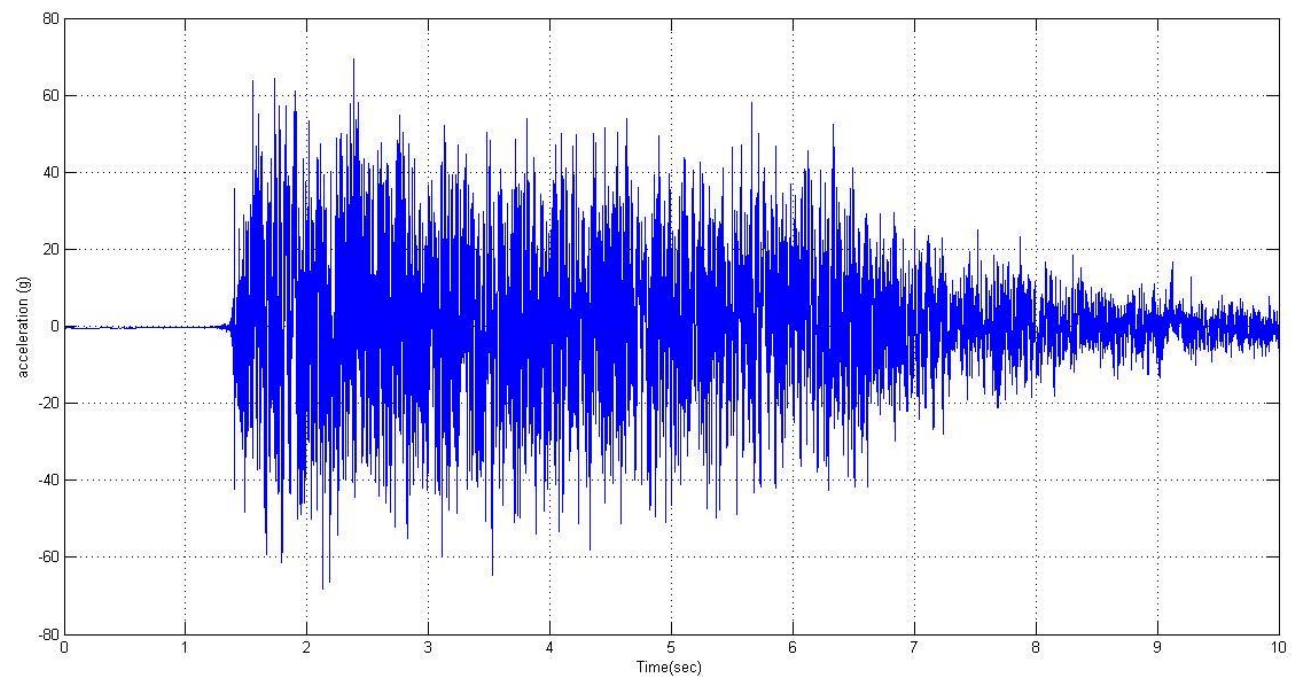

Fig. 6.11: Acceleration vs. time graph for configuration 3.

The structural vibration experienced in the test apparatus is picked up by the accelerometer (Figure. 6.11). During the steady state the vibrational amplitude go up to $40 \mathrm{~g}$. 


\section{Fast Fourier Transform Analysis}

\subsection{Test with $2.5 \mathrm{~mm}$ Nozzle}

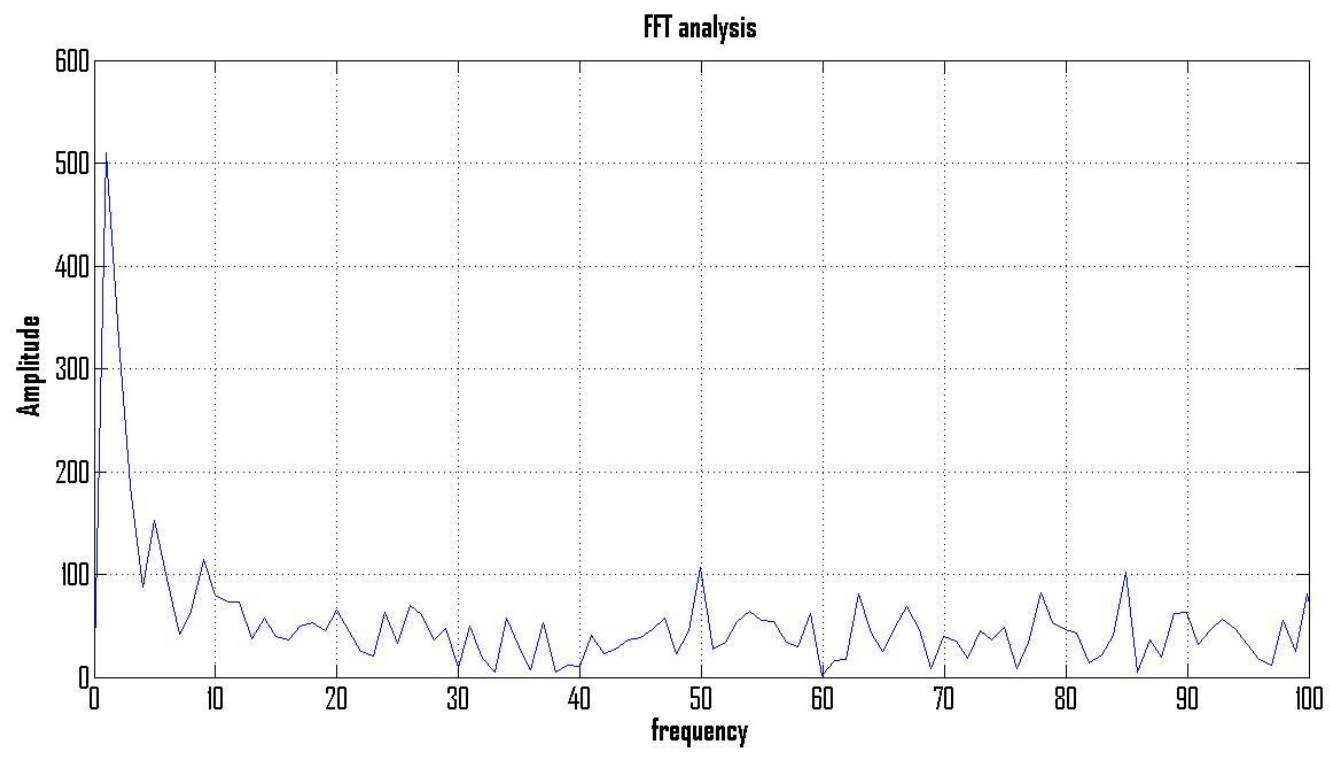

Fig. 7.2: FFT of pressure-time data for configuration 1.

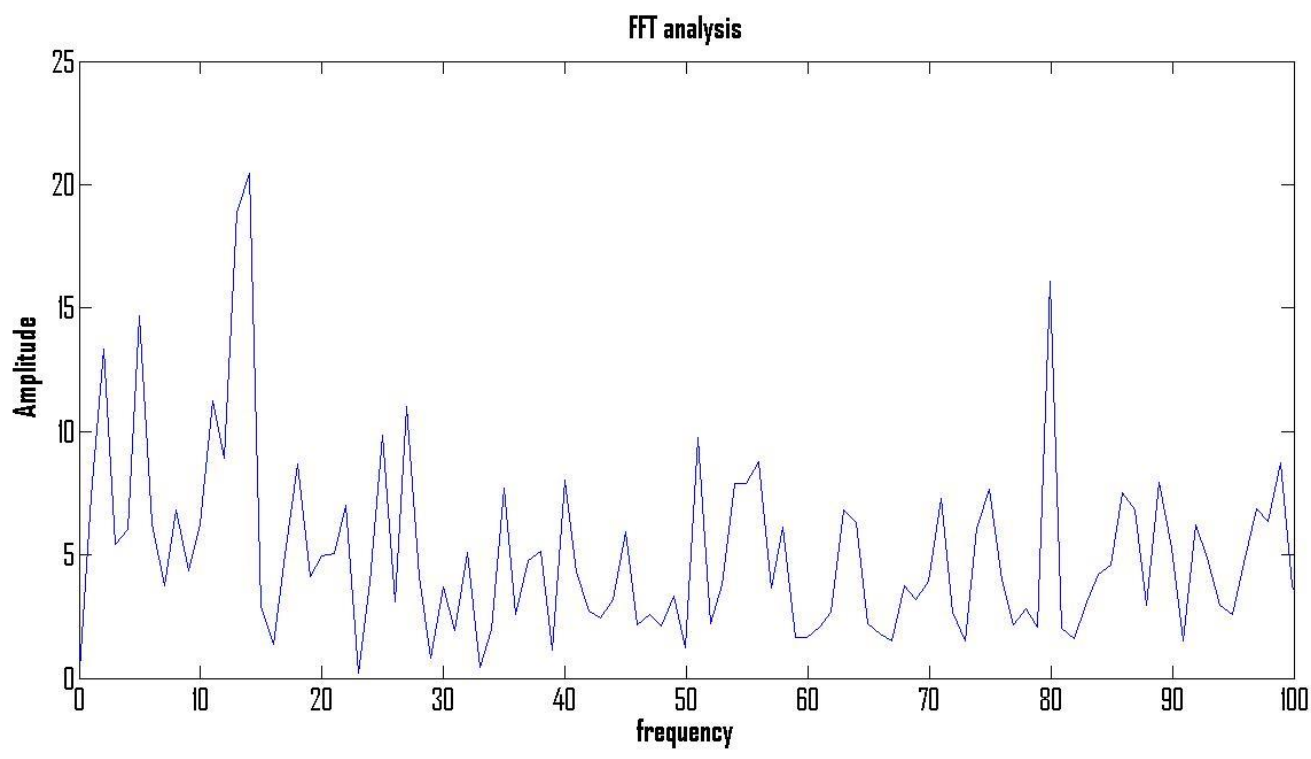

Fig. 7.2: FFT of thrust-time data for configuration 1.

From Figures. 7.1 and 7.2, it can be noted that there is no major peak in the FFT plots (the initial peak in the plot is due to a pseudo-static effect) indicating that there is no highamplitude vibration in the low frequency regime. 
The FFT analysis of the chamber pressure (Figure. 7.1) does not indicate any dominant frequency of chamber pressure oscillations. From the FFT analysis of the thrust data, a dominant peak at $13-15 \mathrm{~Hz}$ can be noted, which suggests that thrust oscillations with a dominant frequency of oscillations is present in the low frequency range. However, the amplitude of the peak at $13-15 \mathrm{~Hz}$ is quite low which does not suggest any catastrophic effect on the test apparatus.

\subsection{Test with $2.79 \mathrm{~mm}$ Nozzle}

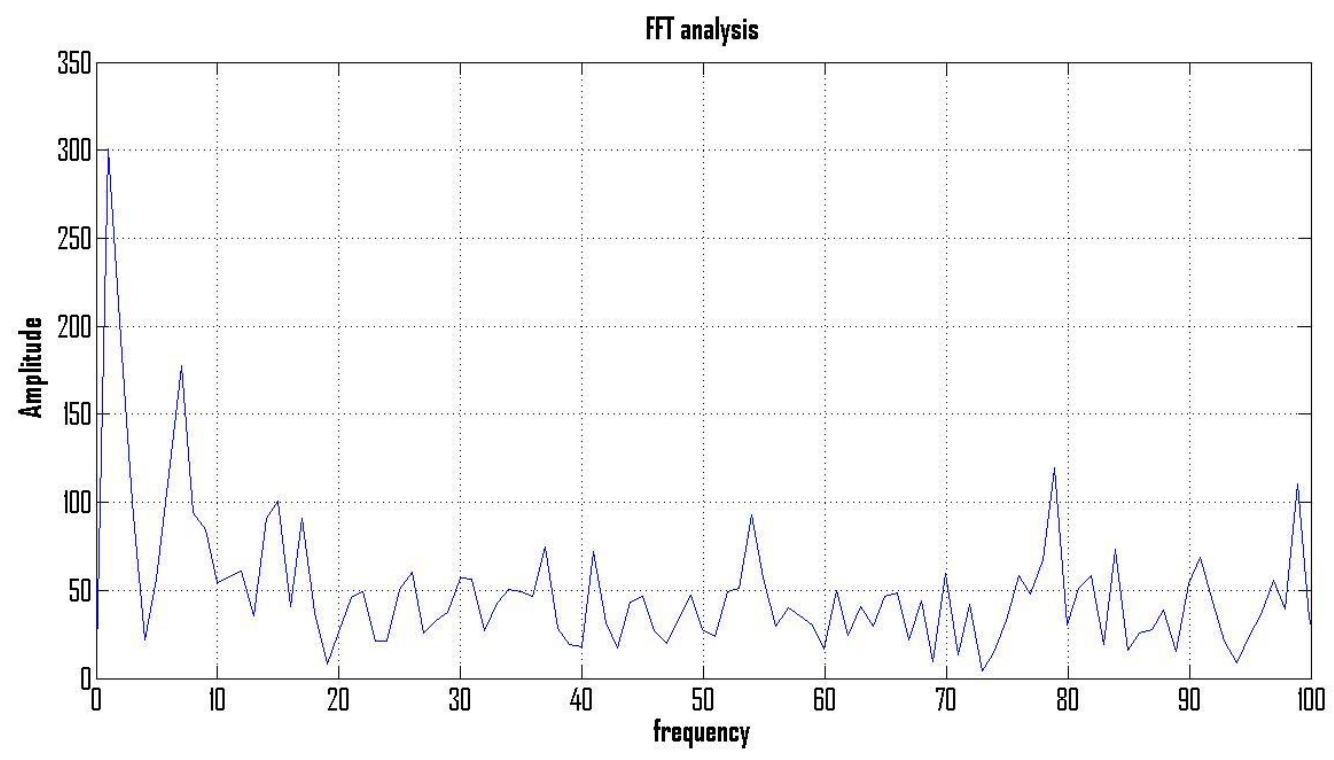

Fig. 7.3: FFT of pressure-time data for configuration 2. 


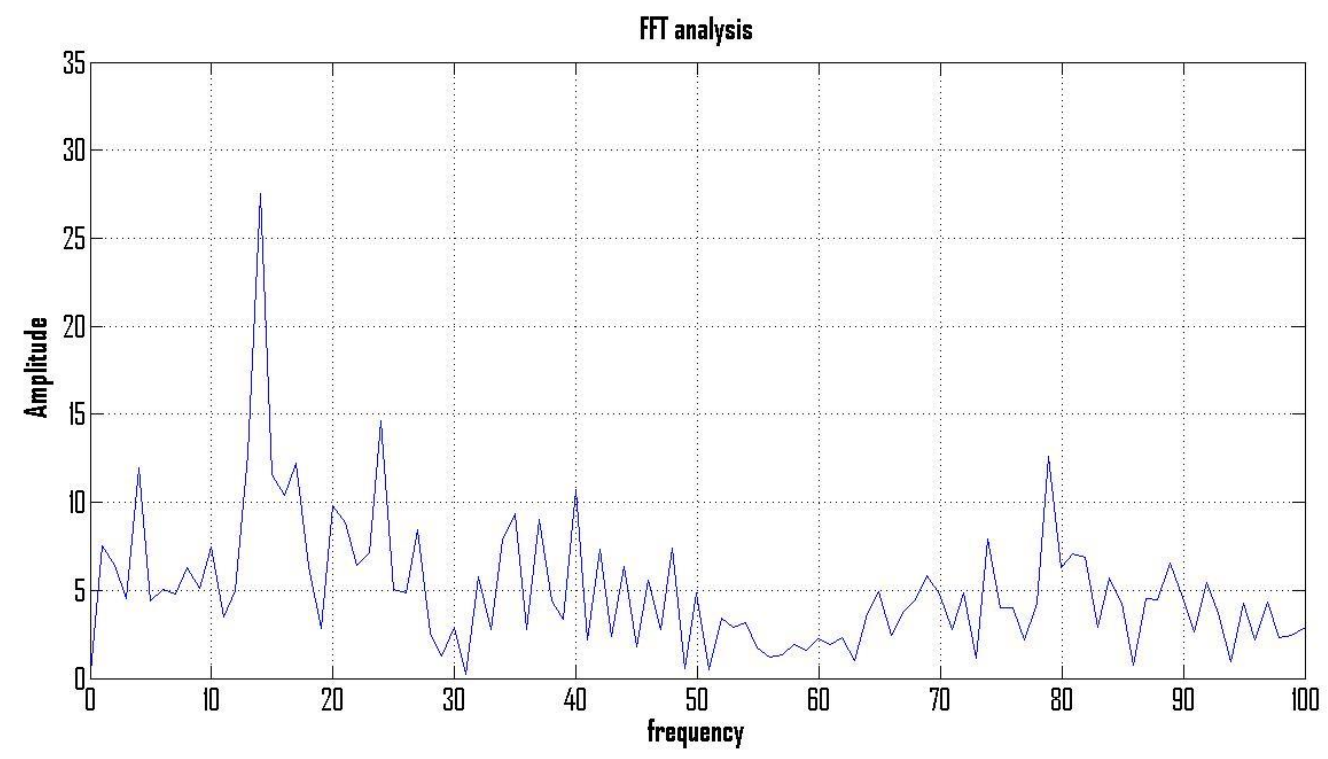

Fig. 7.4: FFT of thrust-time data for configuration 2.

In Figure 7.3 the FFT analysis of chamber pressure for a marginally choked orifice plate is shown. The analysis does not show any dominant frequency of oscillations, similar to the unchoked orifice plate condition.

The FFT analysis of the thrust data for the marginally choked orifice plate configuration is shown in Figure. 7.4. The trend of $13-15 \mathrm{~Hz}$ spike is visible in this configuration. 


\section{$\underline{7.3 \text { Test with } 3.05 \mathrm{~mm} \text { Nozzle }}$}

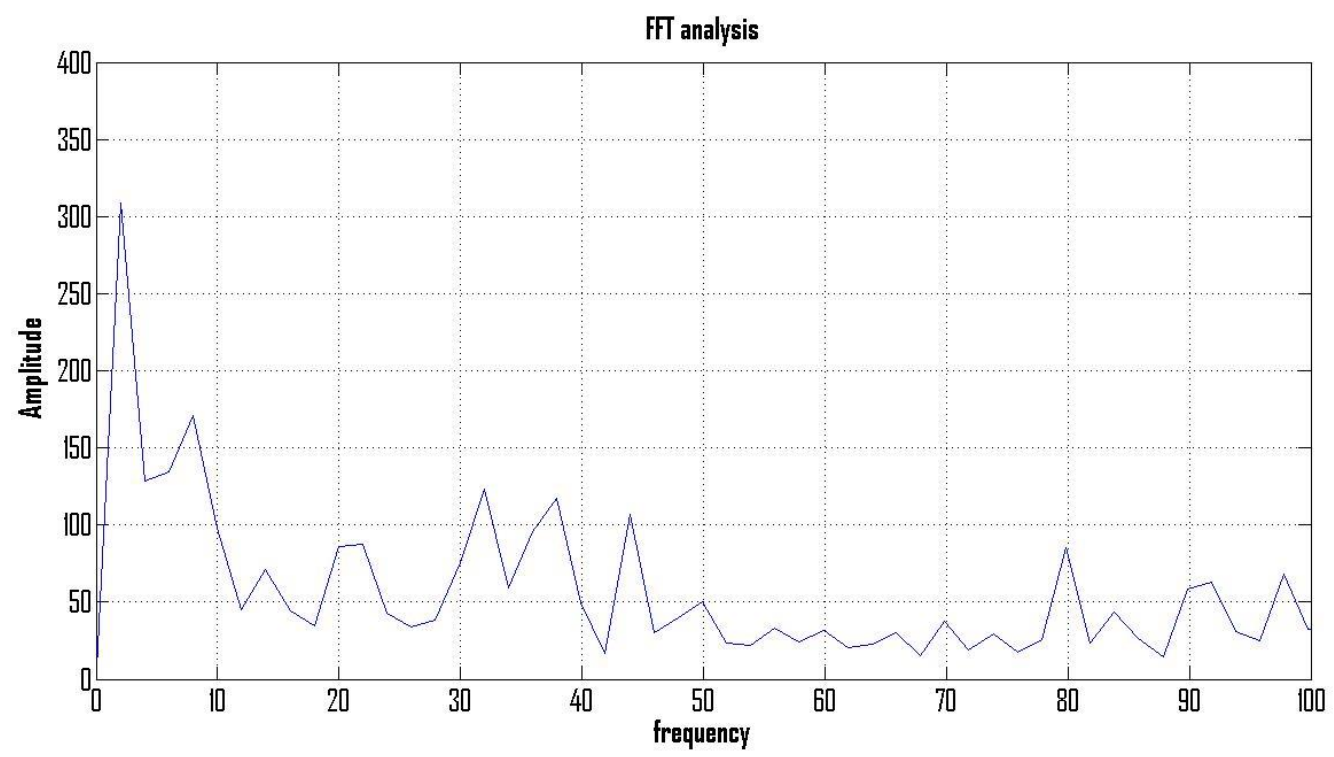

Fig. 7.6: FFT of thrust-time data for configuration 3.

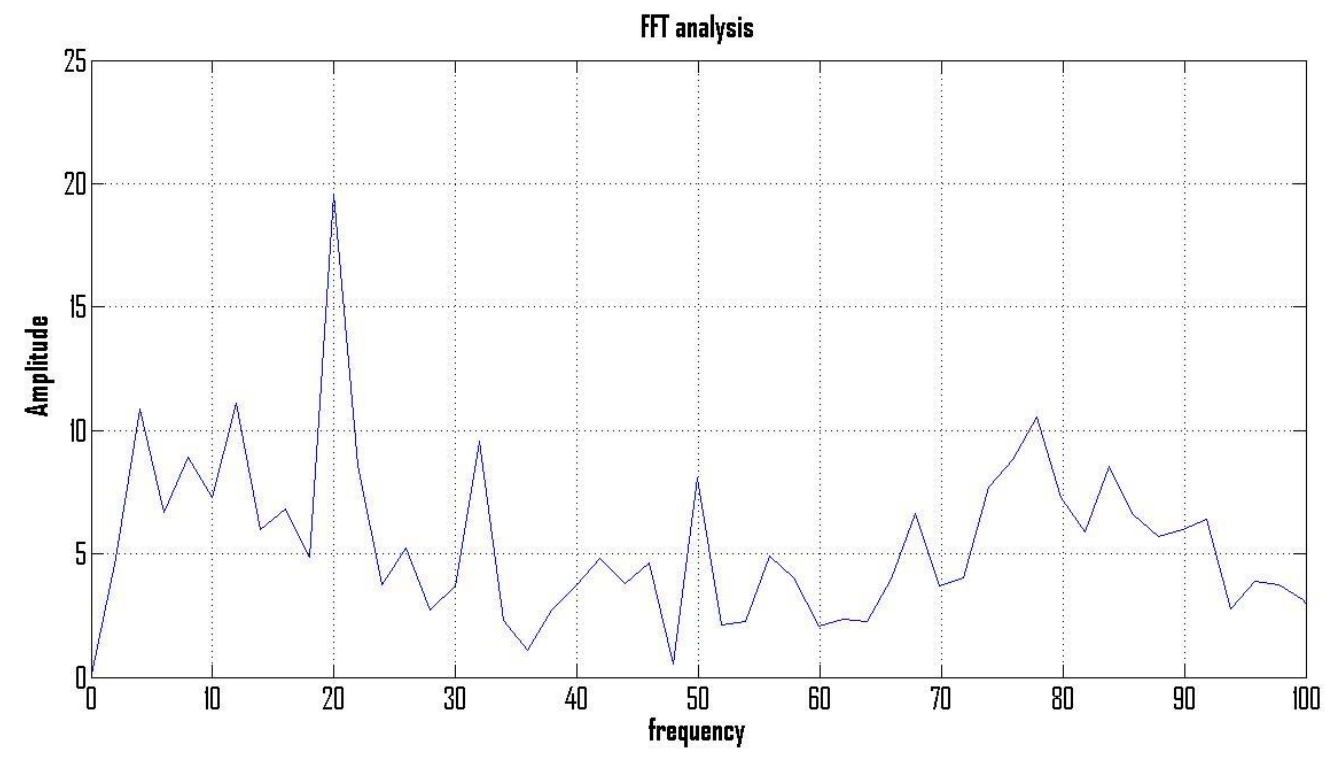

Fig. 7.6: FFT of thrust-time data for configuration 3 .

The thrust FFT analysis shown in Figure. 7.6 shows a spike, though lower in amplitude at $20 \mathrm{~Hz}$. This frequency of thrust oscillation is visible only in the choked orifice plate condition. 


\section{Hammer Test}

A hammer test is conducted on a structure to determine the vibrating modes of the structure. This test was applied to RU's HRE test apparatus, with the engine in place. The mode of vibration of any structure is dependent on its mass, stiffness, damping properties and boundary conditions. Resonant vibration occurs when a structure is excited at one or more of its natural modes of vibration. The frequency at which resonance occurs is termed as the natural frequency of the structure. Any changes to the structure (like cracks, loss of material or change in physical state), material of the structure or boundary conditions, will change the natural frequency of the structure.

In a standard hammer test, much like the one done on the RU apparatus, the following components are used:

- An impact hammer with a load cell (the load cell was not used for the RU hammer test).

- An accelerometer.

- A FFT (Fast Fourier Transform) analyser.

- Post processing modal software. 


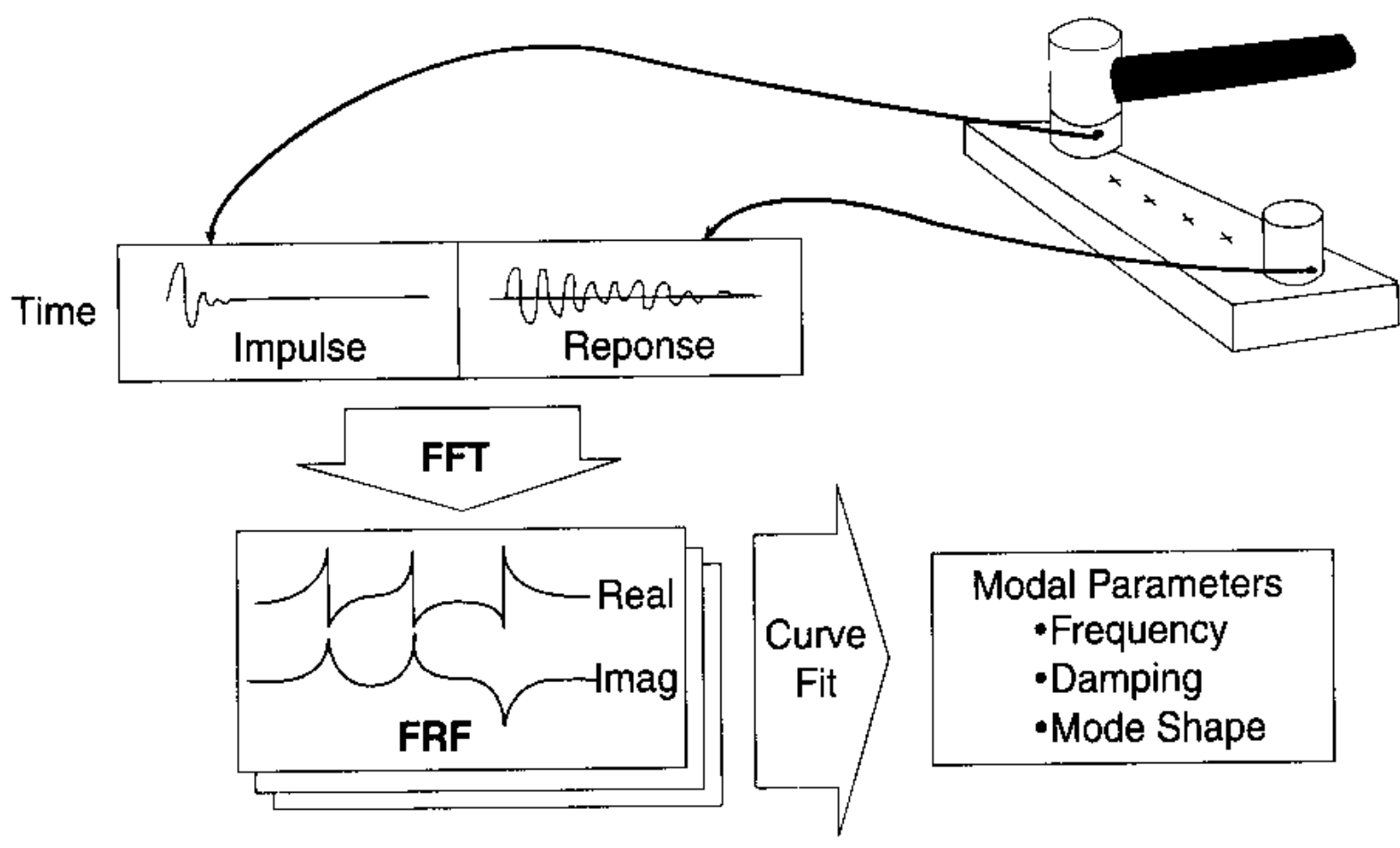

Fig. 8.1: Illustration of standard hammer test method.

Figure. 8.1 shows a basic experimental setup for a hammer test. It shows an accelerometer fixed to the structure. The signal obtained from the accelerometer is amplified by an amplifier and the fed to the FFT analyser. The hammer is commonly fitted with a load cell to measure the impact force. The signal from the load cell is amplified and fed to the FFT analyser and the frequency response function (FRF) is obtained. The FRF includes the natural frequency, phase information and the magnitude of useable frequency.

In the hammer test performed on RU's hybrid rocket test apparatus, no load cell was attached to the hammer, and the accelerometer placed on the flange of the engine was used to pick up displacement and associated vibration data. The roving hammer technique was employed, wherein the accelerometer is fixed at one position on the test structure, and the hammer is impacted at different locations on the test structure. The hammer was impacted longitudinally at different locations on the aft portion of the rocket engine test apparatus. For 
the second test, the hammer was impacted in the longitudinal direction but on the test stand base (the structure housing the load cell). This setup was sufficient to capture the relevant vibration data, and determine the natural frequency of the rocket test apparatus with engine in position.

\subsection{Test Results}

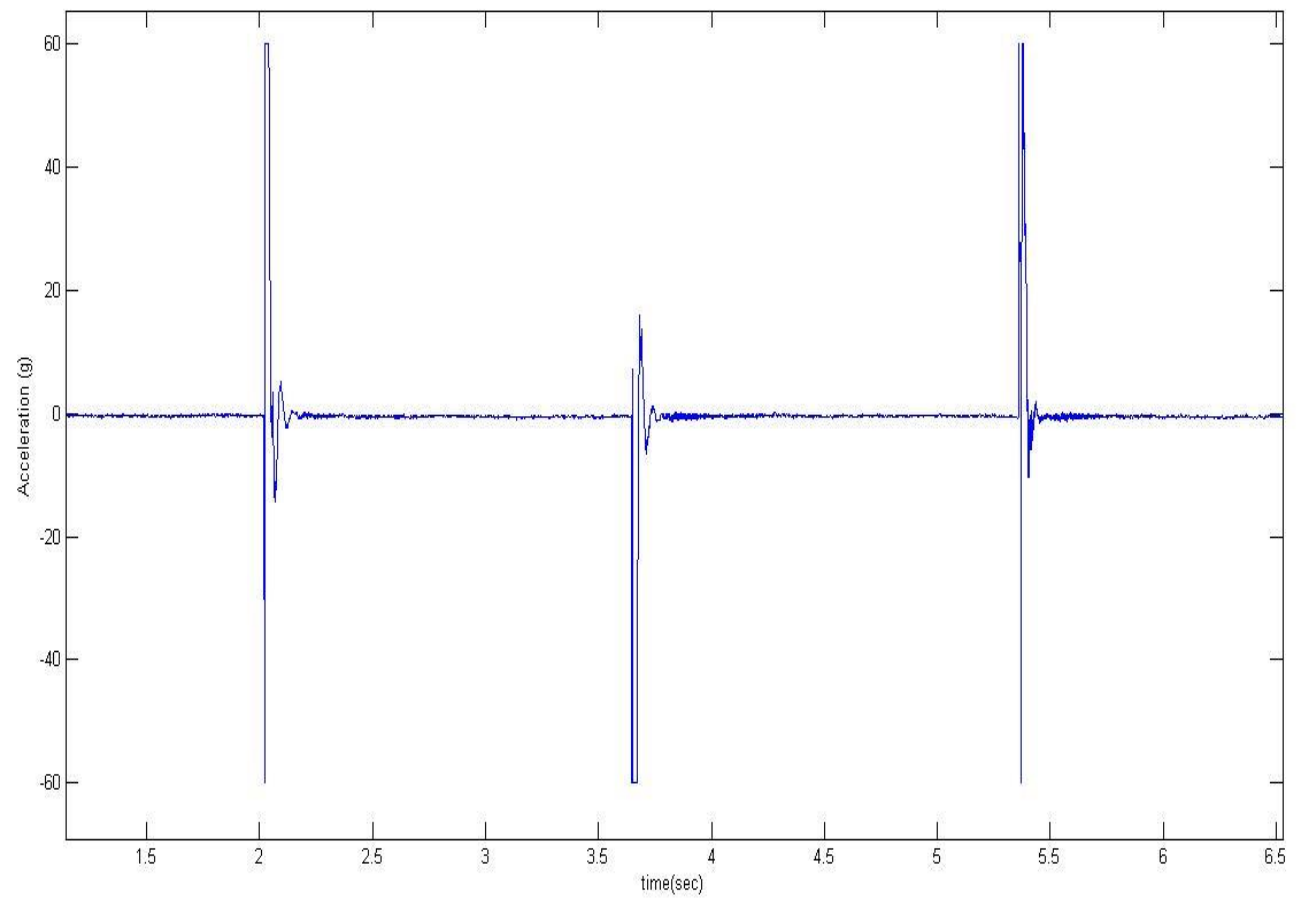

Fig. 8.2: Response obtained when the rocket engine it is struck axially.

Figure. 8.2 shows the hammer test result plot. The plot depicts the acceleration in the axial direction of the test structure when impacted with a hammer. The 3 peaks that are visible in the plot are responses obtained when the structure was impacted at the aft end for 10-second duration. The acceleration experienced is directly proportional to the magnitude of the impact on the structure, and the direction of impact. 


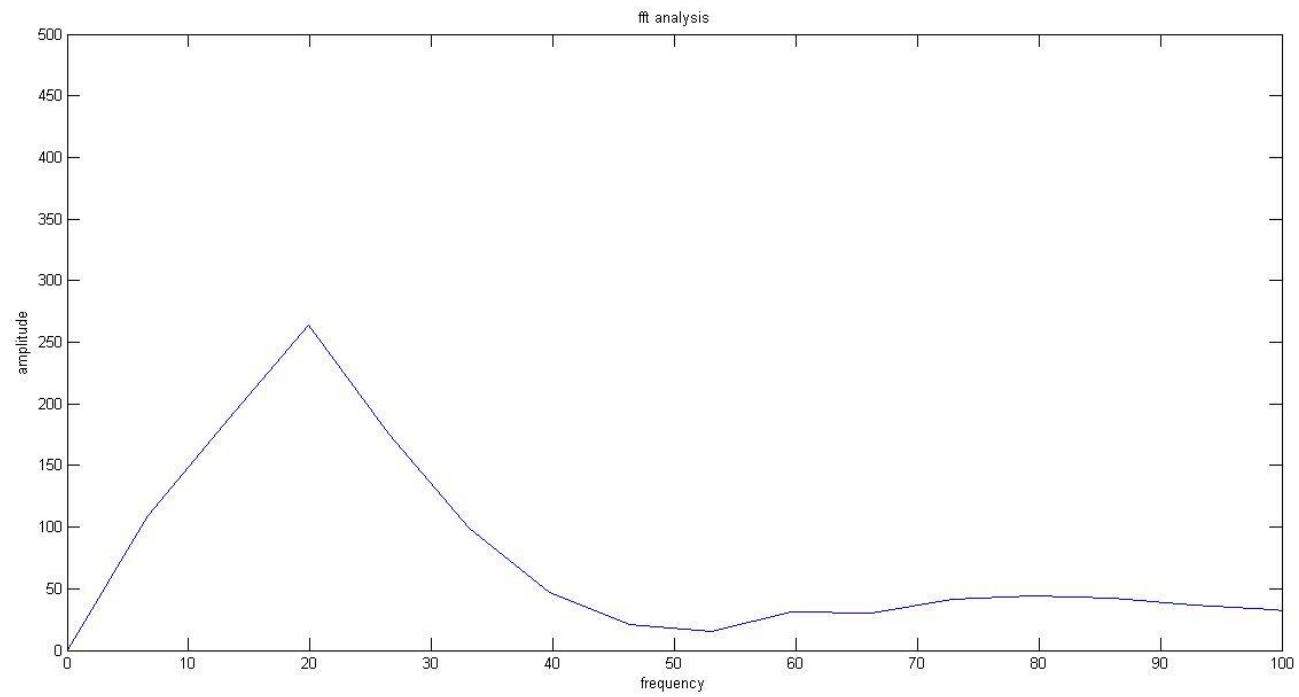

Fig. 8.3: FFT analysis of acceleration data obtained when apparatus axially impacted.

From Figure. 8.3 it can be noted that the natural frequency of vibration of the combustion chamber pipe is around $19 \mathrm{~Hz}$. This validates the work done by Gmeiner [12], where from finite-element numerical simulations it was found that the natural frequency of chamber tube structural vibration is around $19.4 \mathrm{~Hz}$.

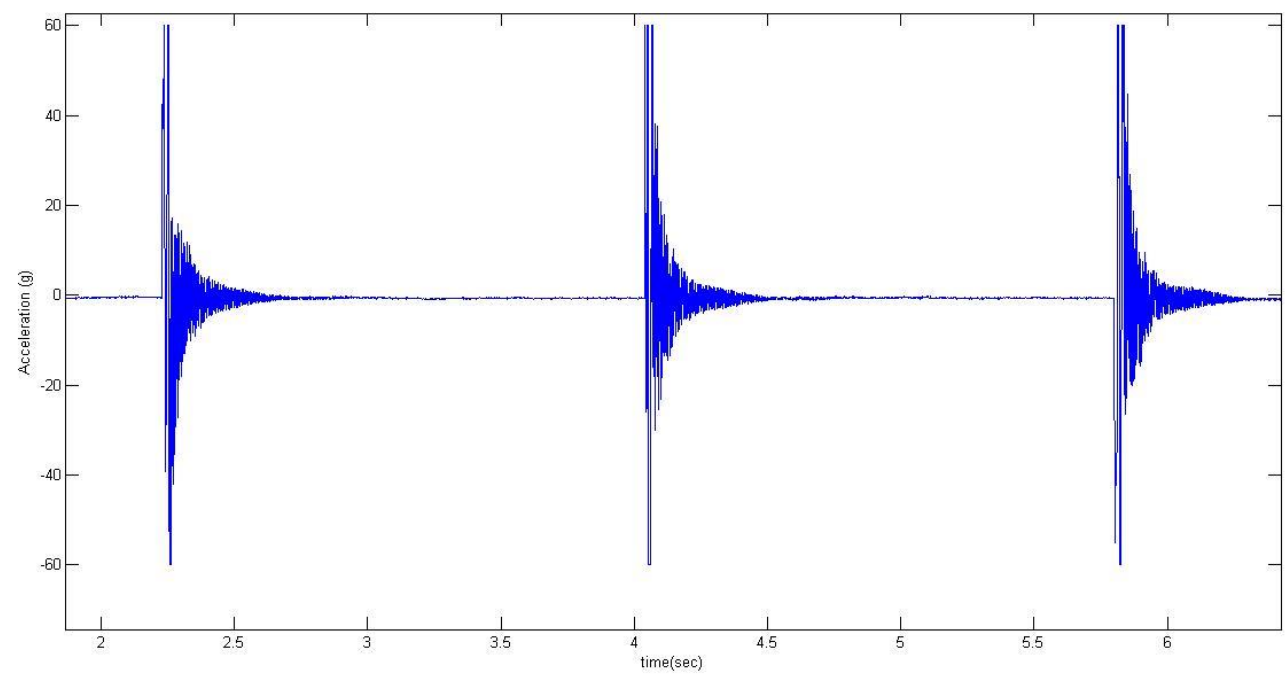

Fig. 8.4: Response obtained when the structure was impacted radially.

Figure. 8.4 shows the response obtained from the accelerometer when the engine was excited in the transverse (radial) direction. A more pronounced standard vibration is 
experienced when the structure is excited in the transverse direction, indicating that the structural vibration in the transverse direction is less damped. The FFT results for this data will provide further information in this regard.

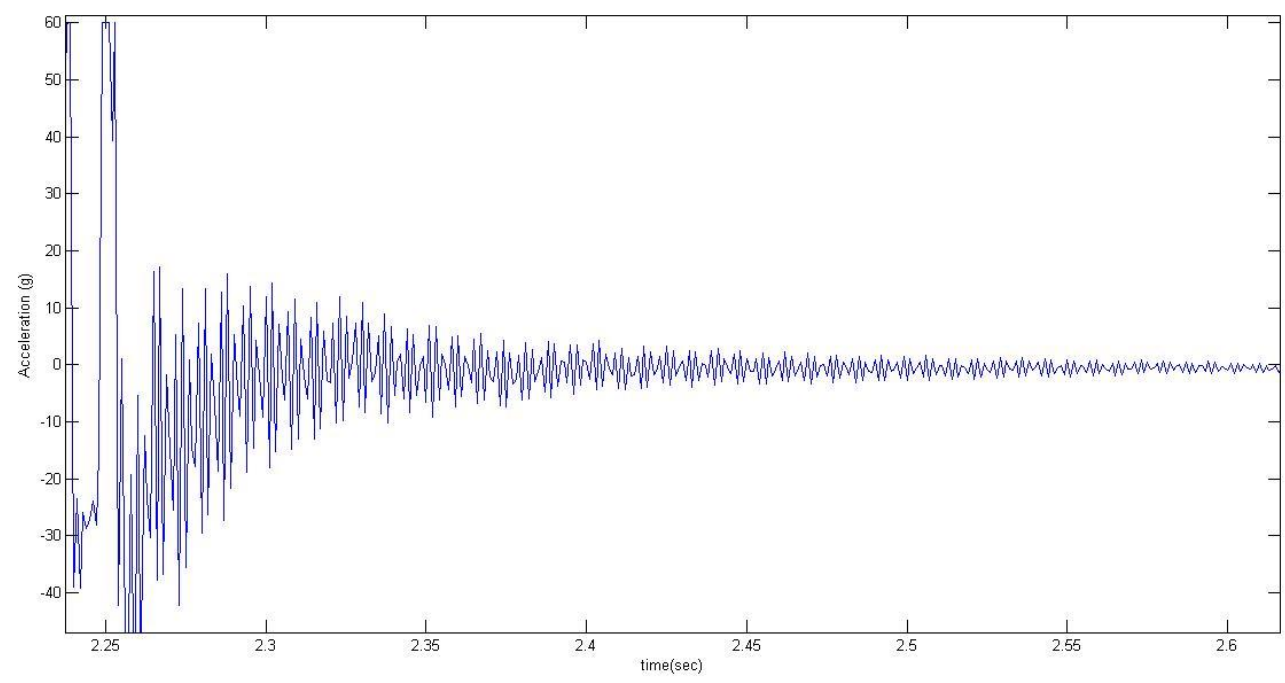

Fig. 8.5: Magnification of Figure. 8.4 near the first peak.

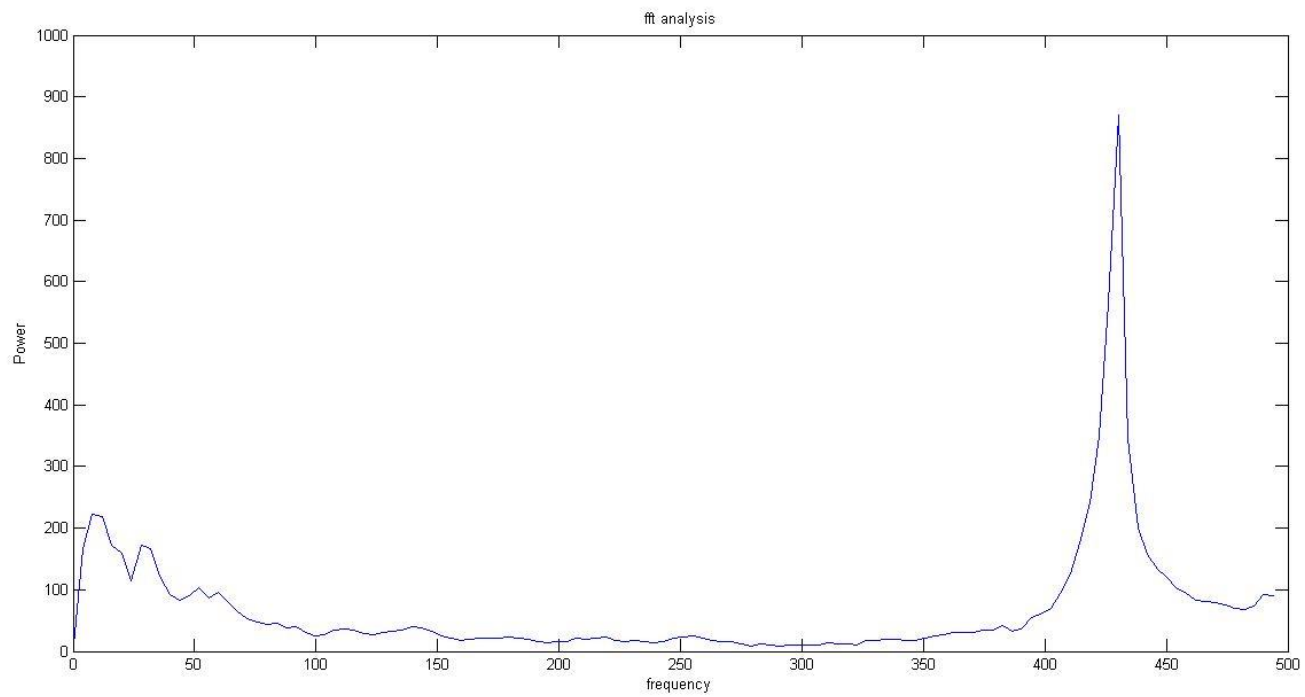

Fig. 8.6: FFT analysis of the data obtained from striking the structure in the transverse direction 
In Figure. 8.6 a sharp peak can be noted at a higher frequency of around $430 \mathrm{~Hz}$. From the Figure. 8.6 it can be noted that the combustion chamber casing wall vibrates radially at higher frequencies, relative to the lower frequencies seen in the axial direction.

\subsection{Vibration Induced by Feed System Coupling}

Figures. 7.5 and 7.6 show the FFT analysis plots of the pressure and thrust data for a choked orifice plate regulator condition. As mentioned previously, a choked regulator condition is desired for isolating the rocket chamber from any flow supply fluctuations and backflow resulting from fluctuating main chamber pressures. From the pressure and thrust plots one can confirm that there is no major oscillation found in the low frequency regime.

From the work of Gmeiner [12], it is found that the $1^{\text {st }}$ structural vibration mode of the rocket chamber is around $19.4 \mathrm{~Hz}$. While observing the FFT analysis of the acceleration data it can be noted that the structure does not appear to vibrate at the resonant frequency. Instead, the structure vibrates at multiple frequencies, over a wide range. 


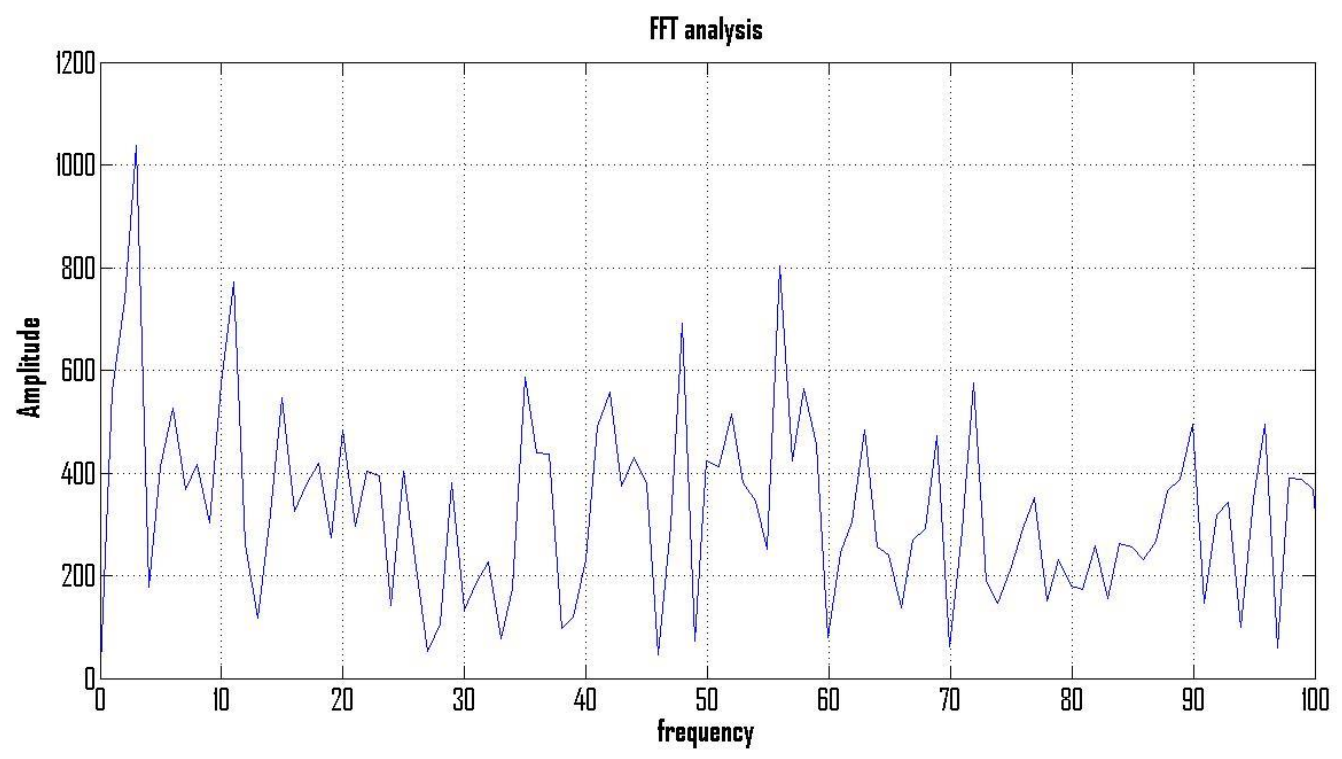

Fig. 8.7: FFT of acceleration data from cold flow test data of unchoked regulator orifice configuation.

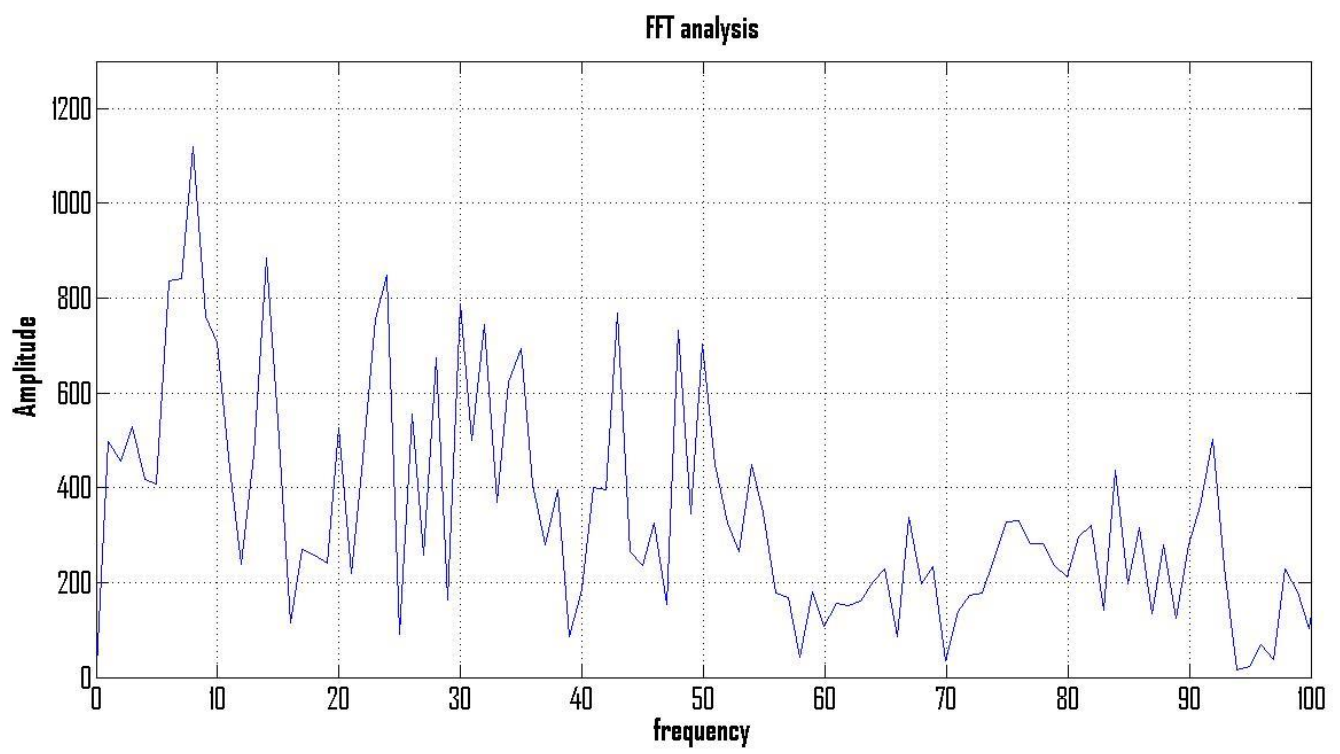

Fig. 8.8: FFT of acceleration data from cold flow test data of marginally choked regulator orifice configuration. 


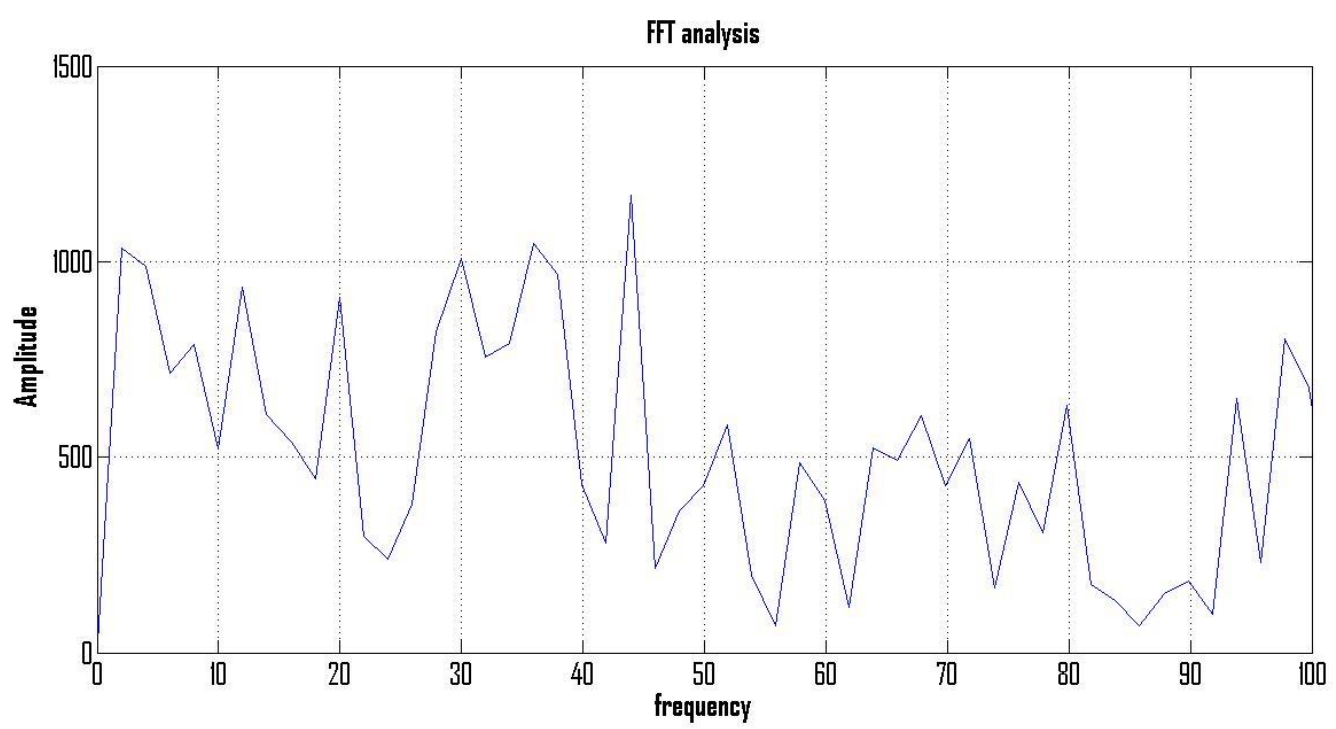

Fig. 8.9: FFT of acceleration data from cold flow test data of choked regulator orifice configuration.

Considering Figures. 8.7, 8.8 and 8.9 which depict the FFT analysis of cold flow test acceleration-time data for all three configurations, it can be noted that a peak of modest amplitude is present around 19-20 Hz in the choked orifice plate condition of Figure. 8.9.

\subsection{Characteristics of the Fuels Used}

As mentioned earlier, two different fuels were used for the firings conducted in October 2010. The first one was UHMWLDPE, while the second fuel was paraffin wax blended with an opacifier. While LDPE is designated as a non-liquefying fuel, paraffin is designated as a liquefying fuel in the literature. Thrust oscillations of higher amplitude were found during the firing of the LDPE fuel. The thrust oscillations found while burning paraffin fuel were not high in amplitude. The chamber pressure oscillations for both cases were relatively low in magnitude, at least as captured by the head-end pressure transducer.

Kim et al [14] conducted slab engine tests to visualize the dynamic behaviour of liquid layer wavelets and fuel droplets during combustion of polyethylene and paraffin wax fuels. From the study, it was found that during the combustion of paraffin fuel, liquid 
wavelets were formed on the fuel surface and these wavelets exhibit periodicity. In addition to liquid wavelets on the fuel surface, liquid fuel droplets were also found in the chamber during combustion.

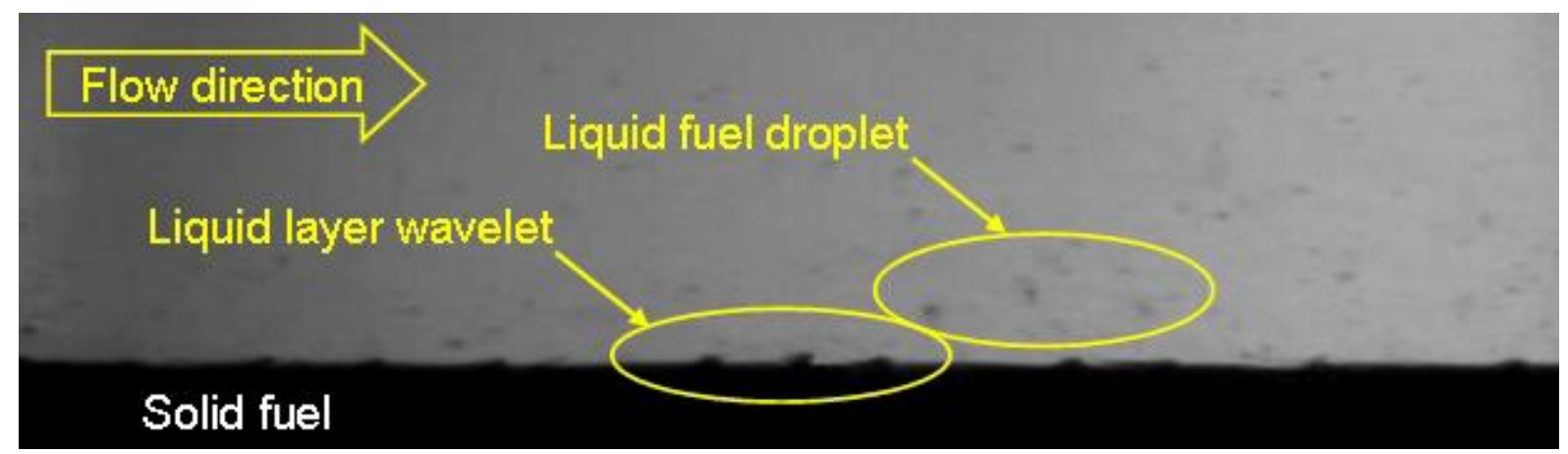

Fig. 8.10: Liquid layer wavelet and fuel droplet of paraffin fuel [14].

During the combustion of the polyethylene fuel it was found that the flame was located near the fuel surface, and fuel droplet scattering in the combustion chamber was not observed.

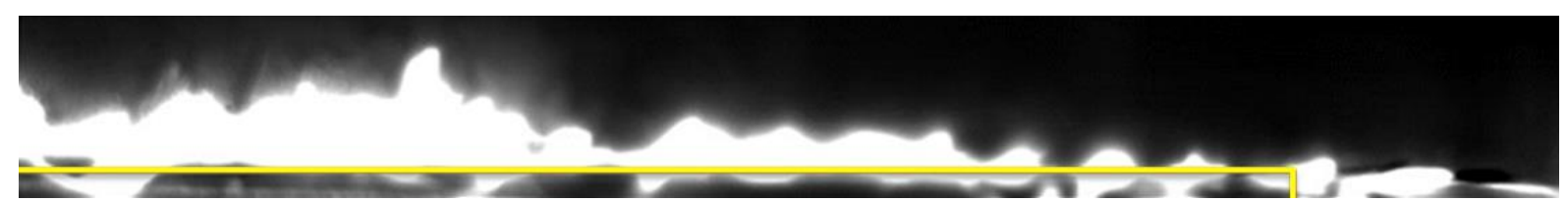

Fig. 8.11: Flame shape of the non-liquefying fuel (HDPE) [14].

Brahmbhatt [10] mentioned that the lower amplitude of thrust oscillation found in the RU paraffin/GOx firing could be attributed to the presence of liquid fuel droplets in the core flow. The presence of droplets stabilizes the flow field, resulting in lower magnitude pressure and thrust oscillations [5,10]. As noted, fuel droplet entrainment in the core flow is not observed when burning polyethylene fuels. Hence, no droplets contributed to flow stabilization in the PE case, which did experience a higher oscillation magnitude.

Karabeyoglu et al suggested an equation to calculate the primary hybrid combustion oscillation frequency [3]: 


$$
f_{l f}=0.234\left(2+\frac{1}{O / F}\right) \frac{4 m_{o x} R T_{a v}}{\pi L_{f} p_{c} D^{2}}
$$

where $D$ is the port diameter, $L_{f}$ is the length of the fuel port, $\dot{m}_{o x}$ is the oxidizer flow rate into the port, $R$ is the specific gas constant and $T_{a v}$ is average gas temperature in the combustion chamber. From the equation it was found that for an oxidizer-fuel ratio of $1.35, \mathrm{R}$ is $330 \mathrm{~J} / \mathrm{kg}$ $\mathrm{K}$ and $\mathrm{T}_{\mathrm{av}}$ is $2800 \mathrm{~K}$, as observed during the earlier part of PE/GOx firing, the frequency of oscillation is around $23 \mathrm{~Hz}$. From the modal analysis conducted by Gmeiner [12] and the hammer test conducted during this study, it was found that the resonant fundamental structure vibration frequency of the combustion chamber is around $19.4 \mathrm{~Hz}$. This close correlation in values suggests a plausible contribution to the higher oscillations observed for the thrust profile of the PE/GOx firing. Since the primary hybrid combustion oscillation frequency is almost the same the as the resonant structural-mode frequency of the combustion chamber, the combustion chamber would, potentially, vibrate at an augmented resonance condition. This higher amplitude oscillatory behaviour was perhaps picked up by the load cell, which produced a substantially higher oscillation in the thrust plot relative to the pressure plot, which was produced by a lesser affected pressure transducer.

For the paraffin/GOx firing, the oxidizer-fuel ratio was about 2.5 , which results in a hybrid combustion oscillation frequency of about $16.6 \mathrm{~Hz}$. This frequency is somewhat lower than the resonant structural-mode frequency of the combustion chamber. Hence, one might argue that the oscillations observed in the thrust plot produced by the axial load cell are not as large as the ones produced in PE/GOx firing at least in part due to the noted frequency difference. Having said that, one would also need to note that the apparent presence of paraffin droplets in the central flow would have a stabilizing effect as well, as per Brahmbhatt $[5,10]$. 


\section{Summary and Conclusion}

This thesis involved the conducting of cold flow tests on the Ryerson University hybrid rocket engine test apparatus, as a means for further understanding the transient oscillation behaviour observed in some earlier hot firing data. The post-test observations made by Brahmbhatt [5] and Gmeiner [12], were helpful to the present work, and provided support to some of the conclusions drawn from the cold flow tests.

From the evaluation of the data obtained from the cold flow tests, it can be stated that the significant oscillation noted in the Oct. 2010 PE/GOx hot-firing thrust data was probably contributed to in part by the axial vibration of the test stand. The fundamental axial vibration frequency of the test apparatus structure was in a relatively close proximity to the fundamental hybrid combustion oscillation frequency, hence helping to support an augmented resonance condition. This resonance condition, leading to higher than normal axial vibration and displacement magnitudes for the test stand, would in turn have been transmitted to the load cell's sensed data. The end result: higher than normal thrust oscillation magnitudes, inconsistent with substantially lower pressure oscillation magnitudes.

Other factors, like feed system instability, were not identified as strongly probable contributors to oscillatory pressure and thrust behaviour, via this cold-flow investigation. Future hot firings, with improved higher bandwidth sensors and sampling rates for higher frequency phenomenon capturing, may yet provide evidence of a feed-system related contribution, or other mechanism that remains as yet less discernible. The preponderance of HRE experimental firing data in the literature reveals some degree of oscillatory thrust or pressure behaviour at the low frequency $(10-100 \mathrm{~Hz})$ end. This low frequency oscillation has largely been attributed to some form of low-level flame instability, as reflected by 
Karabeyoglu's combustion oscillation model in this regard. At the conclusion of this cold flow study, there is no reason to refute the possibility that the baseline contribution to the pressure and thrust oscillations seen in the Oct. 2010 RU HRE firings was indeed a low-level, low-frequency combustion oscillation/ flame instability issue. 


\section{Appendix A: Pressure Transducer Calibration \\ I. OMEGA PX4100 Series Pressure Transducer Calibration}

In this section, OMEGA's PX4100 series strain gauge pressure transducer will be calibrated with the WaveBook. This Transducer has a minimum output of $0 \mathrm{~V}$ and a Maximum output of $20 \mathrm{mV}$ i.e. if the pressure range for the transducer is $0 \mathrm{psi}$ to $600 \mathrm{psi}$, the output from the transducer is $0 \mathrm{~V}$ for $0 \mathrm{psi}$ and $20 \mathrm{mV}$ for $600 \mathrm{psi}$. Any pressure within the pressure range will have an output voltage between $0 \mathrm{~V}$ and $20 \mathrm{mV}$.

\section{Apparatus for The Test}

- Air supply tank

-Push button, non-return valve

-OMEGA PX4100- 600GV Pressure Transducer (0-600 psi)

-WaveBook 516 Data Acquisition system.

-Regulated 10 V dc Supply

-Connecting Cables.

\section{Transducer Specifications}

Excitation: 10 Vdc @ $10 \mathrm{~mA}$ (15 Vdc max) reverse polarity protected

Output: $20 \mathrm{mV}(+/-1 \%)$ ratio metric

Accuracy: +/- 0.25\% FS includes linearity, and hysteresis

Repeatability: $+/-0.1 \%$ FS

Zero Offset: +/-1\% FS

Long Term Stability: +/-0.2\% FS/6 mo.

Compensated/Operating Temperature: -20 to $80^{\circ} \mathrm{C}\left(-4\right.$ to $\left.176^{\circ} \mathrm{F}\right)$

Storage Temperature: -40 to $90^{\circ} \mathrm{C}\left(-40\right.$ to $\left.194^{\circ} \mathrm{F}\right)$ 
Thermal Zero Effect: $<+/-0.08 \%$ FS $/{ }^{\circ} \mathrm{C}$

Thermal Span Effect: $<+/-0.04 \%$ FS $/{ }^{\circ} \mathrm{C}$

Maximum Overpressure: $200 \%$ FS

Vibration: $10 \mathrm{~g}$ to $50 \mathrm{~Hz}$

Shock: $15 \mathrm{~g} @(11 \mathrm{mS})$

Humidity: 95\% RH (non-Cond)

Wetted Parts: $17-4$ SS, 300 Series SS and for ranges $\leq 150$ psi Alumina with nitrile seal

Case: IP65 Sealed, 300 Series Stainless Steel

Pressure Port: 1/4 NPT male

Electrical Connection: Socket to DIN 43650 and Micro-DIN plug (included)

Response Time: $10 \mathrm{~ms}$

Weight: $75 \mathrm{~g}(2.6 \mathrm{oz})$

\section{Test Setup}

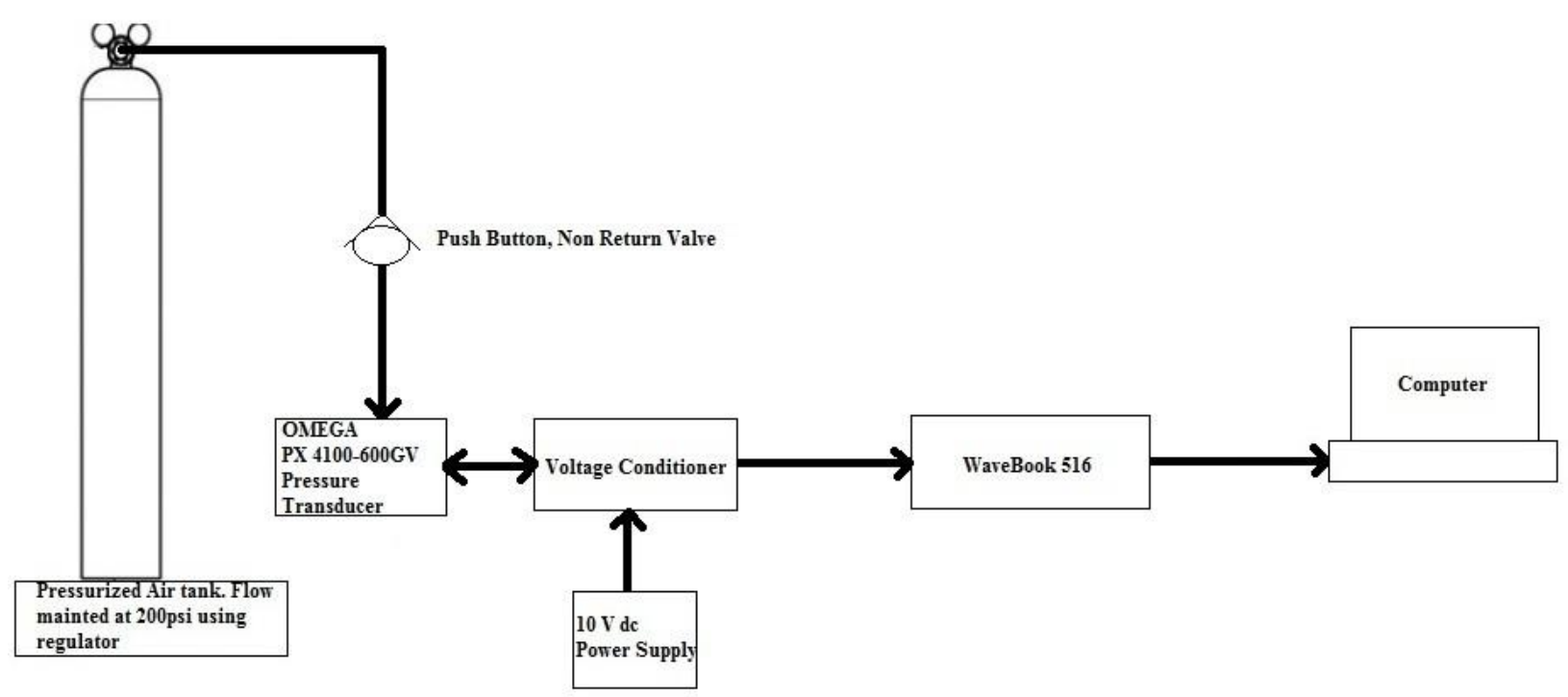

Fig. A.1: OMEGA PX4100 Series Transducer Calibration Setup 


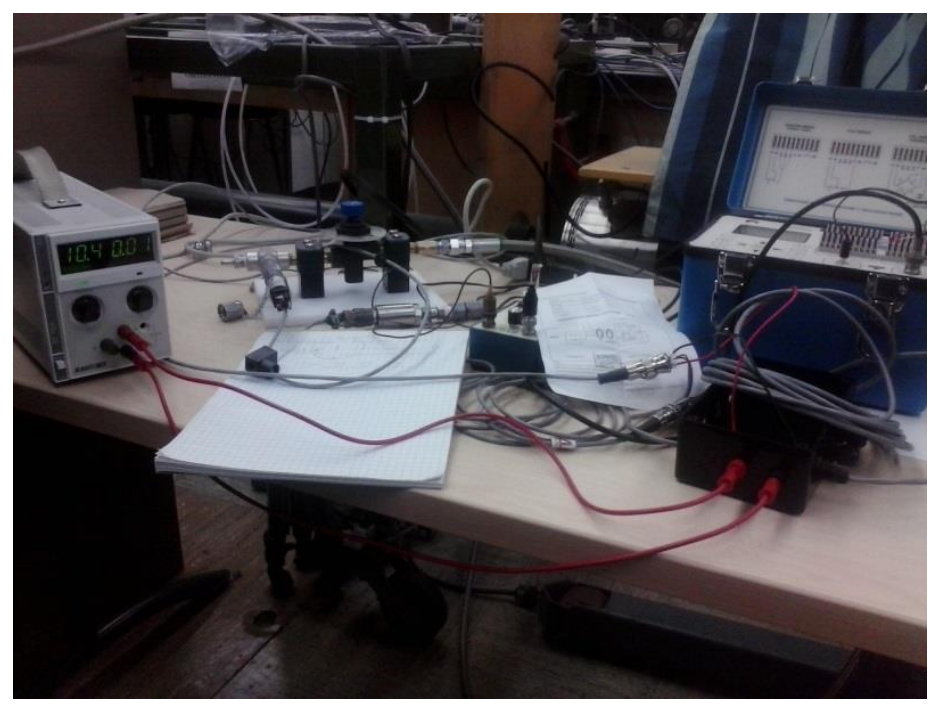

Fig. A.2: Test setup in Laboratory (Propulsion Research Facility)

The apparatus is set up and appropriate connections are made as shown in Figure. A.1. The pressurized air tank is set to supply 200 psi of compressed air which flows to the pressure transducer.

The transducer is supplied with an excitation voltage of $10 \mathrm{~V} \mathrm{dc}$ (minimum $10 \mathrm{Vdc}$, maximum 15 Vdc). The output of the transducer is connected to the WaveBook using BNC connectors. The supply voltage is checked for $10 \mathrm{~V}$ dc output voltage and supplied to the transducer.

Pressurized air at 200 psi is passed from the Air tank to the valve which restricts the flow of air untifl the push button valve is pushed down.

\section{Test Procedure}

The output voltage from the transducer is in the order of millivolts and hence the range is set to millivolts. Since the output is a DC voltage and the maximum is $20 \mathrm{mV}$ the range is set to the minimum $0 \mathrm{~V}$ to $2000 \mathrm{mV}$. The data is sampled at a frequency of $50 \mathrm{~Hz}$ 
and collected for 5 seconds. Any change in pressure activity will be recorded in the $5 \mathrm{sec}$ duration.

The Apparatus is set up and the required power supply is supplied to the transducer and the WaveView Scope is armed. The Triggering is set to immediate mode i.e. the collection of data begins as soon as the WaveView Scope is armed. The push button valve is actuated and air is allowed to flow through the connecting pipes to the transducer. The transducer produces an output proportional to the pressure acting on the transducer.

\section{Test Result}

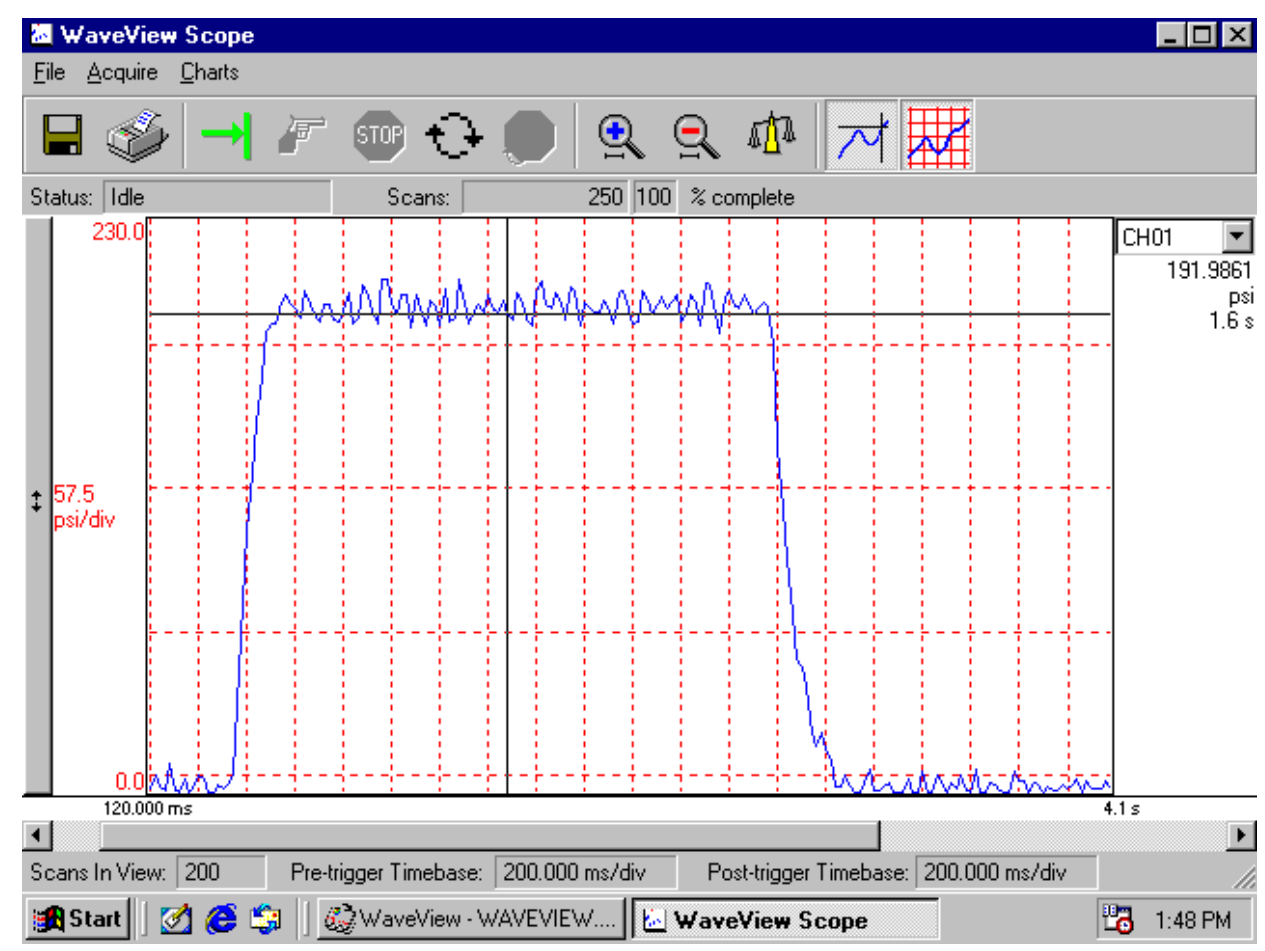

Fig. A.3: OMEGA PX4100 series pressure transducer calibration test result

The above picture shows the result obtained for a short test run. Pressurized air was allowed to act on the transducer for a short duration and the pressure variation activity was captured by the transducer. 


\section{Comparison between Filtered and Unfiltered Power Supplies}

The $10 \mathrm{~V}$ dc power supply, supplied to the transducers has to be from a stable dc source. In this section a test conducted to find the effects of unfiltered and filtered power supply is reported.

\section{Unfiltered}

The apparatus is set up as mentioned in the previous section and the voltage supply to the transducer is given by an unfiltered dc source. The output signal obtained from the transducer is shown below.

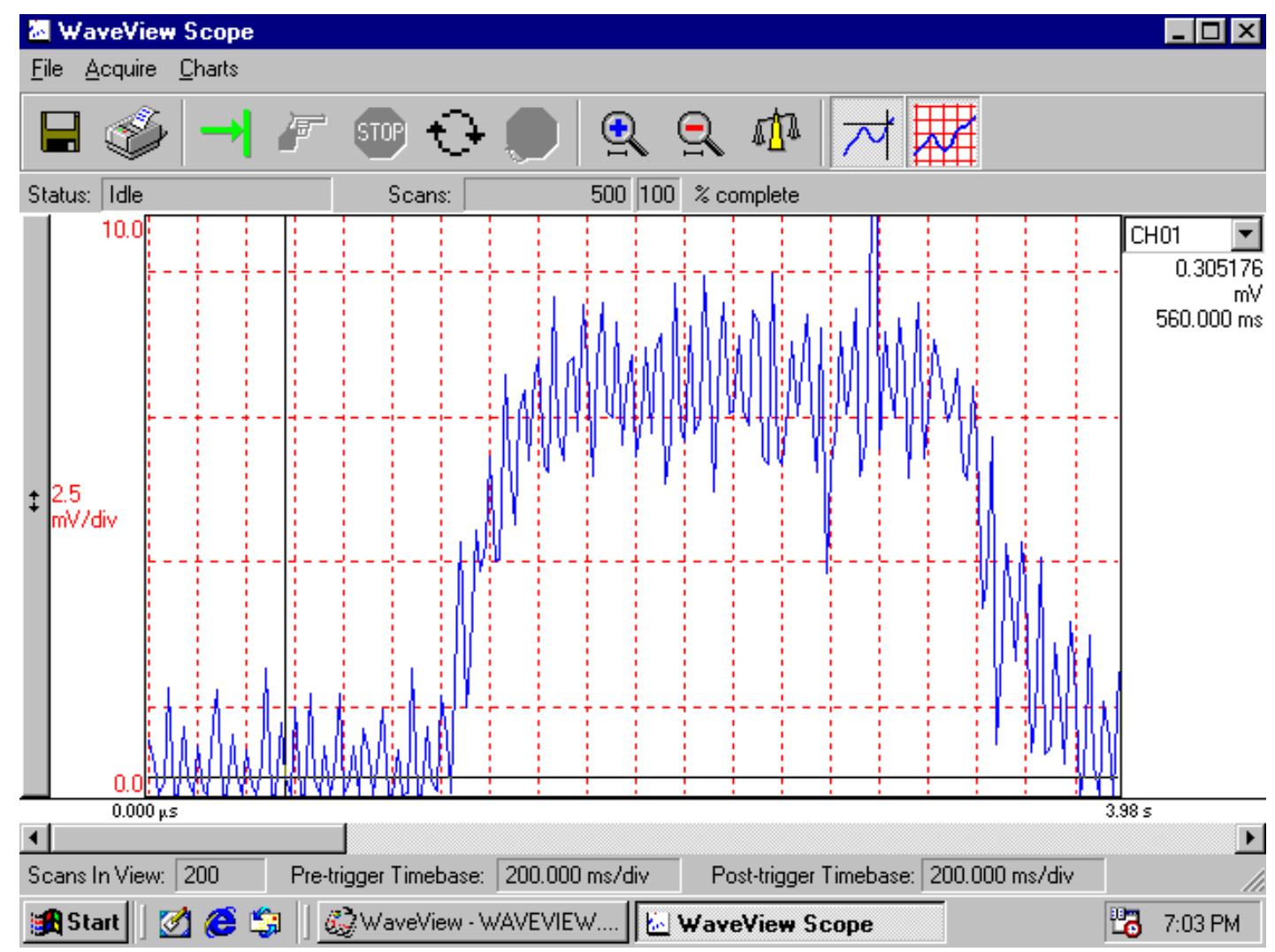

Fig. A.4: Output signal obtained without a filtered input supply voltage 


\section{Filtered}

The same test (as done with unfiltered power supply) is repeated but with a filtered power source to the transducer. The output signal obtained from the transducers is shown below.

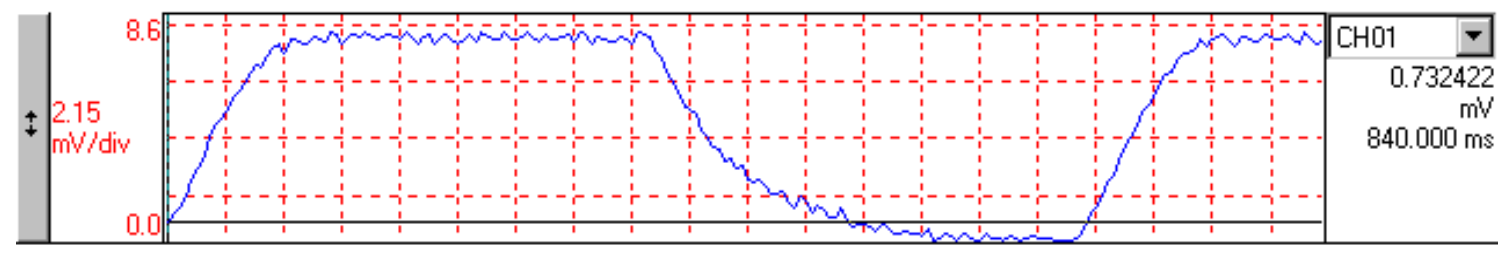

Fig. A.5: Output signal obtained with a filtered supply voltage

\section{Comparison}

It is evident from Figure. A.4 and Figure. A.5. the output obtained when an unfiltered source supplies excitation voltage to the transducer, high noise is observed in the output signal from the transducer. The test conducted with a filtered power source also contains a small amount of noise which can be neglected compromising the accuracy of the results obtained.

When used in actual tests, the pressure oscillation activity will be merged by the high noise signal. This has to be avoided for obtaining proper output from the transducer. Hence, a power source with low or no noise signal has to be used for use with the transducers.

\section{Integrity Test}

Now that the individual transducers are calibrated and check for functioning, the transducers have to be tested for their behavior while functioning in tandem with other sensors and transducers. 


\section{Test Setup}

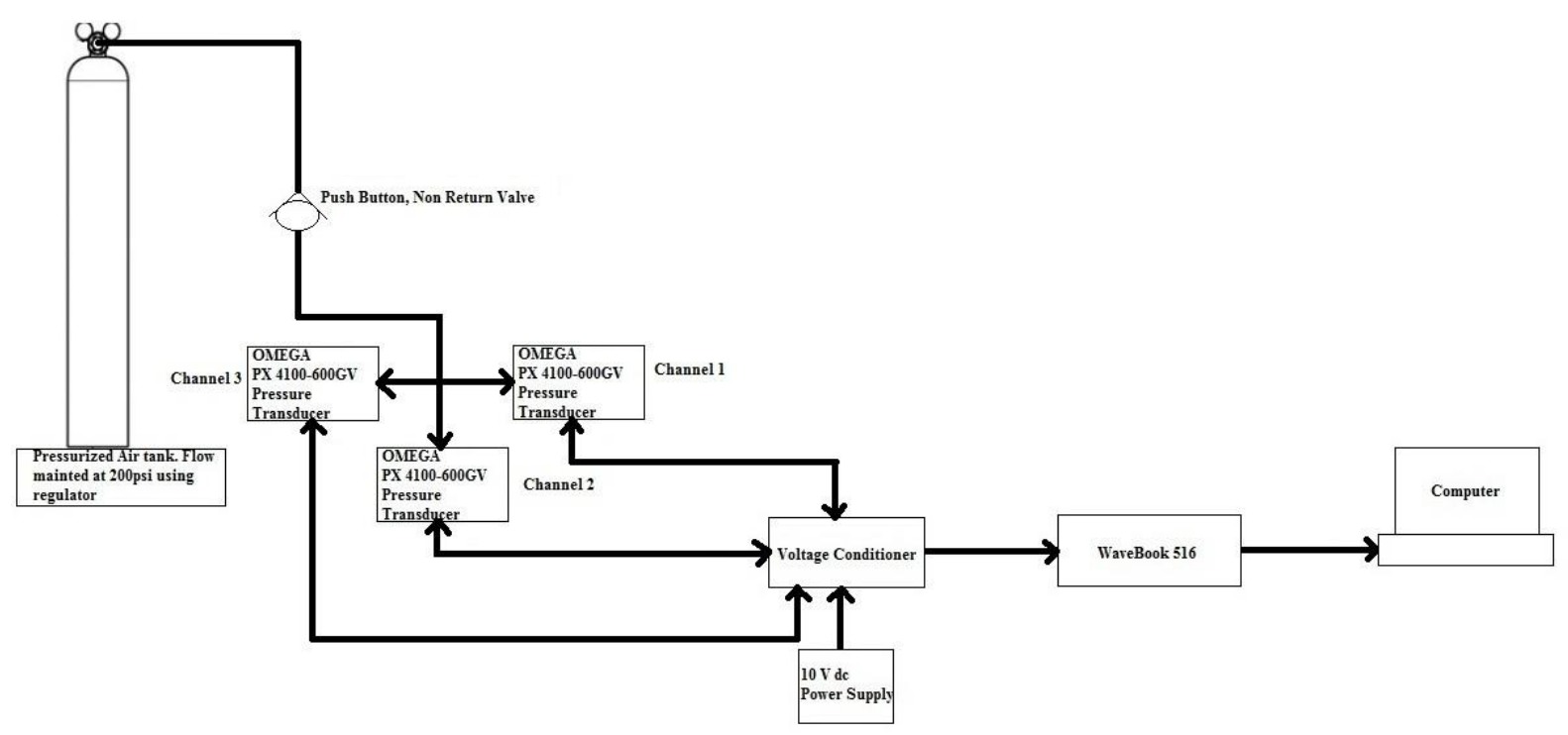

Fig. A.6: Apparatus setup for integrity test

The above shown Figure. A.6 is similar to Figure A.1. The major difference in the two setups is the number of transducers. As the mentioned previously this test is to confirm the integrity and reliability of the transducers. Hence, all the three pressure transducers which will be used for the cold flow test will be used in this test. 


\section{Test Result}

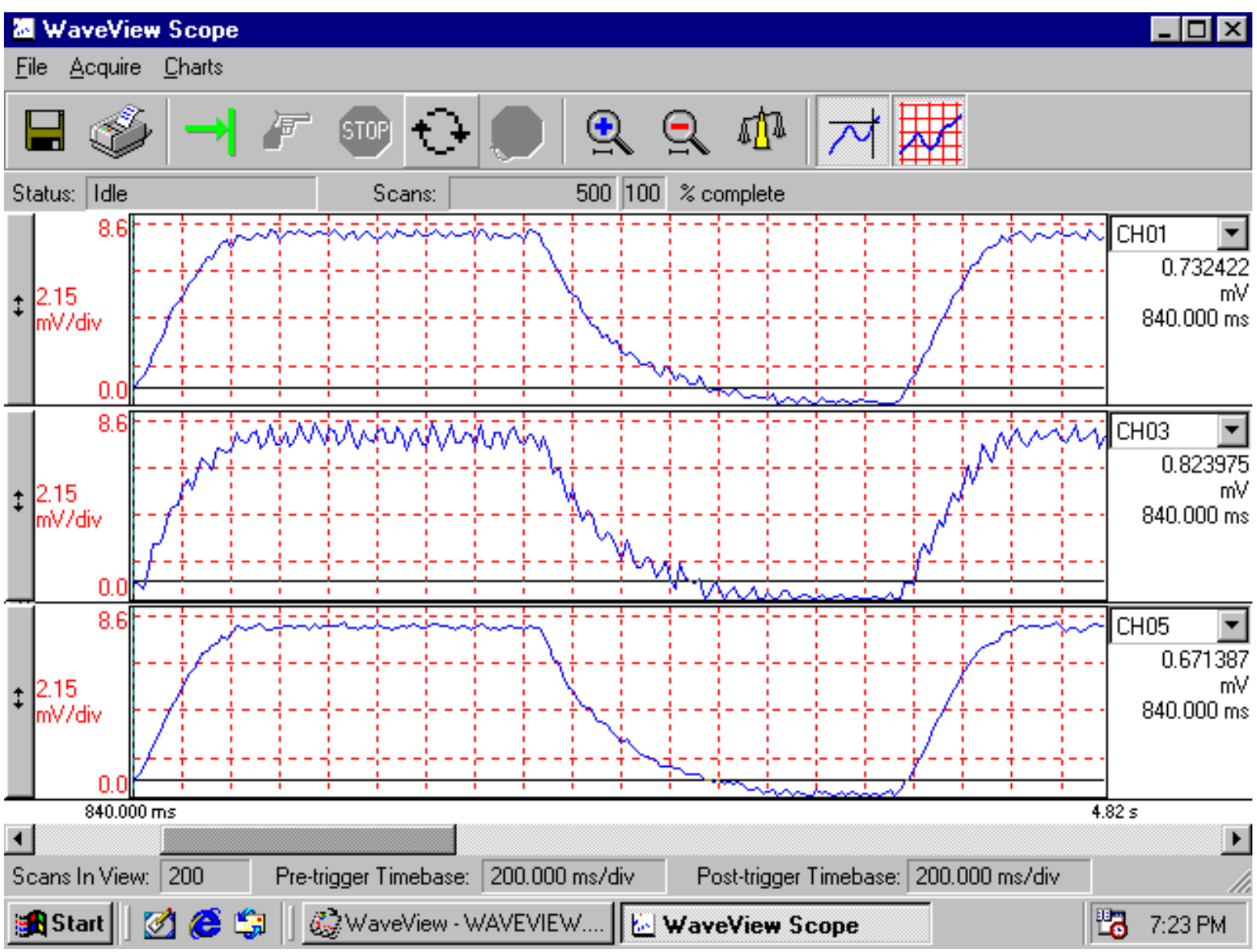

Fig. A.7: Integrity test results

The above figure shows the result obtained when all three transducers are used in tandem to detect the pressure activity.

\section{Observations}

From the test results obtained, it is observed that the transducer placed head on to the flow shows a high noise output signal. This variation in the signal is not due effect of unfiltered voltage supply but due to the pressure activity acting on the transducer. 
Considering the observation, it should be noted that the transducers should be placed perpendicular to the flow (axis of the transducer should be perpendicular to direction of flow) and should not be placed in direction of flow, facing it.

The regulated power supply gives a small noise signal which is obtained at the output of the transducer. This noise signal overlaps the pressure activity signal from the transducer. To avoid this effect a pure stable dc source should be used to supply excitation voltage to the transducer. This source can be given by a $12 \mathrm{~V}$ dc battery (automobile battery). The use of such a stable source will reduce the noise to a very low level (close to zero).

The main drawback of using a $12 \mathrm{~V}$ dc source is that, the transducer has to be re calibrated. This is not a major issue as it can be done easily.

\section{Supplying Voltage to Transducer Using 12 V dc Supply.}

The noise generated due to the voltage source providing excitation voltage to the transducer can be reduced using a pure DC source, a battery. Here a $12 \mathrm{~V} \mathrm{dc} 80$ Amp battery is used to supply the excitation voltage to the transducer. 


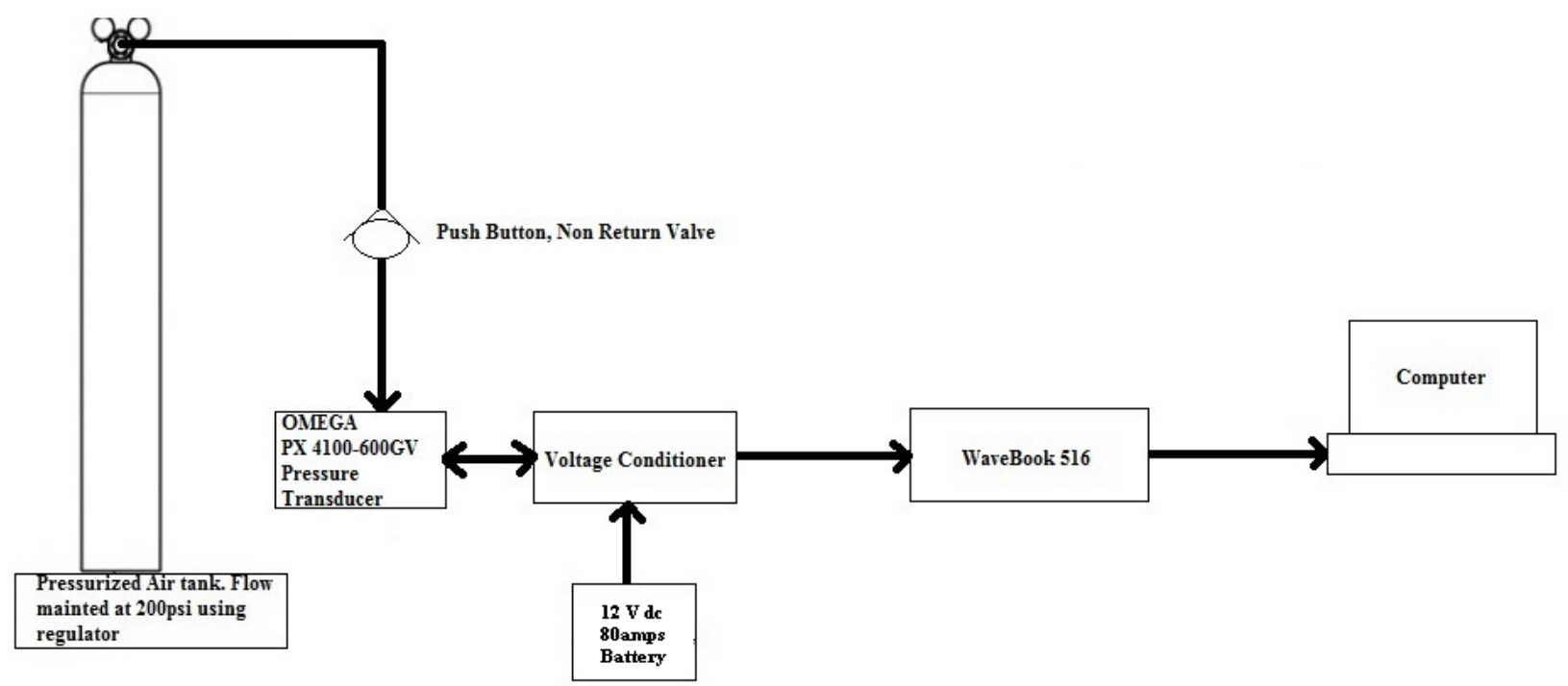

Fig. A.8: OMEGA PX4100 Series Transducer Calibration Setup using 12V dc battery

\section{Calibration Results}

The transducers, when calibrated using a battery gives an average output of 1.5 $\mathrm{mV}$ higher than the output obtained using a regulated power source.

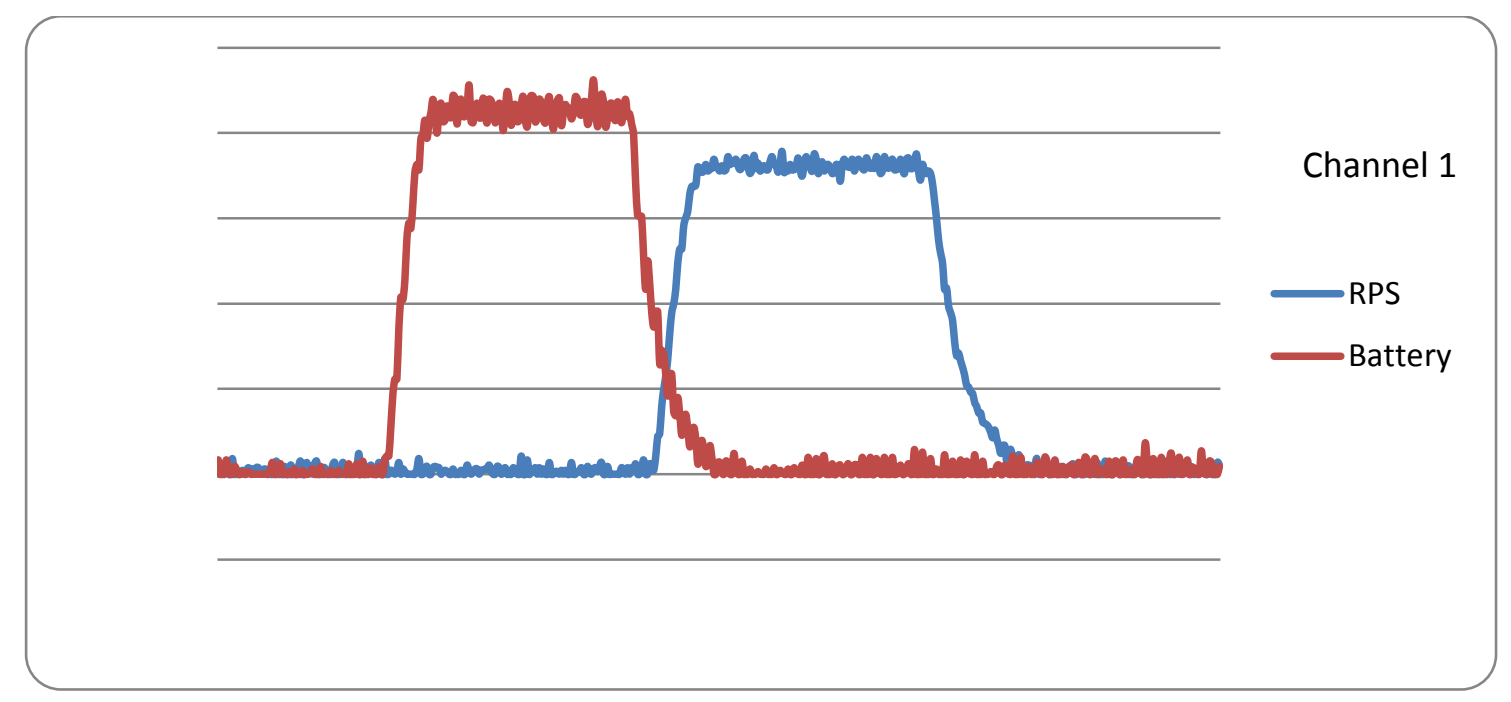

Fig. A.9: Comparison of test results obtained form two methods of supplying exitation voltage

Three PX4100-600GV transducers were calibrated using the previously mentioned setup (employing battery). PX4100-1KGV pressure transducer belongs to the PX4100 series voltage type transducer. This transducer has a range detection range of $0-1000$ psi with the 
output voltage range of $0-2 \mathrm{mV}$. A $10 \mathrm{~V}$ dc excitation voltage has to be supplied to the transducer (Max $15 \mathrm{~V} \mathrm{dc}$ ). The calibration was done as mentioned in section XIII and section XV.I.

Final calibration constants.

Channel1:- PX4100-1KGV,\#134684, M=33500

Channel2:- PX4100-600GV,\#101744, M=20000

Channel3:- PX4100-600GV,\#101746, M=21800

Channel6:- Load Cell $\quad \mathrm{M}=1330$ (Set auto zero at the beginning of every test)

Channel5:- Accelerometer \#4370950037 M=30

The Channel \#4 of the WaveBook 516 DAQ system has an internal leakage of $60 \mathrm{~Hz}$ AC current. This leakage tends to amplify with the gain factor. Also for future signal processing the $60 \mathrm{~Hz}$ data should be filtered out before any analysis. 


\section{Appendix B: MATLAB Code Used for FFT Process}

The following block of codes was employed in MATLAB for FFT process.

clc

clear all

filename='filename....xlsx'; $\quad \%$ (name of the file containing the data)

$\mathrm{Fs}=1000$;

$\%$ (Sampling frequency)

$\mathrm{x}=\mathrm{xlsread}($ filename,-1$) ; \quad \%($ Reading the data $)$

signal_avr=sum $(\mathrm{x}) /$ length $(\mathrm{x}) ; \quad \%($ obtaining the average value of the signal)

nfft=length $(\mathrm{x})$;

for $\mathrm{i}=1: 1: \mathrm{nff}$

$\%($ length of the signal)

$\mathrm{x} 1(\mathrm{i})=\mathrm{x}(\mathrm{i})$-signal_avr

$\%$ removing the DC component from the signal)

end

$X=f f t(x 1, n f f t)$

$\%$ (obtaining FFT of the data)

$\mathrm{X}=\mathrm{X}(1: \mathrm{nfft} / 2)$

$\mathrm{mx}=\operatorname{abs}(\mathrm{X})$;

$\mathrm{f}=(0: \mathrm{nfft} / 2-1)^{*} \mathrm{Fs} / \mathrm{nfft}$;

figure(1)

$\operatorname{plot}(\mathrm{f}, \mathrm{mx})$;

$\operatorname{axis}\left(\left[\begin{array}{llll}0 & 100 & 0 & 3000\end{array}\right)\right.$;

title('fft analysis');

xlabel('frequency');

$\%$ (Plotting the FFT data)

ylabel('Amplitude'); 


\section{Appendix C: Sensor and Transducer Calibration Certificate}

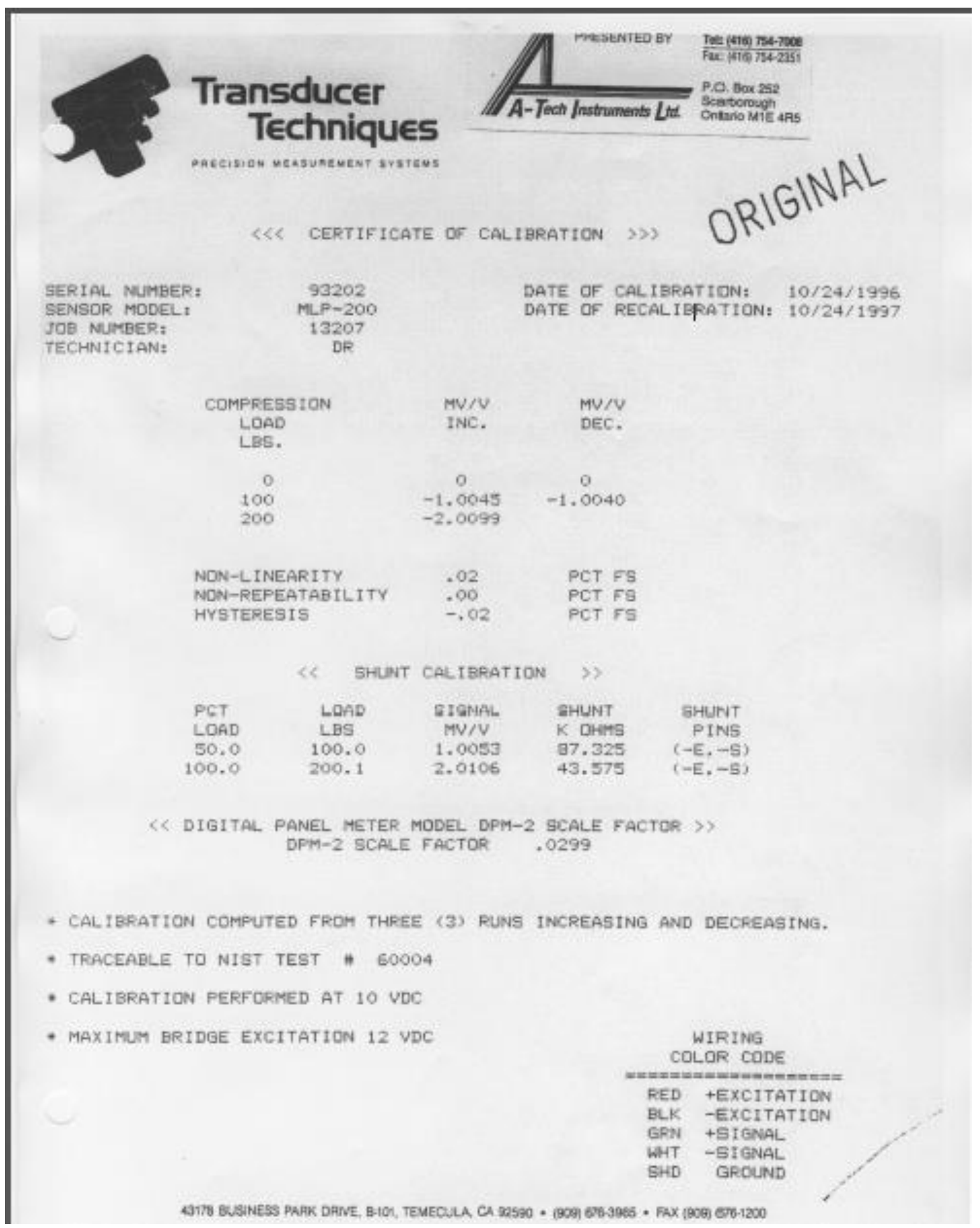




\section{Pressure Transducer Technical Details}

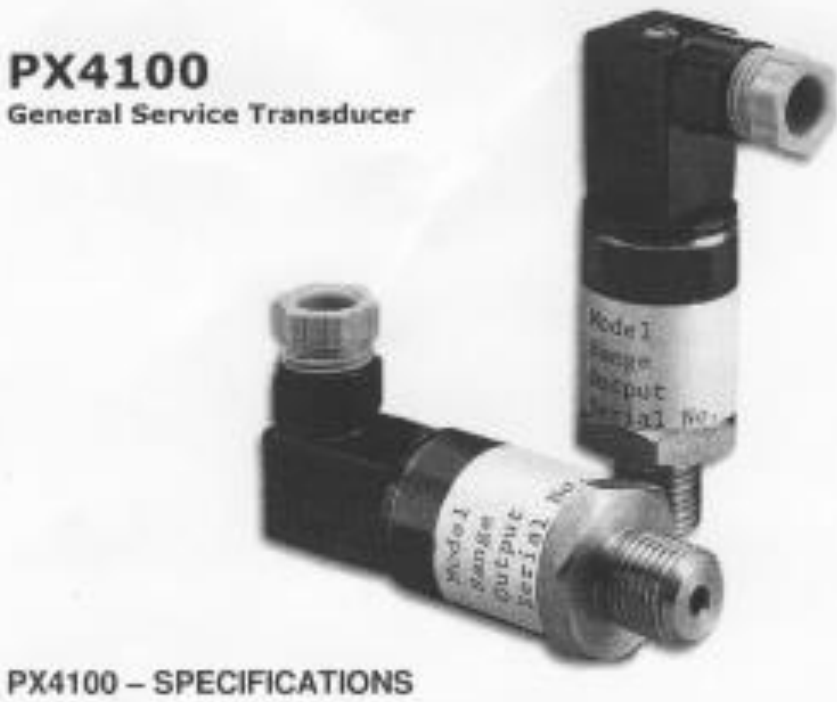

Excitation: 10 Vdc @ $10 \mathrm{~mA}$ (15 Vdc max) reverse polanity protected Output: $20 \mathrm{mV}( \pm 1 \%$ ) Ratiometric

Accuracy: $00.25 \%$ FS includes linearity, and hysteresis

Repeatability: $\pm 0.1 \%$ FS

Zero Oftset: $\pm 1 \%$ FS

Long Term Stability: $\pm 0.2 \%$ FS/ 6 mo.

Compensated/Operating Temperature: -20 to $80^{\circ} \mathrm{C}\left(-4\right.$ to $\left.176{ }^{\circ} \mathrm{F}\right)$

Storage Temperature: -40 to $90^{\circ} \mathrm{C}(-40$ to $194 \mathrm{~A})$

Thermal Zero Effect: $<+0.08 \%$ FS/ ${ }^{\circ} \mathrm{C}$

Thermal Span Effect: $< \pm 0.04 \%$ FS/ ${ }^{\circ} \mathrm{C}$

Maximum Overpressure: $200 \%$ FS

Vibration: $10 \mathrm{~g}$ to $50 \mathrm{~Hz}$

Shock: $15 \mathrm{~g} @$ (11 mS)

Humidity: $95 \%$ RH (non-Cond)

Wetted Parts: 17-4 SS

Case: IP65 Sealed, 300 Series Stainless Steel,

Pressure Port: $1 / 4^{*}$ NPT male

Electrical Connection: Socket to Din 43650 and Micro-DIN plug (included)

Response Time: $10 \mathrm{~ms}$

Weight: $75 \mathrm{~g}(2.6 \mathrm{oz})$

\begin{tabular}{|c|c|}
\hline Part Number & Description \\
\hline PX4100-150GV & 150 psi transducer with a 20 mV output \\
\hline PX4100-300GV & 300 psi transducer with a 20 mV output \\
\hline PX4100-600GV & 600 psi transducer with a 20 mV output \\
\hline PX4100-1KGV & 1000 psi transducer with a 20 mV output \\
\hline PX4100-1.5KGV & 1500 psi transducer with a $20 \mathrm{mV}$ output \\
\hline PX4100-3KGV & 3000 psi transducer with a $20 \mathrm{mV}$ output \\
\hline PX4100-6KGV & 6000 psi transducer with a 20 mV output \\
\hline PX4100-10KGV & 10,000 psi transducer with a 20 mV output \\
\hline
\end{tabular}




\section{Pressure Transducer Calibration Certificates}
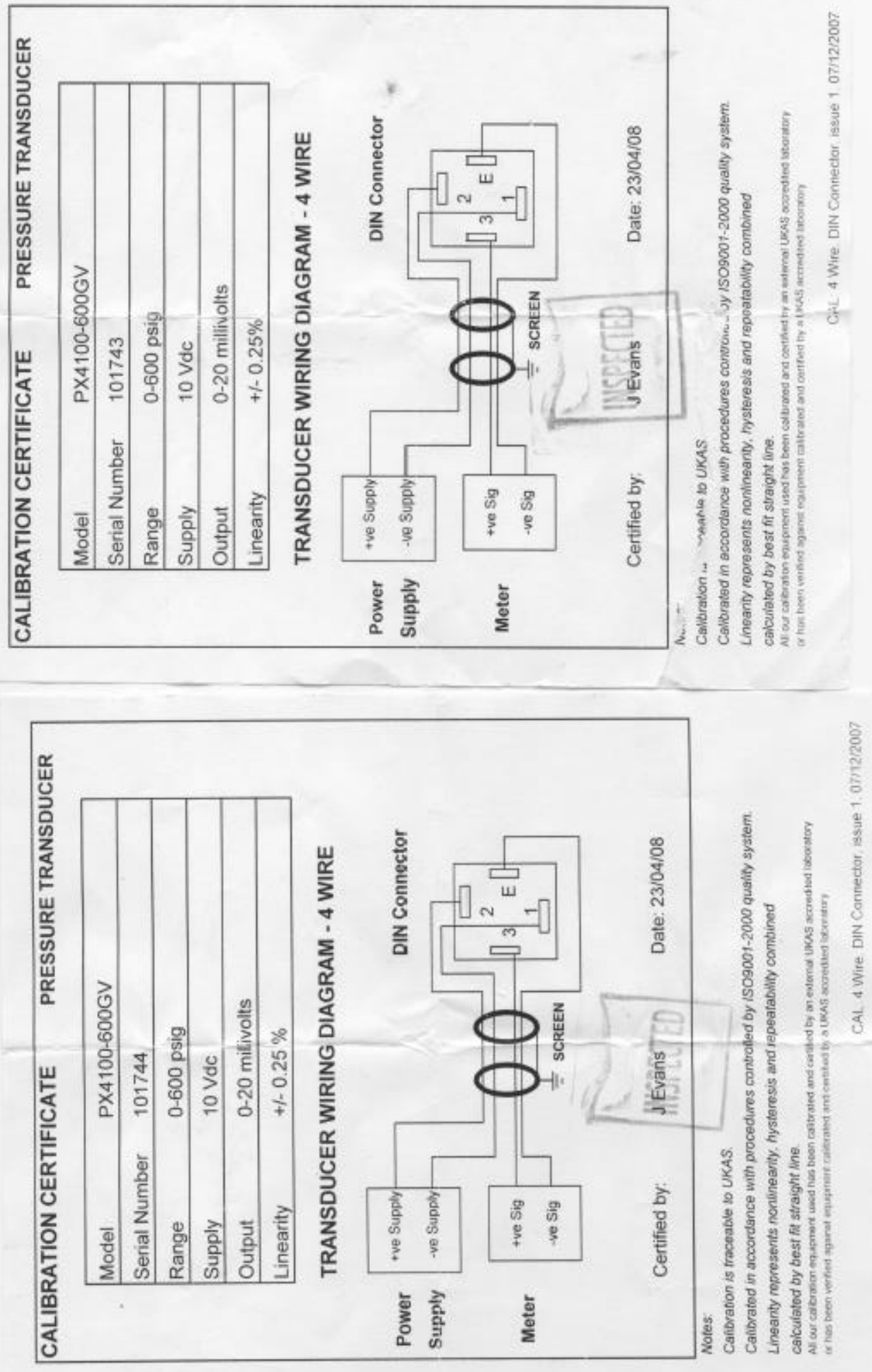


CALIBRATION CERTIFICATE
\begin{tabular}{|ll|}
\hline Model & PRESSURE TRANSDUC \\
\hline Serial Number & 101746 \\
\hline Range & $0-600$ psig \\
\hline Supply & $10 \mathrm{Vdc}$ \\
\hline Output & $0-20 \mathrm{mill}$ volts \\
\hline Linearity & $+1-0.25 \%$ \\
\hline
\end{tabular}

\section{TRANSDUCER WIRING DIAGRAM - 4 WIRE}
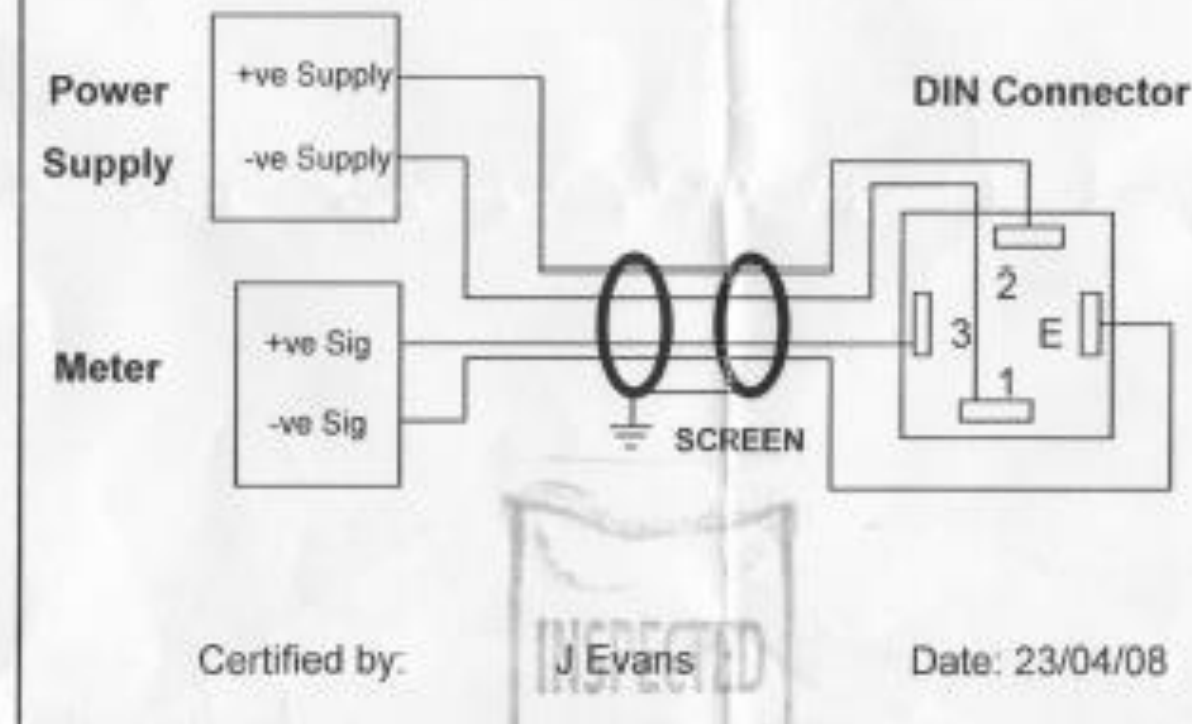

\section{Notes:}

Canibration is traceabie to UKAS.

Calibrated in accordance with procedures cantrolled by $1509001-2000$ quality system. Lineanily represents nonlineavity, hysteresis and repeatabiwty cambined caiculated by best fit straight Nine.

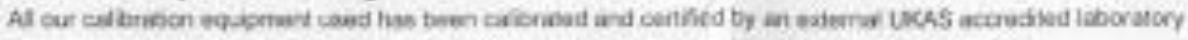

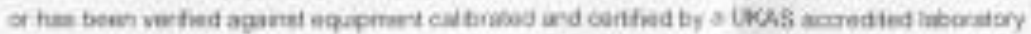




\section{References}

[1] D.R. Greatrix, Powered flight - the engineering of aerospace propulsion, SpringerVerlag London, 2012.

[2] A. Karabeyoglu, "Combustion instabiltiy and transient behaviour in hybrid rocket motors," in Fundamentals of Hybrid Rocket Combustion and Propulsion, Progress in Astronautics and Aeronautics,Vol. 218, AIAA, 2007, pp. 323-411.

[3] A. Karabeyolgu, "Modelling of hybrid rocket low frequency instabilities," Journal of Propulsion and Power, Vol. 21, No. 6, pp. 1106-1116, Nov.-Dec. 2005.

[4] A. Karabeyoglu, "Transient combusiton in hybrid rockets",Ph.D. dissertation Stanford University, Stanford, 1998.

[5] V. Brahmbhatt, "Evaluation of laboratory scale hybrid rocket engine's performance," Master's thesis ,Aachen University of Applied Sciences, Aachen, 2012.

[6] B. Greiner and R. A. Frederick, "Results of labscale hybrid rocket motor investigation," in $28^{\text {th }}$ AIAA/ASME/SAE/ASEE Joint Propulsion Conference \& Exhibit, AIAA 923301 Nashville, TN, July 1992.

[7] T.A. Boardman, "An experimental investigation of pressure oscillations and suppression in subscale hybrid rocket motors," in $31^{\text {st }}$ AIAA/ASME/SAE/ASEE Joint Propulsion Conference and Exhibit, AIAA 95-2689, San Diego, CA, July 1995.

[8] R.M. Jenkins and J.R. Cook, "A preliminary analysis of low frequency pressure oscillations in hybrid rocket motors," in $31^{\text {st }}$ AIAA/ASME/SAE/ASEE Joint Propulsion Conference and Exhibit, AIAA 95-2690, San Diego, CA, 1995.

[9] W. D. Cruit and R.M. Jenkins, "Cold flow study of hybrid rocket motor flow dynamics," in $32^{\text {nd }}$ AIAA/ASME/SAE/ASEE Joint Propulsion Conference and Exhibit, AIAA 1996-2843, Lake Buena Vista, 1996.

[10] V. Brahmbhat, D.R. Greatrix, J. Karpynczyk and A.P. Trumour, "Evaluation of laboratory scale hybrid rocket engine's performance," procedings of International Symposium on Special Topics in Chemical Propulsion \& Energetic Materials, Quebec city, Canada, 2012.

[11] A.P. Trumpour, 'Hybrid rocket engine research in support of prototype development and testing', M.A.Sc. thesis, Ryerson University, Toronto 2010.

[12] T.A. Gmeiner, Investigation of hybrid rocket test apparatus, B.Eng thesis, Ryerson University, Toronto, 2012. 
[13] C.W. Silva, Computer techniques in vibration, Taylor \& Francis Group, 2007.

[14] S. Kim and J. Cho, "Effect of paraffin-LDPE blended fuel in hybrid rocket motor," in $46^{\text {th }}$ AIAA/ASME/SAE/ASEE Joint Propulsion Conference \& Exhibit, Nashville, TN, July 2010.

[15] Marxman, G. A., Wooldridge, C. E., and Muzzy, R. J., "Fundamentals of hybrid boundary layer combustion," Progress in Astronautics and Aeronautics, Vol. 15, Academic Press, New York, 1964, pp. 485-522.

[16] M.W. Beckstead and E.W. Price, "Nonacoustic combustor instability," AIAA Journal, Vol. 5, No. 11, pp. 1989-1996, Nov. 1967.

[17] M.A. Karabeyoglu, J. Stevens and B. Cantwell, "Investigation of feed system coupled low frequency combustion instabilities in hybrid rockets," in $43^{\text {rd }}$

AIAA/ASME/SAE/ASEE Joint Propulsions Conference and Exhibit, AIAA 20075366, Cincinnati, OH, July 2007.

[18] S. Yuasa, T. Morita, K. Kitagawa, T. Shimada and S. Yamaguchi, "Low-frequency feedsystem-coupled combustion instability in hybrid rocket motors," in Journal of Thermal and Science and Technology, Vol. 8, No. 2, pp. 380-394, Feb. 2013.

[19] C. Carmicino, "Acoustics, vortex shedding, and low-frequency dynamics interaction in an unstable hybrid rocket," Journal of Propulsion and Power, Vol. 25, No. 6, pp. 1322 1335, Nov.-Dec. 2009.

[20] Perry, Robert H. and Green, Don W. Perry's Chemical Engineers Handbook, $6^{\text {th }}$ edition, McGraw hill, 1984 